Marcação de regiões de interesse em 3d sobre imagens radiológicas utilizando a web 



\title{
Marcação de regiões de interesse em $3 d$ sobre imagens radiológicas utilizando a web
}

\author{
Cleber Castro Hage \\ Orientador: Prof. Dr. Dilvan de Abreu Moreira \\ Dissertação apresentada ao Instituto de Ciências \\ Matemáticas e de Computação - ICMC-USP, como \\ parte dos requisitos para obtenção do título de Mestre \\ em Ciências - Ciências de Computação e Matemática \\ Computacional. VERSÃO REVISADA.
}


Ficha catalográfica elaborada pela Biblioteca Prof. Achille Bassi e Seção Técnica de Informática, ICMC/USP, com os dados fornecidos pelo(a) autor(a)

Hage, Cleber Castro
H141m Marcação de regióes de interesse em 3d sobre
imagens radiológicas utilizando a web / Cleber
Castro Hage; orientador Dilvan Moreira. -- São
Carlos, 2014 .
95 p.
Dissertação (Mestrado - Programa de Pós-
Graduação em Ciências de Computação e Matemática
Computacional) -- Instituto de Ciências Matemáticas
e de Computação, Universidade de São Paulo, 2014.
1. Sistemas Web. 2. Tecnologia da informação
aplicada à biomedicina. 3. Radiologia. 4.
Marcação 3D. 5. WebGL. I. Moreira, Dilvan,
orient. II. Título.


“É melhor tentar e falhar, que preocupar-se e ver a vida passar. É melhor tentar, ainda que em vão, que sentar-se fazendo nada até o final. Eu prefiro na chuva caminhar, que em dias tristes em casa me esconder. Prefiro ser feliz, embora louco, que em conformidade viver ...” (Martin Luther King) 



\section{Agradecimentos}

Agradeço, primeiramente, aos meus pais, Elias Hage Junior e Maria da Graça Castro Hage, pelos exemplos e ensinamentos sem os quais eu não chegaria aonde pude e poderei chegar. O contínuo apoio e incentivo de minha família, especialmente de meus pais, para continuação de meus estudos foram de suma importância para definição de meus objetivos de vida, incluindo minha inserção no mundo acadêmico e realização deste trabalho de pesquisa. Agradeço também à minha irmã, Gracielli Castro Hage-Kautz que, com seus exemplos de vida acadêmica, me deu forças na realização de meus trabalhos e sempre me ajudou nos momentos difíceis. Quero agradecer à minha esposa maravilhosa, Sabrina Di Salvo Mastrantonio, por ser exemplo e por não me deixar perder o ânimo diante dos obstáculos. Minha família é a fonte de minha energia.

Dedico um agradecimento especial ao Prof. Dr. Dilvan de Abreu Moreira que, com seu apoio, me deu a oportunidade de voltar ao mundo acadêmico por meio deste trabalho. Sempre serei grato por seus conselhos e por sua motivação que vão além da orientação deste trabalho. Levarei seus ensinamentos comigo. Meu obrigado também à sua equipe de pesquisa que proporcionou um ambiente de colaboração admirável, incluindo a equipe de pesquisa do Department of Radiology da Stanford University, Prof. Daniel Rubin, Debra Willrett e Martin O’Connor.

Meu agradecimento a todos os meus colegas do ICMC, especialmente ao Kleberson Junio do Amaral Serique que me ajudou no desenvolvimento deste trabalho.

Agradeço também ao Instituto de Ciências Matemáticas e de Computação e à Universidade de São Paulo pela estrutura oferecida para realização deste projeto. 



\section{Resumo}

Este trabalho faz parte de um projeto maior, o electronic Physician Annotation Device (ePAD). O ePAD permite a criação de uma base de conhecimento médico usando anotações semânticas sobre lesões em imagens radiológicas, usando uma plataforma Web. Essas anotações servirão para identificar, acompanhar e reason sobre lesões tumorais em pesquisas médicas (especialmente sobre câncer). A informação adquirida e persistida pelo sistema permite avaliação automática por computadores; recuperação de imagens hospitalares e outros serviços relacionados a exames médicos. O ePAD é um desenvolvimento conjunto de grupos de pesquisas do ICMC-USP e do Department of Radiology da Stanford University. O principal trabalho, apresentado neste texto, é um novo conjunto de funcionalidades na Web para adicionar a marcação de lesões em imagens radiológicas em três dimensões ao ePAD. Elas permitirão a obtenção de dados mais precisos acerca de medidas tridimensionais de lesões como volume, posição e cálculo de maior diâmetro. O objetivo é facilitar o trabalho dos profissionais de radiologia na análise de diagnósticos e acompanhamento de lesões produzindo um acompanhamento mais acurado da evolução de doenças como o câncer. Anotações podem ser conectadas a lesões e conter informações semânticas, usando termos biomédicos da ontologia RadLex. Essas novas funcionalidades são baseadas em HTML5, com o auxílio de WebGL para visualização e manipulação de objetos 3D. As maiores contribuições deste trabalho são o software para visualização de séries de imagens radiológicas em 3D usando planos ortogonais, os protótipos de vídeo mostrando as três possíveis interfaces para marcação de lesões em 3D, a pesquisa com radiologistas (usando os protótipos de vídeo) para determinar que o cursor esférico era a melhor interface para marcar lesões em 3D e o protótipo dessa interface no ePAD. Este trabalho contou com a ajuda de usuários do Department. of Radiology da Stanford University e do Hospital das Clínicas da Universidade de São Paulo em Ribeirão Preto.

Palavras-chaves: Sistemas Web; Tecnologia da Informação Aplicada à Biomedicina; Radiologia; Web Semântica; Ontologia; Marcação 3D; WebGL; HTML5. 



\section{Abstract}

This work is part of a larger project, the electronic Physician Annotation Device (ePAD) project. The ePAD allows the creation of a medical knowledge base using semantic annotation on lesions found on radiological images using the Web platform. The annotation will serve to identify, follow-up and reason about tumor lesions in medical research projects (specially about cancer). The information acquired and persisted by the system allows automatic evaluation by computers; retrieval of hospital images and other services related to medical exams. ePAD is a joint development of the ICMC-USP and the Department of Radiology of the Stanford University research groups. The main work, presented here, is a new set of functionalities on the Web to add recording of lesions on radiological images in three dimensions to ePAD. They will lead to more accurate data about three dimensional lesion measurements, such as volume, position and longest diameter calculations. The objective is to ease the work of radiology professionals doing diagnostic analysis and lesion tracking producing more accurate follow-ups of disease evolution, such as of cancer. Annotation can be attached to lesions and hold semantic information, using biomedical ontology terms from RadLex. These new functionalities are based on HTML5 with the help of WebGL for visualization and manipulation of $3 D$ objects. The main contributions of this work are the software for visualization of radiological image series in 3D using orthogonal planes, the video prototypes showing the three possible interfaces to mark lesions in $3 D$, the survey with radiologists (using the video prototypes) to determine that the spherical cursor was the best interface to mark lesions in $3 D$ and the prototype of this interface in ePAD. This work received help from users of the Department of Radiology of the Stanford University and the Clinics Hospital of Ribeirão Preto of the University of São Paulo.

Keywords: Web Applications; Information Technology Applied to Biomedicine; Radiology; Semantic Web; Ontology; 3D Markup; WebGL; HTML5. 



\section{Sumário}

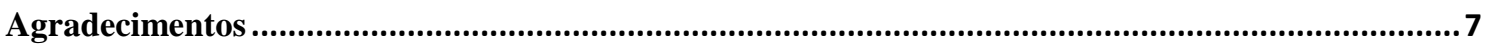

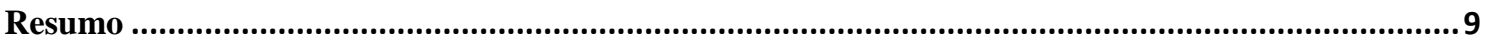

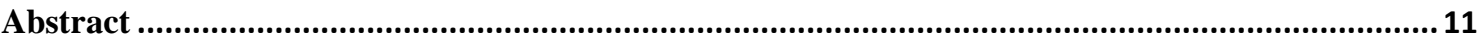

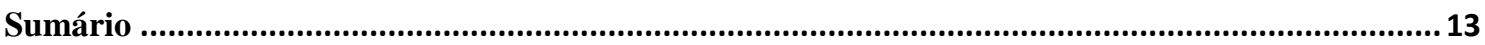

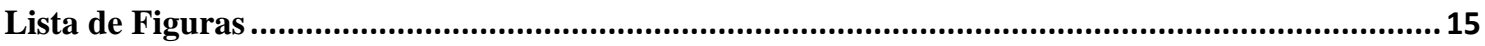

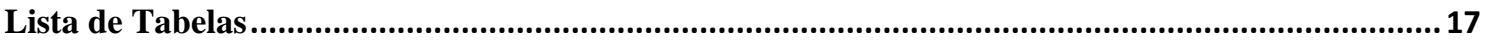

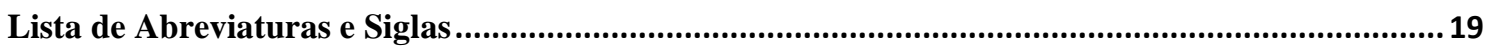

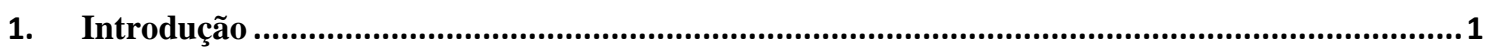

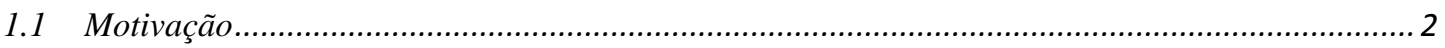

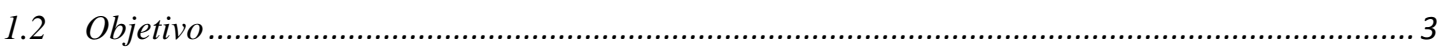

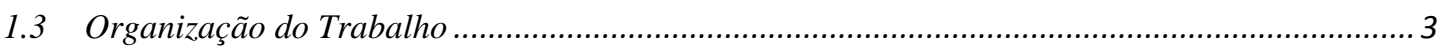

2. Tecnologia da Informação Aplicada à Biomedicina ................................................................5

2.1 Prontuário Eletrônico do Paciente (PEP)........................................................................... 6

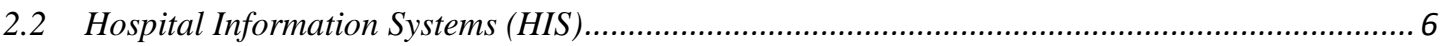

2.3 Picture Archiving and Communication System (PACS) .......................................................... 7

2.4 Padronização de dados e de comunicação............................................................................... 9

2.4.1 Digital Imaging and Communication in Medicine (DICOM) ............................................ 9

2.4.2 Web Access to DICOM Persistent Objects (WADO) ....................................................... 11

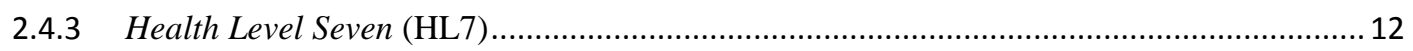

2.4.4 Logical Observation Identifier Names and Codes (LOINC) .......................................... 12

2.4.5 Tecnologias utilizadas na ferramenta ePAD .............................................................. 12

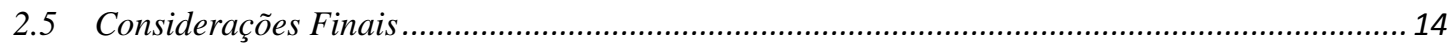

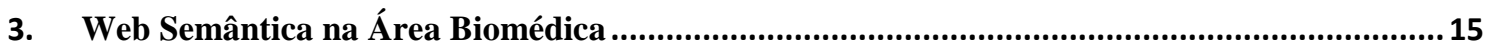

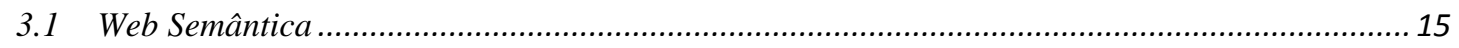

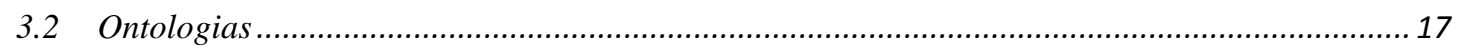

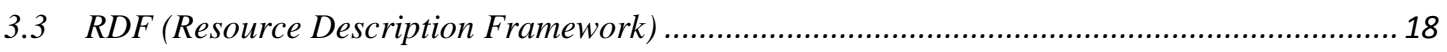

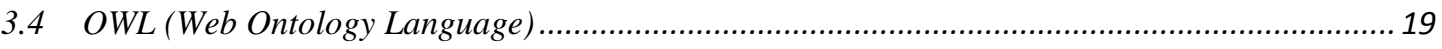

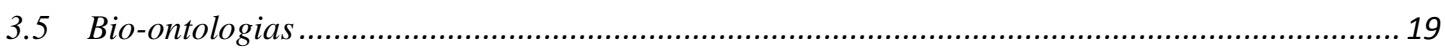

3.6 Índice ACR e o Medical Imaging Resource Center................................................................... 19

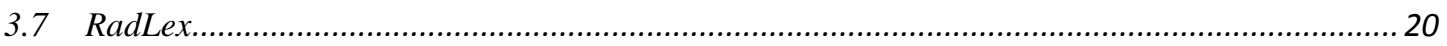

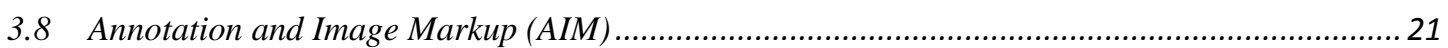

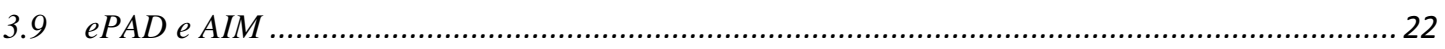

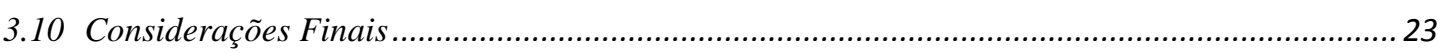

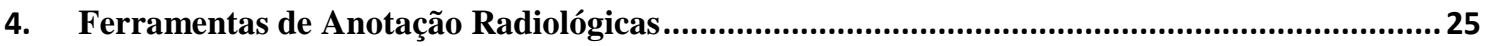

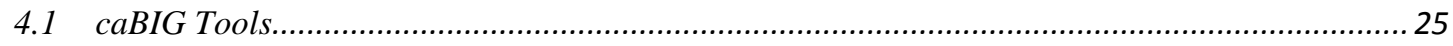

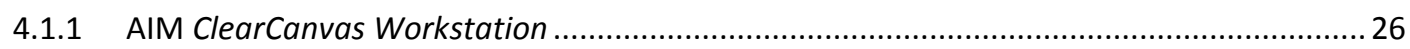

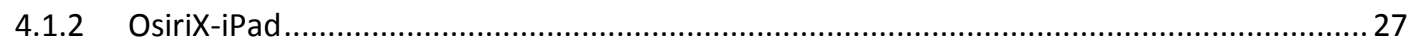

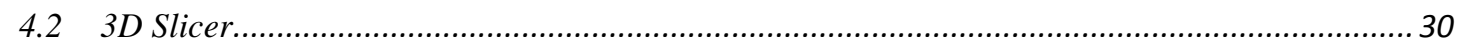

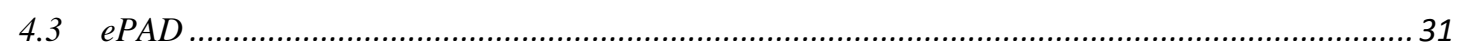

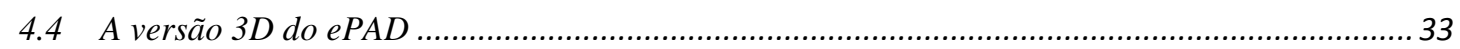

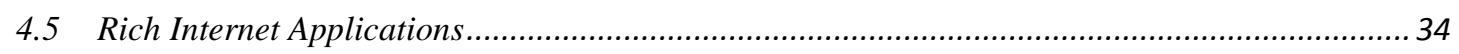

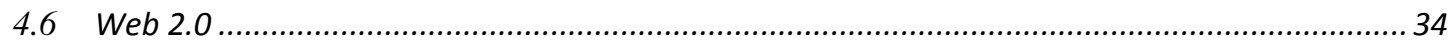

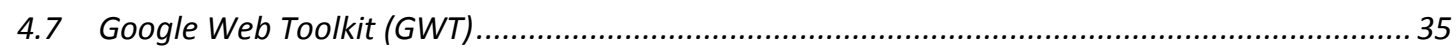

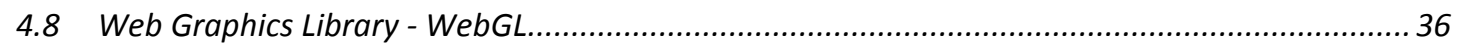


4.8.1 Estrutura de uma aplicação WebGL..............................................................................38

4.8.2 GLSL ES (OpenGL ES Shading Language) ...............................................................41

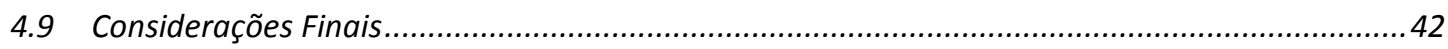

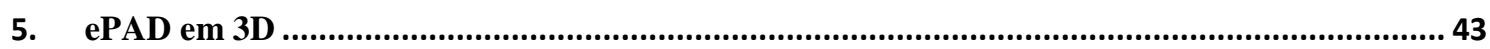

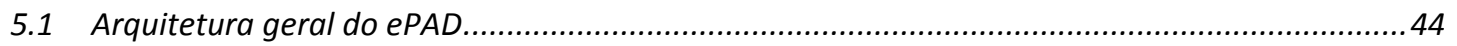

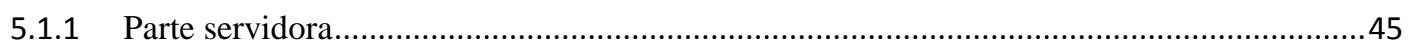

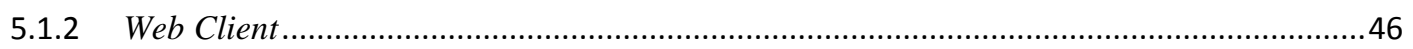

5.1.3 Recuperação de Imagens no Cliente ...........................................................................46

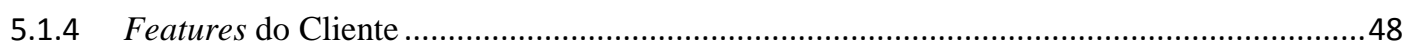

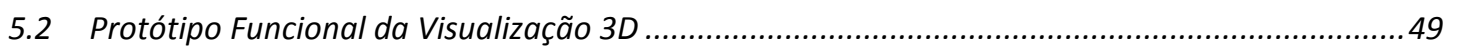

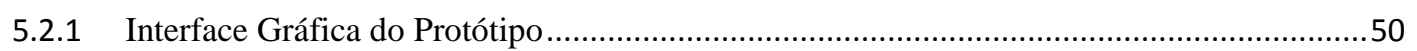

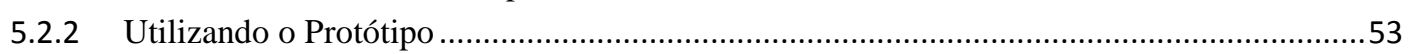

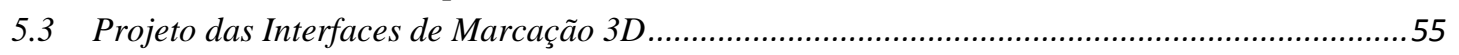

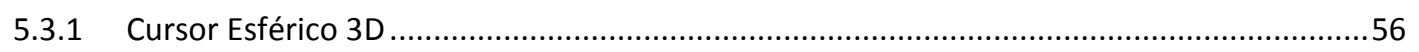

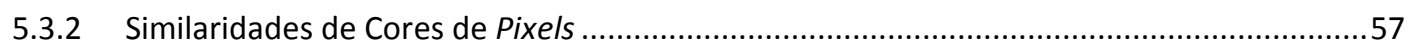

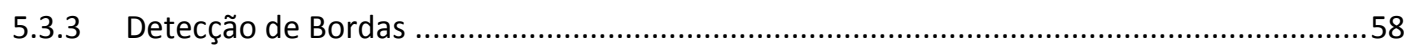

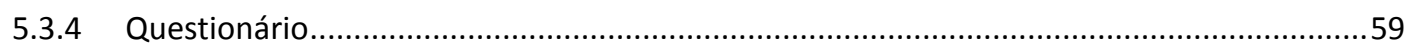

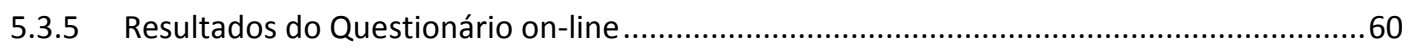

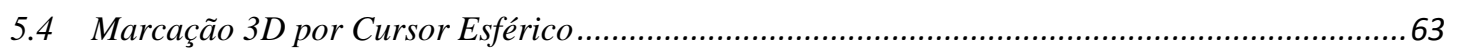

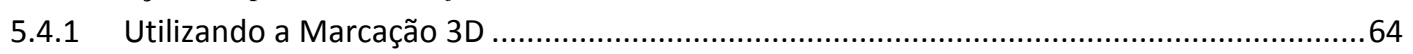

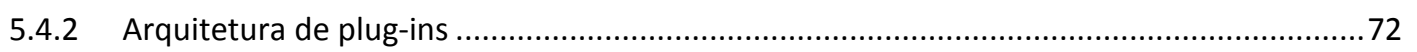

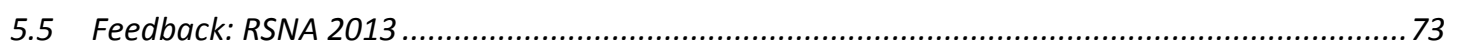

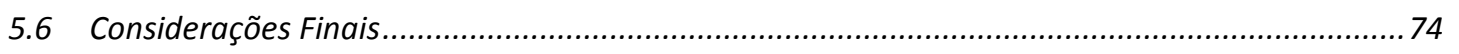

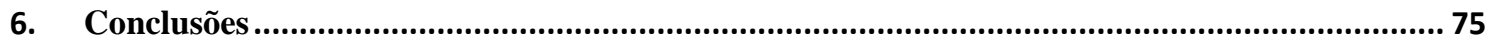

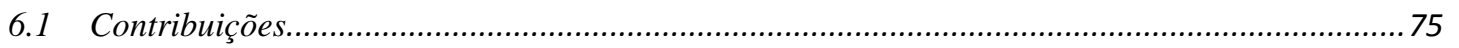

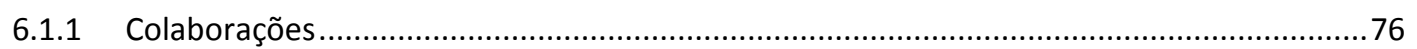

6.1.2 Publicação Relacionada ao Trabalho...................................................................................... 76

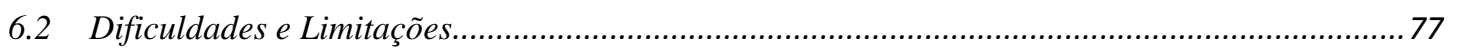

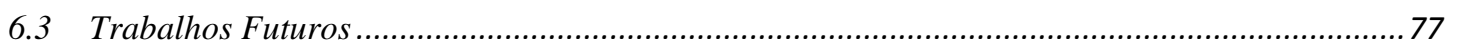

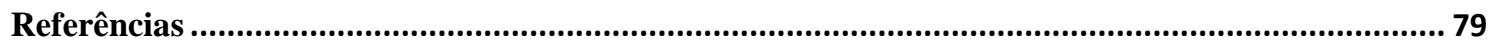

Apêndice A - Questionário aplicado com usuários ................................................................... 83

Apêndice B - Resultados do questionário aplicado aos usuários ............................................. 94 


\section{Lista de Figuras}

Figura 2.1: Fluxos de dados e principais componentes de um PACS (Bui e Taira, 2010). ......8 Figura 2.2: Hierarquia dos objetos do padrão DICOM. ........................................................ 11

Figura 2.3: Arquitetura da plataforma ePAD (Rubin et al, 2014)........................................ 13

Figura 3.1: Arquitetura "Bolo de Noiva" da Web Semântica (Pollock, 2009). ...................... 16

Figura 3.2: Representação de uma tripla do RDF. Fonte: W3C............................................. 18

Figura 3.3: Conjunto de triplas RDF e seu diagrama representativo...................................... 18

Figura 3.4: AIM. Anotações de imagem com medidas, localizações anatômicas e tipos de

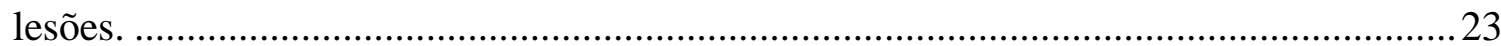

Figura 4.1: Anotação Semântica e marcação de imagem no AIM ClearCanvas ..................... 27

Figura 4.2: Arquitetura com os componentes do OsiriX-iPad (Rosset et al., 2006)................ 28

Figura 4.3: Anotação semântica marcada com o OsiriX-iPad (Rubin et al., 2008). ................29

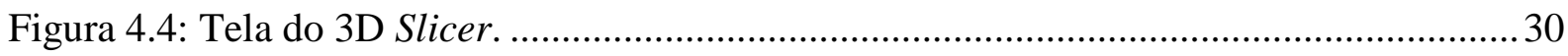

Figura 4.5: Planos ortogonais anatômicos (Axial, Frontal e Sagital) (YassineMrabet/CC-BY-

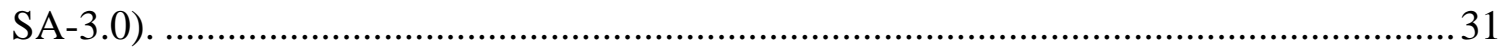

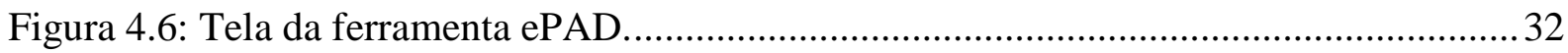

Figura 4.7: Web 2.0, camadas de tecnologias (Shah, 2008)................................................ 35

Figura 4.8: Visão geral da compilação de um programa em GWT......................................... 36

Figura 4.9: Ecossistema relacionado à OpenGL (Khronos, 2008)......................................... 37

Figura 4.10: Pipeline de renderização WebGL (Cantor e Brandon, 2012). ............................. 39

Figura 4.11: Cálculo das cores de pixels individuais (Cantor e Brandon, 2012)....................40

Figura 4.12: Renderização de objetos 3D por vértices e índices (Cantor e Brandon, 2012)....41

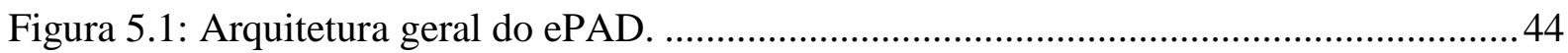

Figura 5.2: Arquitetura da parte servidora do ePAD ......................................................... 45

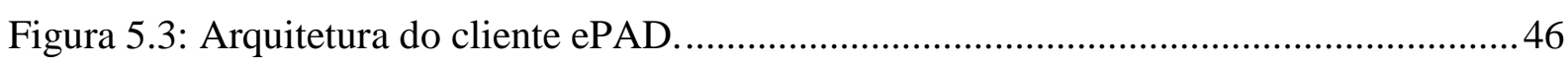

Figura 5.4: 16 imagens (4 linhas por 4 colunas de imagens). ........................................... 48

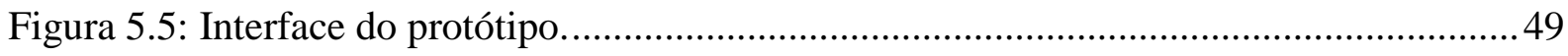

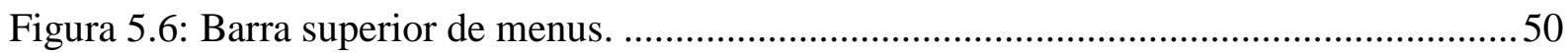

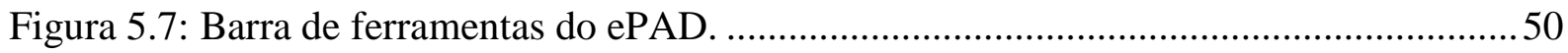

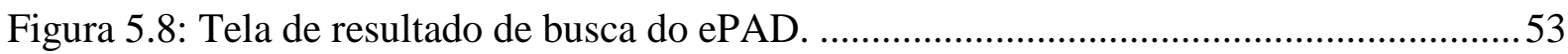

Figura 5.9: Tela de visualização de imagem do ePAD (Display). .........................................54

Figura 5.10: Usuário seleciona posição em que se encontra a lesão a ser marcada. ................55 


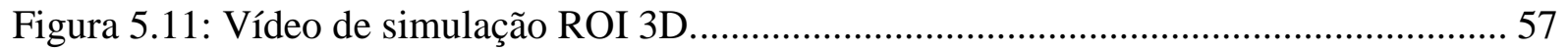

Figura 5.12: Vídeo de similaridades de cores de pixels........................................................ 58

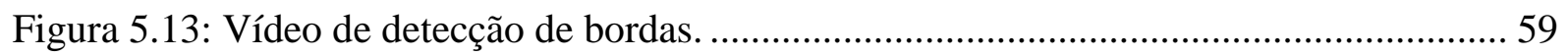

Figura 5.14: Questionário on-line de usabilidade, consistência e visibilidade. ...................... 60

Figura 5.15: Marcação por cursor esférico (em vermelho) sobre imagens (Axial)................. 61

Figura 5.16: Cursor esférico projetado no plano Axial na cor amarela. ................................. 64

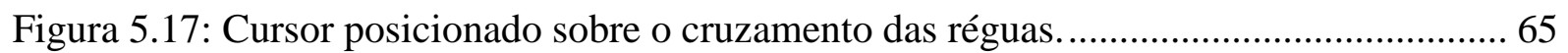

Figura 5.18: Cursor redimensionado com a tecla shift e botão de rolamento do mouse .......... 65

Figura 5.19: Marcação simultânea nos três planos ortogonais (círculos de cor vermelha)..... 66

Figura 5.20: Imagem ampliada com marcação em vermelho e cursor em amarelo.................. 67

Figura 5.21: navegação pelo conjunto inicial de fatias da região volumétrica marcada. ........ 68

Figura 5.22: Navegação em direção à coluna vertebral do paciente (plano Frontal)................ 68

Figura 5.23: Navegação em direção ao lado direito do paciente (plano Sagital)..................... 69

Figura 5.24: Áreas marcadas de forma irregular em todos os planos. ..................................... 70

Figura 5.25: Imagem ampliada com marcação de área irregular........................................... 70

Figura 5.26: Imagem ampliada com marcação irregular no plano Frontal.............................. 71

Figura 5.27: Imagem ampliada com marcação irregular no plano Sagital. ............................. 71

Figura 5.28: Anotação com termos léxicos para armazenamento em AIM XML................... 72 


\section{Lista de Tabelas}

Tabela 1: Partes atuais do padrão DICOM (Parte 9 e 13 foram retiradas).............................. 10

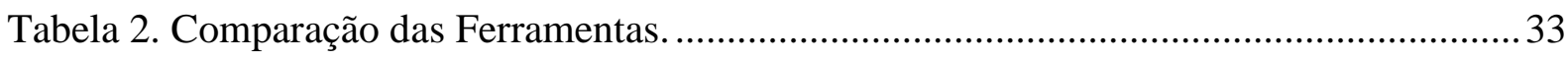

Tabela 3: Lista de funcionalidades da barra de ferramentas. ............................................... 50 



\section{Lista de Abreviaturas e Siglas}

\begin{tabular}{|c|c|}
\hline AIM & Annotation and Image Markup Project \\
\hline ACR & American College of Radiology \\
\hline Ajax & Asynchronous Javascript And XML \\
\hline BIMM & Biomedical Image Metadata Manager \\
\hline BMIR & Biomedical Informatics Research \\
\hline caBIG & Cancer Biomedical Informatics Grid \\
\hline $\mathrm{CCMC}$ & Ciências de Computação e Matemática Computacional \\
\hline CDA & Clinical Document Architecture \\
\hline $\mathrm{CT}$ & Computed Tomography \\
\hline DICOM & Digital Imaging and Communication in Medicine \\
\hline PEP & Prontuário Eletrônico do Paciente \\
\hline ePAD & Electronic Physician Annotation Device \\
\hline ER & Entidade Relacionamento \\
\hline FMA & Foundational Model of Anatomy \\
\hline GLSL & OpenGL Shading Language \\
\hline GWT & Google Web Toolkit \\
\hline HIS & Hospital Information Systems \\
\hline HL7 & Health Level Seven \\
\hline HTML & HyperText Markup Language \\
\hline HTTP & Hypertext Transfer Protocol \\
\hline ICMC & Instituto de Ciências Matemáticas e de Computação \\
\hline Índice ACR & American College of Radiology Index \\
\hline IOM & Institute of Medicine \\
\hline iPad & Image Physician Annotation Device \\
\hline ISO & International Standardization Organization \\
\hline ITK & Insigth Segmentation and Registration Toolkit \\
\hline JPEG & Joint Photographic Experts Group \\
\hline LII & Laboratory of Imaging Informatics \\
\hline LIS & Laboratory Information Systems \\
\hline LOINC & Logical Observation Identifer Names and Codes \\
\hline MIRC & Medical Imaging Resouce Center \\
\hline MPR & Multiplanar Reconstruction \\
\hline MVC & Model View Controller \\
\hline NAS & Network-Attached Storage \\
\hline
\end{tabular}


NCBO National Center for Biomedical Ontology

NCI National Cancer Institute

NEMA National Electrical Manufacturers Association

OWL Web Ontology Language

PACS Picture Archiving and Communication System

PC Personal Computer

PNG Portagle Network Graphics

RadLex Radiology Lexicon

RDF Resource Description Framework

RIA Rich Internet Applications

RIS Radiology Information Systems

ROI Region of interest

RSNA'S Radiological Society of North America's

SAN Storage Area Network

TI Tecnologia da Informação

UID Unique Identifiers

UML Unified Modeling Language

URI Uniform Resource Identifier

USP Universidade de São Paulo

VTK Visualization Toolkit

W3C World Wide Web Consortium

WADO Web Access to DICOM Persistent Objects

WebGL Web Graphics Library

XML Extensible Markup Language

XTK X-Ray Tookit 


\section{Introdução}

A Biomedicina, com seu avanço em estudos e pesquisas no campo entre Biologia e Medicina, tem sido fator de grande importância para a busca de causas para as doenças humanas, seus fatores ambientais e ecoepidemiológicos. Ela tem recebido apoio da informática para a análise e processamento da informação gerada por resultados de suas pesquisas. Esse auxílio computacional torna possível não somente identificar fatores causadores diretos de patologias, de modo mais acelerado, como também permite a produção de uma base de conhecimento sobre fatores correlacionados, às vezes pouco perceptíveis ao olhar médico. A quantidade de dados gerados pelas pesquisas em Biomedicina é surpreendentemente alta e a tecnologia da informação aplicada à biomedicina permite a análise dos mesmos através de técnicas avançadas de computação. A radiologia pode ser inclusa nessa realidade.

Imagens radiológicas podem oferecer uma enorme quantidade de informações de origem anatômica e patológica. Contudo, na maioria das vezes, parte dessas informações não são explicitadas pelos profissionais de Radiologia e, assim, não podem ser armazenadas e automaticamente processadas. Para que sistemas informatizados possam utilizar essas informações de modo compreensível, é importante ter o conteúdo semântico dessas imagens explicitado, juntamente com os diagnósticos dos radiologistas. Esse conteúdo semântico descreve os problemas encontrados e permite a descoberta de novos conjuntos de dados em grandes volumes de imagens.

Para capturar esse conteúdo semântico, o modelo Annotation and Image Markup (AIM) é usado em pesquisas em Radiologia. O modelo AIM foi desenvolvido no projeto cancer Biomedical Informatics Grid (caBIG) - iniciativa do National Cancer Institute (NCI) (Rubin et al. 2008 a). Ele fornece um esquema XML que descreve a estrutura anatômica e as observações visuais em imagens médicas. As anotações sobre as informações da imagem são gravadas no AIM XML compatível com o AIM schema, permitindo uma representação consistente, armazenamento e transferência de significados semânticos sobre imagens. O AIM pode utilizar a terminologia RadLex (RSNA, 2011) para realizar anotações sobre imagens radiológicas (Tomografias, Raios-Xs, etc). Ela foi definida pela Academia de Radiologia Americana e consiste em terminologias para a indexação e recuperação uniforme de informações sobre imagens radiológicas. 
Ferramentas estão sendo desenvolvidas para criar anotações sobre imagens radiológicas em formato AIM XML, como por exemplo, o OsiriX-iPad (Rubin et al. 2008 b) - disponível para Mac OS, o AIM ClearCanvas Workstation (Serique et al. 2012) - para Windows e o ePAD (Serique et al, 2012) - disponível para Web. As duas primeiras são ferramentas standalone de código aberto que permitem aos pesquisadores e clínicos criarem anotações semânticas em imagens radiológicas. Elas escondem a complexidade do modelo de informação das anotações dos usuários e permitem que eles descrevam as imagens e suas regiões usando uma interface gráfica que mapeia, de forma semiautomática, as suas descrições para termos de ontologias ou terminologias. O ePAD, por sua vez, levou as funcionalidades do OsiriX-iPad para a plataforma Web, permitindo maior flexibilidade e colaboração ao trabalho dos radiologistas. O ePAD é desenvolvido numa colaboração do ICMC-USP e do Department of Radiology da Stanford University. Ferramentas como o OsiriX-iPad, o ePAD e o AIM ClearCanvas Workstation podem ajudar a reduzir o esforço para se recolher informação estruturada sobre imagens e podem, finalmente, permitir que pesquisadores e médicos possam explorar grandes volumes de imagens usando as relações biológicas e fisiológicas entre os conteúdos das mesmas.

\subsection{Motivação}

Nenhuma das 3 ferramentas mencionadas, AIM ClearCanvas Workstation, OsiriX-iPad e ePAD (versão 1.0), permite a marcação e anotação semântica tridimensionais sobre imagens radiológicas - como Raio-X, Tomografia Computadorizada, Ressonância Magnética e Mamografia - usando um navegador Web. Elas apenas permitem associar anotações a regiões de interesse (Regions of Interest - ROI) em duas dimensões (usando AIM 3.x, no caso do ePAD 1.0), usando linhas, círculos, polígonos, etc. Desse modo, a precisão na obtenção de dados, como parâmetros volumétricos e cálculos de maior diâmetro de lesões, é prejudicada.

De fato, atualmente, não há referências na literatura a ferramentas que permitam a marcação de lesões em imagens radiológicas em três dimensões na plataforma Web sem necessidade de instalação de software local.

Uma nova versão do ePAD está sendo desenvolvida para resolver esse problema. Como a versão 1.0, ela é uma Rich Internet Application (RIA) rodando como uma aplicação Web em um navegador e usa a tecnologia Asynchronous Javascript And XML (AJAX) e o framework Google Web Toolkit (GWT). A biblioteca WebGL (Web Graphics Library) é utilizada para 
permitir a renderização de imagens em 2D e 3D com o auxílio de hardware de aceleração gráfica.

Essa nova versão, o ePAD 2.0, também é resultado da colaboração entre o nosso grupo de pesquisas do ICMC-USP e o do Dr. Daniel Rubin do Laboratory of Imaging Informatics (LII) - Dept. of Radiology da Stanford University School of Medicine.

\subsection{Objetivo}

O objetivo principal deste trabalho foi desenvolver um novo cliente Web para o sistema ePAD que seja capaz de visualizar imagens radiológicas em três dimensões e permitir a marcação de lesões usando superfícies tridimensionais. Sendo um cliente Web, esse cliente é uma ferramenta independente de sistema operacional que não necessita de instalação local.

Será demonstrado, através de testes com usuários especialistas (médicos radiologistas da Stanford University e da Universidade de São Paulo), que o sistema é tecnicamente viável e que, apesar desse cliente executar em um navegador, ele oferece as mesmas características básicas de ferramentas desktop nativas.

São objetivos específicos deste trabalho:

- O desenvolvimento de um protótipo de visualização de imagens radiológicas em 3D usando os três planos de projeção ortogonais - os planos Axial, Frontal e Sagital;

- A proposta de interfaces para marcação das anotações em 3D com a criação de protótipos de vídeo mostrando cada uma delas;

- Determinar, usando a opinião de usuários especialistas, médicos radiologistas (pesquisadores e profissionais da área), a melhor das interfaces para marcação;

- Criação e teste de um protótipo do cliente para o ePAD;

Este projeto foi desenvolvido de maneira colaborativa com o Department of Radiology Stanford University, coordenado pelo professor Dr. Daniel Rubin, e com ajuda também de pesquisadores do Stanford Center for Biomedical Informatics Research (BMIR).

\subsection{Organização do Trabalho}

Este trabalho está estruturado da seguinte maneira:

O capítulo 2 aborda a tecnologia da informação aplicada à biomedicina, sua situação atual, as tecnologias aplicadas na área médica e de pesquisa médica. No capítulo 3, a Web 
Semântica é apresentada e discutida juntamente com seus avanços na criação de tecnologias úteis. São mencionados Bio-ontologias, Índice ACR, RadLex e projeto AIM. O capítulo 4 apresenta ferramentas relacionadas ao projeto proposto enfatizando as atividades de visualização e anotação de imagens médicas e as tecnologias de desenvolvimento de interfaces Web interativas como RIA, GWT e WebGL. No capítulo 5, o protótipo do cliente ePAD em 3D é apresentado e seu desenvolvimento discutido. Por fim, no capítulo 6, são apresentadas as conclusões deste trabalho juntamente com os resultados alcançados e sugestões para trabalhos futuros. 


\section{Tecnologia da Informação Aplicada à Biomedicina}

O uso de computadores na área da saúde tem contribuído para o aumento da qualidade de pesquisas e tratamentos clínicos (Haux, 2010). A computação tem ajudado na redução de custos e na melhoria de análises em acompanhamentos médicos.

Particularmente, prontuários convencionais de pacientes (não-eletrônicos) tornaram-se difíceis de serem acompanhados e acessados por médicos por incluírem informações de naturezas diferentes (como imagens radiológicas, relatórios em texto, etc.), e em formatos diferentes (como papel e mídia eletrônica) (Haux, 2010).

Atualmente, com o advento do uso de Prontuários Eletrônicos do Paciente (PEP), os dados de pacientes tornaram-se mais acessíveis aos médicos sendo utilizados em Sistemas de Informações Hospitalares (Hospital Information Systems - HIS), Sistemas de Arquivamento de Imagens e Comunicação (Picture Archiving and Communication Systems - PACS), Sistemas de Informação Radiológica (Radiology Information Systems - RIS) e Sistemas de Informação Laboratorial (Laboratory Information Systems - LIS) (Bui e Taira, 2010).

A tecnologia da informação aplicada especificamente em radiologia é responsável pelo esforço para a melhoria da eficiência, precisão e confiabilidade dos serviços radiológicos dentro da área médica (Branstetter, 2007). Embora os serviços de arquivamento de imagens e de sistemas de comunicação sejam importantes em informática radiológica, existem outras maneiras pelas quais a tecnologia pode melhorar a eficiência do trabalho dos radiologistas.

Neste capítulo, são apresentados os conceitos relacionados ao PEP e a tecnologia da informação aplicada à biomedicina. Na seção 2.1 são apresentados os conceitos gerais referentes aos PEPs. Em seguida, na seção 2.2, são apresentados os Hospital Information Systems. Na seção 2.3, Picture Archiving and Communication Systems são abordados. Por fim, na seção 2.4, é discutida a padronização de dados e de comunicação na área da tecnologia da informação aplicada à radiologia. 


\subsection{Prontuário Eletrônico do Paciente (PEP)}

Prontuários Eletrônicos do Paciente (PEPs) têm um papel importante e crítico em serviços de saúde modernos (Weber-Jahnke e Mason-Blakley, 2011). Eles são baseados em sistemas computacionais e estão substituindo os modelos em papel, permitindo gerenciamento e acesso informatizados aos dados de pacientes. Os registros médicos fazem parte do chamado prontuário eletrônico, que possui os históricos médicos individuais de pacientes como, por exemplo, os resultados laboratoriais, sinais vitais, dados demográficos, relatórios de medicamentos e de resultados de exames de radiologia.

O Institute of Medicine (IOM), uma organização independente e que faz parte da United States National Academies, divulgou um relatório em 2003 que destaca quatro principais benefícios do PEP (Tang, 2003):

1. PEPs são uma coleção longitudinal de informações eletrônicas de saúde para e sobre pessoas na qual a informação é definida como: informação pertinente à saúde de um indivíduo ou à assistência de saúde oferecida a um indivíduo.

2. PEPs proveem acesso eletrônico imediato a informações de nível pessoal e populacional apenas a usuários permitidos.

3. PEPs fornecem conhecimento e suporte a decisões que aumentam a qualidade, segurança, e eficiência do tratamento de pacientes.

4. PEPs dão suporte a processos eficientes para serviços de assistência à saúde.

Os sistemas de PEP foram desenvolvidos a partir das necessidades dos fluxos de trabalho em áreas da medicina. A seguir, serão discutidos os HIS e como eles alimentam os PEPs com dados de exames de laboratório, informações de receitas médicas, bases de dados demográficos, etc. Também serão apresentados os PACS, que focam no armazenamento e comunicação de imagens médicas.

\subsection{Hospital Information Systems (HIS)}

Os Hospital Information Systems (HIS) existem há mais de trinta anos e podem ser descritos como sistemas que podem possuir coleções de informações, gerar relatórios, permitir análise, comparação e descrição da evolução de dados hospitalares (Reichertz, 2006). Várias funcionalidades principais dos PEPs foram incluídas nos HIS: atendimento clínico, protocolos clínicos, lembretes e alertas, gestão administrativa, ensino e pesquisa, 
possibilitando a exploração e mineração de dados e, consequentemente, a descoberta de tendências em uma população.

Um subconjunto dos HIS são os Radiology Information Systems (RIS), que abordam as funcionalidades dos HIS concentrando-se em radiologia. Eles utilizam os PACS, oferecendo recursos para gerenciamento de imagens de estudos radiológicos e seus resultados. Enquanto os RIS focam nos dados das imagens, os PACS preocupam-se com os fatores de armazenamento e fluxo dos dados da imagem. Contudo, é necessário o uso conjunto dos HIS com os RIS para que radiologistas tenham um histórico vasto do paciente, facilitando o acompanhamento adequado com menos erros de interpretação e garantindo a cooperação entre os médicos e a divulgação de dados entre si.

Os Laboratory Information Systems (LIS), subconjunto dos HIS, lidam com o fluxo de trabalho dos serviços de laboratório e de patologia, oferecendo interfaces de comunicação com os diversos dispositivos utilizados para avaliações químicas e de imunologia, microbiologia, genética e marcadores hispatológicos. Os LIS podem ser compreendidos como um modelo de monitoramento, validação de resultados e divulgação eletrônica destes aos médicos solicitantes.

\subsection{Picture Archiving and Communication System (PACS)}

Os PACS foram inicialmente criados para a Radiologia com o intuito de prover captura, armazenamento e recuperação de imagens médicas digitais através de dispositivos, como scanners, e aplicações de software envolvendo imagens. PACS são úteis por promoverem sustentabilidade e menor custo ao diminuir o uso de papel e filme radiológico, permitindo revisões periódicas, compartilhamento de imagens entre diferentes dispositivos e o aumento da precisão de diagnósticos, além de permitir a visualização por diferentes profissionais de saúde.

As dificuldades no desenvolvimento de um sistema PACS estão relacionadas às diferentes naturezas dos exames radiológicos e o tamanho dos conjuntos de imagens adquiridas, que podem variar de 2 a até mais de 800 MB (Bui e Taira, 2010). Os problemas a serem considerados incluem: o armazenamento de longo prazo, a recuperação e difusão rápidas em rede das imagens para revisão clínica e a indexação de dados das mesmas.

A infraestrutura necessária para um PACS é constituída por sistemas com diferentes componentes, tais como, dispositivos de armazenamento e de intercâmbio de imagens, servidores, redes de comunicação e visualizadores (Huang, 2004). 


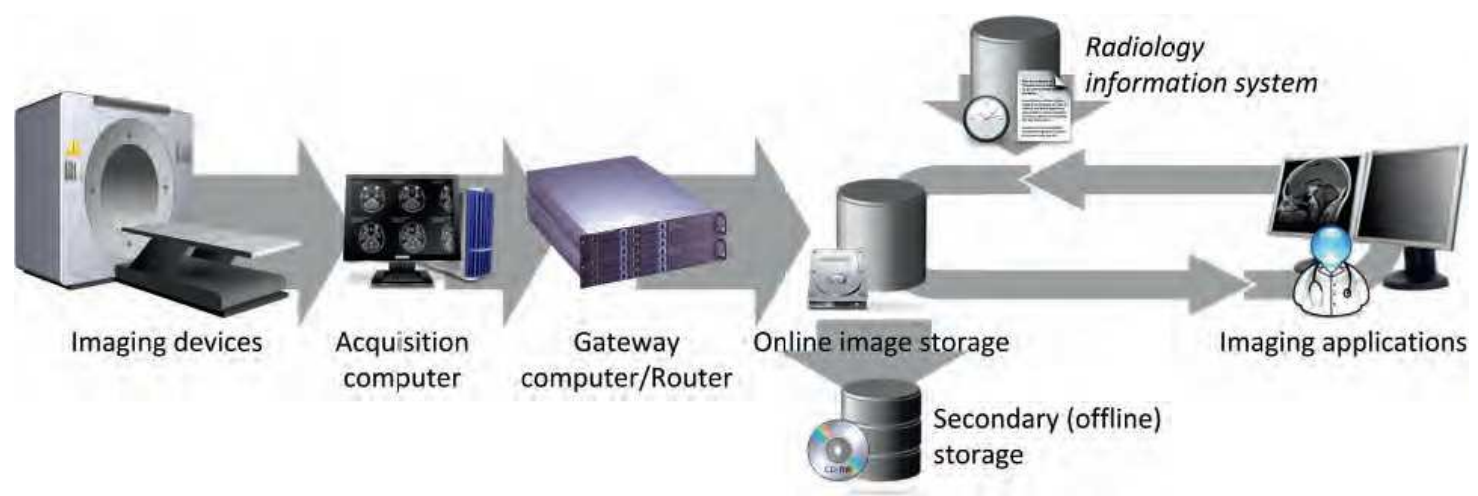

Figura 2.1: Fluxos de dados e principais componentes de um PACS (Bui e Taira, 2010).

A Figura 2.1 mostra os componentes principais de um PACS e o fluxo de informação entre eles. Começando por dispositivos de imagem, sistema de aquisição gateway até o armazenamento online. Desse armazenamento online, imagens podem ser armazenadas offline ou processadas por aplicações médicas. Imagens resultantes desse processamento podem ser armazenadas para uso futuro.

Dispositivos de imagem e computadores de aquisição: Com a introdução dos PACS, as aquisições de imagens médicas transitaram do modo analógico - processo baseado em filme para um sistema de aquisições digitais por dispositivos. Tomografia Computadorizada (CT), Ressonância Magnética (RM), Radiografia Computadorizada (CR), Tomografia por Emissão de Pósitrons (PET), e Raios-X digitais são exemplos desses dispositivos. Em muitos casos, os dispositivos de aquisição de imagens fornecem sinais brutos que precisam ser reconstruídos em fatias ou volumes de imagens. Os computadores de aquisição mantêm uma pequena quantidade de dados armazenados localmente para conjuntos de dados recentes adquiridos e, em seguida, enviam os estudos (imagens) para os PACS, através de um gateway, para o armazenamento definitivo de longo prazo.

O computador gateway ou roteador: é responsável por auxiliar nas tarefas de receber as imagens do computador de aquisição e encaminhá-las para armazenamento ou para outros dispositivos, como estações de trabalho, por exemplo.

Armazenamento de imagens online e armazenamento secundário: $\mathrm{O}$ armazenamento online consiste em um banco de dados de imagens contendo informação sobre as mesmas, armazenamento online de imagens recentes, e armazenamento secundário off-line para estudos mais antigos. O banco de dados é usado para organizar e indexar estudos de imagens (por exemplo, por identificação de paciente, data, etc.) e é atualizado conforme as novas imagens são enviadas pelo gateway. Desse modo, o banco é também capaz de responder a requisições sobre estudos disponíveis e iniciar sua recuperação. $\mathrm{O}$ armazenamento online 
consiste em uma área de armazenamento de acesso rápido, como os Network-Attached Storage (NAS) ou Storage Area Network (SAN). O armazenamento secundário utiliza dispositivos mais lentos para persistência permanente dos arquivos de imagens como, por exemplo, matrizes de discos óticos. Regras que indicam quando imagens deverão ser movidas de armazenamento online para off-line e, vice-versa, fazem parte do arquivo de imagem. Esse recurso é uma forma de garantir a disponibilidade mais eficiente das imagens mais utilizadas ou mais recentes.

Aplicações de imagem: o componente final do PACS são aplicativos clientes que realizam requisições de imagens. Em radiologia, são aplicações em estações de trabalho para visualização de imagens equipadas com dispositivos de alta resolução para análise e diagnóstico. Atualmente, o desenvolvimento de aplicações baseadas na Web vem tornando navegadores Web capazes de realizar a visualização e interação com essas imagens (Bui e Taira, 2010). Outros serviços de processamento de imagens, como simulação em 3D, também estão incluídos nessa camada cliente de imagens.

\subsection{Padronização de dados e de comunicação}

Dada a natureza dos dados médicos e das funções do PEP sua implementação torna-se complexa e multifacetada. A heterogeneidade da informação se apresenta como um problema para a criação de sistemas capazes de acessar e integrar a diversidade dos bancos de dados de pacientes. Padrões foram criados, nas últimas duas décadas, para comunicação entre os diferentes componentes do PEP - citados a seguir.

\subsubsection{Digital Imaging and Communication in Medicine (DICOM)}

O padrão DICOM, estabelecido em 1993, foi criado a partir do padrão ACR-NEMA (American College of Radiology e National Electrical Manufacturers Association) e provê interoperabilidade de dados e de comunicação entre os componentes e fabricantes de dispositivos que integram um PACS (Bui e Taira, 2010).

O padrão DICOM especifica (Bui e Taira, 2010):

1. O conjunto de protocolos de comunicação em rede seguidos pelos dispositivos;

2. Uma sintaxe e semântica para os comandos e informações associadas que podem ser trocadas por esses protocolos; 
3. Um conjunto de meios de armazenamento para ser seguido por dispositivos compatíveis com o padrão, bem como um formato de arquivo, e uma estrutura de diretórios (para facilitar o acesso às imagens, aos dados tipo waveform e informações relacionadas).

O padrão completo do DICOM está disponível online (DICOM, 2009), e não apresenta detalhes de implementação mas oferece um guia e estrutura para a comunicação e armazenamento de imagens médicas digitais. Ele é constantemente atualizado e adaptado para acompanhar as mudanças nas tecnologias associadas à imagens médicas e as necessidades dos usuários.

O padrão atual do DICOM, versão 3.1 de 2008 (Tabela 1), especifica 16 partes oficiais e independentes, padronizadas pela International Organization for Standardization (ISO) (Bui e Taira, 2010) e (Huang, 2010).

Tabela 1: Partes atuais do padrão DICOM (Parte 9 e 13 foram retiradas).

$\begin{array}{ll}\text { Parte } & \text { Descrição } \\ 1 & \text { Introdução e Visão Geral } \\ 2 & \text { Conformidade } \\ 3 & \text { Definições de Objetos de Informações } \\ 4 & \text { Especificação de Classes de Serviços } \\ 5 & \text { Estruturas de Dados e Codificação } \\ 6 & \text { Dicionário de Dados } \\ 7 & \text { Troca de Mensagens } \\ 8 & \text { Apoio à Comunicação em Rede } \\ 10 & \text { Armazenamento de Mídia e Formato de Arquivo } \\ 11 & \text { Perfis de Aplicação de Mídia de Armazenamento } \\ 12 & \text { Formato de Mídia e Meios Físicos } \\ 14 & \text { Exibição de Padrões de Tons de Cinza } \\ 15 & \text { Perfis de Segurança e de Gerenciamento de Sistema } \\ 16 & \text { Recursos de Mapeamento de Conteúdo } \\ 17 & \text { Informações Explicativas } \\ 18 & \text { Acesso Web a Objetos Persistentes DICOM }\end{array}$

O modelo DICOM envolve duas ideias essenciais:

Classes de objetos: todos os dados são representados por uma classe de objetos de informação. Assim, cada entidade, como dados do paciente e de imagens, é especificada por uma classe de objeto. 
Classes de serviços: uma classe de serviço refere-se a um processo no qual dados são gerados, transformados, ou comunicados. Exemplos de serviços são: armazenamento, requisição, recuperação e impressão de imagens.

O núcleo do modelo de dados do DICOM utiliza uma estrutura de Entidade de Relacionamento (ER) e conceitos de orientação a objetos como fundamento para as classes de objetos. A Figura 2.2 mostra a base da hierarquia dos objetos do DICOM, onde o paciente é o objeto do topo da hierarquia.

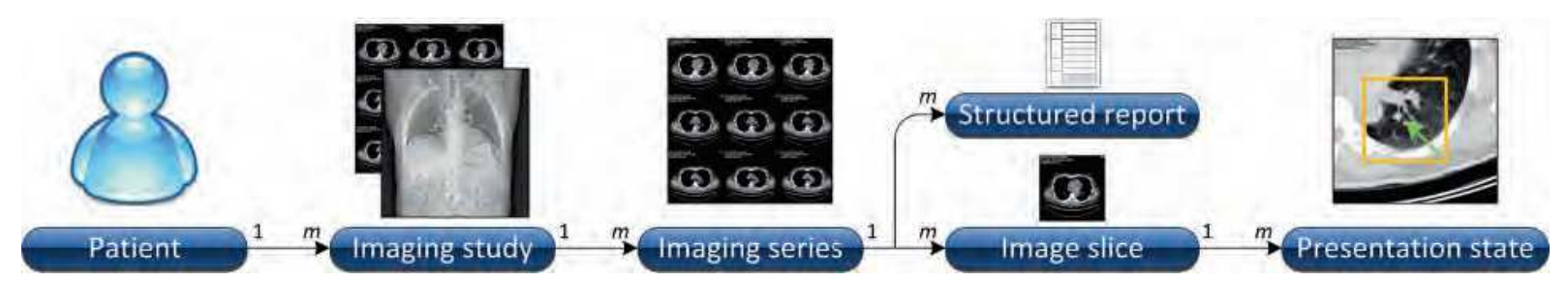

Figura 2.2: Hierarquia dos objetos do padrão DICOM.

Uma imagem em um arquivo DICOM difere de uma imagem PNG ou JPG, pois os valores que ela armazena não são níveis de cinza mas medições (por exemplo, o níveis de raios-X retornados de um ponto em uma Tomografia Computadorizada).

\subsubsection{Web Access to DICOM Persistent Objects (WADO)}

O Acesso Web a Objetos persistentes DICOM (WADO) não é um novo protocolo de comunicação, mas sim uma visão Web do DICOM, ou seja, um serviço para acessar e apresentar objetos DICOM persistentes e um mecanismo simples para visualizar e processar esses objetos. Isso ocorre através de requisições em Hypertext Transfer Protocol (HTTP) (Koutelakis e Lymperopoulos 2006).

Os documentos são obtidos através do protocolo HTTP utilizando um DICOM UID (Unique Identifier) - mundialmente único. Os dados podem ser recuperados em um formato pronto para apresentação, como o JPG, GIF ou DICOM nativo (Huang, 2010).

Servidores PACS DICOM, que provêm o serviço WADO, podem ser utilizados para integração de diversos sistemas na área médica como, por exemplo, o compartilhamento de imagens médicas e prontuários de pacientes. O padrão WADO oferece uma maneira simples e eficiente para o compartilhamento de imagens de diversos centros médicos e, quando necessário, para manter a privacidade dos dados do paciente (Almeida et al. 2008). 


\subsubsection{Health Level Seven (HL7)}

Criado em 1987, o HL7 é um padrão de troca de informações entre sistemas de informação para a área de saúde (Bui e Taira, 2010). O HL7 refere-se ao sétimo nível da camada do modelo OSI (Open Systems Interconnection) - o qual especifica o formato e a estrutura da troca de informações. O objetivo fundamental do HL7 é prover um sistema central de dados de pacientes, bem como um ambiente mais distribuído no qual as informações residem em sistemas departamentais.

\subsubsection{Logical Observation Identifier Names and Codes (LOINC)}

Em 1994, pesquisadores do Regenstrief Institute começaram a desenvolver um sistema universal de codificação para exames laboratoriais - o LOINC. Atualmente, o banco de dados do LOINC contém mais de 50.000 códigos para resultados laboratoriais, medidas clínicas e descobertas em testes diagnósticos. O LOINC tornou-se o padrão de codificação para os Laboratory Information Systems (LIS) e seu principal propósito é codificar a variedade de observações vistas na prática clínica. Juntamente com o HL7, que provê métodos para comunicação eletrônica na área da saúde, o LOINC fornece uma padronização da comunicação dos resultados e observações nas mensagens HL7.

\subsubsection{Tecnologias utilizadas na ferramenta ePAD}

A ferramenta ePAD utiliza as tecnologias mencionadas anteriormente para se integrar a sistemas médicos já existentes. Essa integração consiste não somente na comunicação com repositórios de imagens médicas (PACS), como no entendimento do formato dessas imagens e dos metadados associados a elas.

A Plataforma ePAD é mostrada na Figura 2.3. Ela é formada por cinco componentes principais:

1. O ePAD viewer - um visualizador de imagens e editor de anotações, que roda como uma aplicação no navegador Web. Ele provê uma interface gráfica para visualizar e gravar interpretações de imagens e outros metadados;

2. A aplicação ePAD Web Services, que provê uma interface Web para acesso remoto aos recursos da plataforma;

3. Uma base de dados de imagens. Essas imagens são armazenadas num PACS e acessadas através dos Web Services do ePAD; 
4. Uma base de dados de anotações. Essa base de dados guarda as anotações feitas pelos médicos nas imagens (usando uma linguagem XML, que será discutida no capítulo 3); e

5. Módulos analíticos (plug-ins) para o processamento das anotações das imagens. No caso de clinical trials, existe um módulo para a geração de relatórios da evolução das lesões em cada paciente e uma comparação entre o resultado das diferentes drogas usadas.

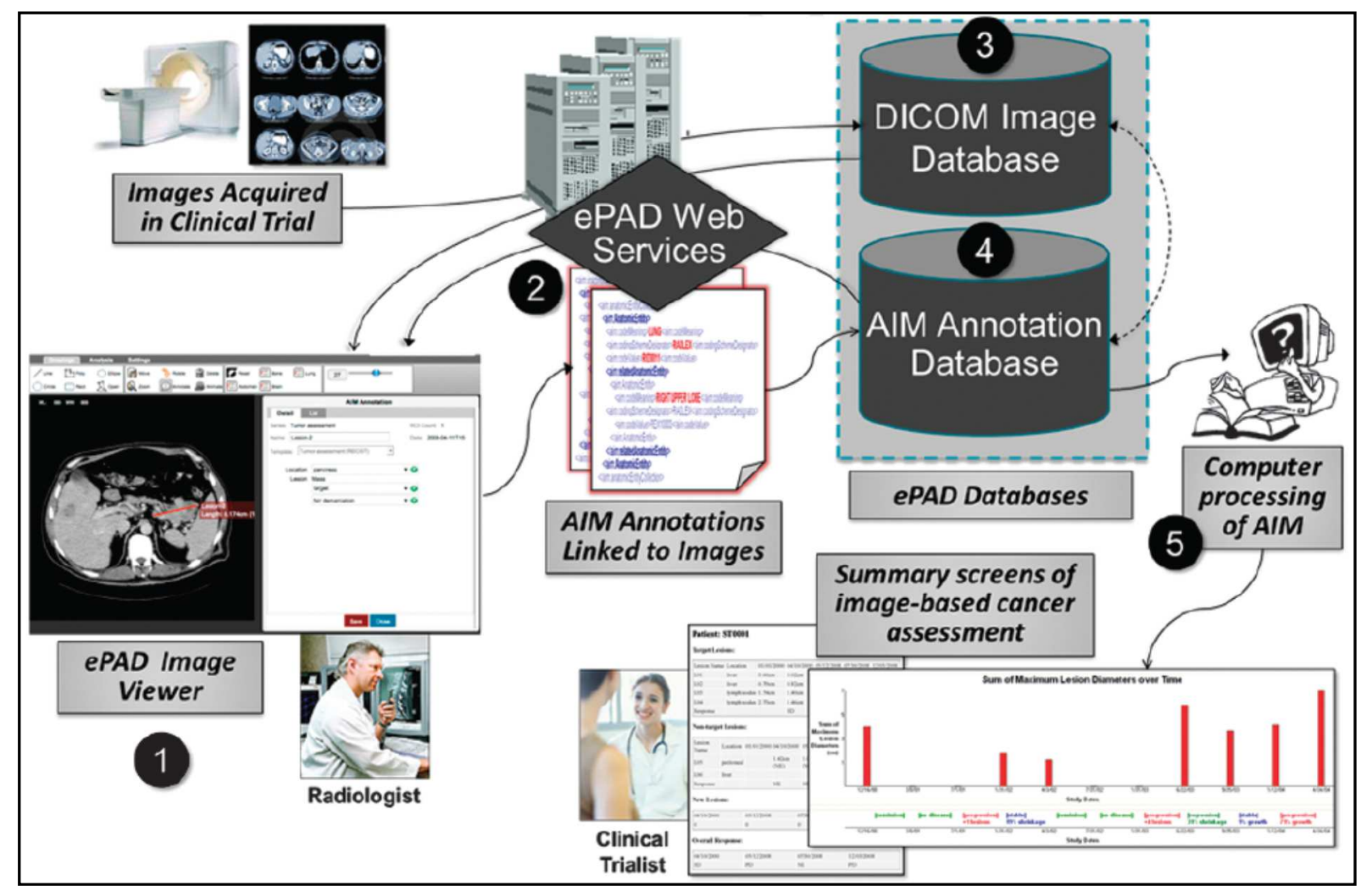

Figura 2.3: Arquitetura da plataforma ePAD (Rubin et al, 2014).

O fluxo de trabalho típico para o processamento de um conjunto de imagens, tiradas de um paciente, e analisadas pelo ePAD num clinical trial é:

a. As imagens são obtidas e armazenadas no PACS;

b. O radiologista usa o $e P A D$ viewer para revisar e anotar as imagens, realizando medidas sobre lesões cancerígenas. Como essa é uma aplicação Web, o médico só precisa apontar o navegador para o endereço do ePAD viewer;

c. Depois que o radiologista escolhe o conjunto de imagens que quer trabalhar, o ePAD viewer se conecta ao ePAD Web Services para obter as imagens;

d. O radiologista usa o ePAD viewer para marcar lesões e adicionar a elas informações semânticas (anotações), na forma de termos de uma ontologia (ver Figura 2.3), e medidas de dimensões. 
e. Todas as anotações sobre as lesões são salvas, pelo ePAD viewer usando o ePAD Web Services, na base de dados de anotações (no formato AIM XML). As anotações têm links para as imagens a que se referem (armazenadas no PACS);

f. Uma variedade de aplicações podem utilizar a base de dados de anotações para acessar os metadados das imagens para diferentes propósitos, como a listagem de medidas de lesões ou a geração de um resumo de acompanhamento de resposta do paciente;

As anotações de informações pertinentes, feitas por profissionais da radiologia, permitem que computadores possam processar esses dados de forma automática. Sem o uso do ePAD, esses dados estariam implícitos em relatórios médicos e, em alguns casos, poderiam estar incompletos. Dados incompletos sobre um paciente podem levar a que esse paciente tenha que ser retirado do clinical trial. Isso aumenta os já altos custos de se conduzir clinical trials, sendo que pacientes extras têm que ser incluídos para compensar a saída de alguns.

\subsection{Considerações Finais}

A tecnologia da informação tem contribuído para o aumento da qualidade em processos de trabalho na área médica. Para isso, pesquisas são realizadas para superar o problema mais grave: a integração de dados médicos de natureza heterogênea. Nas últimas décadas, pesquisas sobre sistemas de informação e de como eles deveriam interoperar resultaram no surgimento de tecnologias como os PEP, HIS e PACS. Padrões para a comunicação entre sistemas de informação e dispositivos médicos foram desenvolvidos e constantemente atualizados como o DICOM, HL7 e LOINC.

Este capítulo mostrou a contribuição da tecnologia da informação no avanço da gestão dos dados de atendimento a pacientes na área de saúde. Esses dados, agora disponíveis em formato eletrônico, e os padrões que os descrevem, permitem trabalhos como o ePAD. Também foi mostrado como o sistema ePAD utiliza ferramentas, como os PACS, para ter acesso a imagens médicas. 


\section{Web Semântica na Área Biomédica}

A área de medicina e ciências da saúde tem despertado o interesse dos pesquisadores da Web Semântica, em parte pelo fato da área médica já usar ferramentas semânticas, como ontologias, e ter muitos dados abertos. Como resultado, o W3C criou o Semantic Web Health Care and Life Sciences Interest Group (HCLS IG) ${ }^{1}$. Sua missão é desenvolver, advocar e suportar o uso de tecnologias da Web Semântica em assistência médica, ciências da vida, pesquisa clínica e na transformação de descobertas em ferramentas de diagnóstico, medicamentos e procedimentos médicos. Através desse e outros grupos, a tecnologia da informação aplicada à biomedicina tem tido sucesso ao aproveitar-se das tecnologias da Web Semântica para obter melhores resultados através da compreensão de informações por computadores.

\subsection{Web Semântica}

A força motriz da iniciativa da Web Semântica é Tim Berners-Lee - a mesma pessoa que inventou o WWW no fim dos anos 1980. Ele possui a visão na qual o significado da informação executa um papel muito mais importante do que na Web atual (Antoniou e Harmelen, 2008).

A maior parte do conteúdo atual na Web é adequada para o consumo de informações pelo ser humano. Até mesmo o conteúdo que é gerado automaticamente, através de bancos de dados, é apresentado sem a estrutura original da informação. O uso típico por usuários envolve pessoas procurando e utilizando a informação, pesquisando e entrando em contato com outras pessoas, realizando compras e outras atividades. As ferramentas mais valiosas e indispensáveis a esses usuários são as de busca. Entretanto, há sérios problemas associados ao seu uso como: baixa precisão (alto número de resultados pouco relevantes) ou resultados sensíveis ao vocabulário.

A proposta da Web Semântica é representar o conteúdo Web de uma forma que ele seja mais facilmente processável por máquinas e utilizar técnicas inteligentes que aproveitem essa representação. O objetivo é permitir o gerenciamento de conhecimento na Web na seguinte forma:

\footnotetext{
${ }^{1}$ http://www.w3.org/blog/hcls/
} 
- Conhecimento será organizado em espaços conceituais de acordo com seu significado;

- Ferramentas automatizadas suportarão a manutenção pela checagem de inconsistências e extração de novos conhecimentos;

- Busca por palavras-chave será substituída por respostas a requisições: conhecimento requisitado será obtido, extraído e apresentado de forma amigável ao ser humano;

- Respostas a requisições englobando vários documentos serão suportadas;

- Definições sobre quem poderá ver certas partes da informação;

Em 2000, durante uma conferência sobre XML, Tim Berners-Lee propôs um modelo de camadas para a arquitetura da Web Semântica, conhecida como "Bolo de Noiva" (Breitman, 2005). O modelo atual, apresentado na Figura 3.1, expõe as camadas das principais tecnologias da Web Semântica.

\begin{tabular}{|c|c|c|c|c|}
\hline \multicolumn{5}{|c|}{ Semantic Web Applications } \\
\hline & & \multicolumn{3}{|c|}{ Trust } \\
\hline & & \multicolumn{2}{|c|}{ Proof } & \\
\hline \multicolumn{4}{|c|}{ Unifying Logic } & \\
\hline \multirow{2}{*}{$\begin{array}{l}\text { SPAROL } \\
\text { (Query) }\end{array}$} & OWL 10 & & \multirow{2}{*}{$\begin{array}{c}\text { RIF } \\
\text { (Rules) }\end{array}$} & $\vec{z}$ \\
\hline & RDFS (Gra & lema) & & \\
\hline \multicolumn{4}{|c|}{ RDF (Graph Data) } & $=$ \\
\hline \multicolumn{2}{|c|}{ Other (Serialization) } & \multicolumn{2}{|c|}{ XML (Serialization) } & \\
\hline \multicolumn{4}{|c|}{ Uniform Resource Identifier } & \\
\hline \multicolumn{4}{|c|}{ Unicode } & \\
\hline
\end{tabular}

Figura 3.1: Arquitetura "Bolo de Noiva" da Web Semântica (Pollock, 2009).

A ideia central desse modelo de camadas é adicionar gradualmente cada nova camada, trazendo novas funcionalidades, como o aumento de expressividade, possibilidade de realizar inferência e autenticação, gradativamente. A arquitetura permite construir algo novo em cima do que já existe e não reinventar tudo novamente (Breitman, 2005). A justificativa para isso é que, na internet, é fácil obter consenso sobre pequenas modificações, enquanto é muito difícil conseguir apoio a mudanças radicais.

Na Figura 3.1, as tecnologias RDF (Resource Description Framework) e OWL (Web Ontology Language) fazem parte da base da Web Semântica, desde o momento em que esses padrões foram recomendados em 2004. Elas têm demonstrado serem estáveis mesmo desde suas primeiras versões. 
A RDF, ontologias e a OWL são detalhadas nas Seções 3.2, 3.3 e 3.4, respectivamente, por estarem envolvidas nas camadas da Web Semântica, ilustradas na Figura 3.1.

As ontologias foram criadas para auxiliar a Web Semântica por meio de termos e relacionamentos, seguindo um padrão para compartilhamento de informação entre agentes, incluindo softwares.

\subsection{Ontologias}

O termo ontologia originou-se da Filosofia. Nesse contexto, ele é usado como o nome de um subcampo da Filosofia - o estudo da natureza da existência, o ramo da Metafísica preocupado com a identificação dos tipos de coisas que realmente existem e como descrevêlas (Antoniou e Harmelen, 2008). Por exemplo, a observação de que o mundo é feito de objetos específicos que podem ser agrupados em classes abstratas baseadas em propriedades compartilhadas é um compromisso ontológico. Na Web Semântica, o papel das ontologias é de explicitar termos e relacionamentos utilizados e de servir como padrão para o compartilhamento de informação de modo significativo entre agentes, softwares e aplicações (Breitman, 2005).

Em geral, uma ontologia descreve formalmente um domínio. Ela consiste de uma lista de termos e dos relacionamentos entre eles. Os termos referem-se a conceitos (classes de objetos) importantes como funcionários, estudantes, cursos, auditórios e disciplinas (usando-se o ambiente universitário). Os relacionamentos incluem hierarquias de classes. Uma hierarquia especifica uma classe C como uma subclasse de outra classe C' se todo objeto em C estiver também incluso em C'. Por exemplo, secretário faz parte do quadro de funcionários. Uma ontologia também especifica axiomas e instâncias, além de ser expressa por meio de uma linguagem de construção. Os componentes básicos de uma ontologia são definidos por meio de uma linguagem de representação. Diferentes linguagens para ontologias proporcionam diferentes facilidades (Horridge et al., 2004).

As linguagens da Web Semântica, usadas para representar ontologias, são baseadas em extensões do RDF (Resource Description Framework). A principal linguagem baseada em RDF foi a OWL, sendo recomendada e mantida pela W3C. 


\subsection{RDF (Resource Description Framework)}

O Resource Description Framework (RDF), recomendação do W3C de fevereiro de 2004, é uma linguagem baseada em XML com o propósito geral de representar informação na Web (W3C, 2004). Como mostrado na Figura 3.1, ele é a base da arquitetura de camadas da Web Semântica.

O RDF contém uma estrutura básica de sentenças baseadas em triplas de termos, o sujeito, predicado e objeto, que juntos e nesta ordem representam uma declaração em RDF, veja na Figura 3.2.

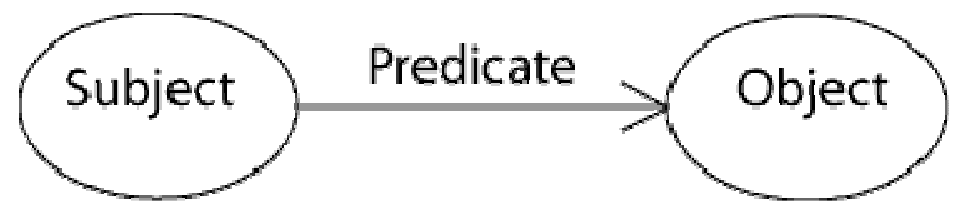

Figura 3.2: Representação de uma tripla do RDF. Fonte: W3C

O Sujeito é a primeira parte de uma expressão RDF, ele identifica o recurso sendo descrito. Este pode ser uma página Web, parte de uma página, uma palavra contida em uma página, o site inteiro ou até mesmo um objeto do mundo real, por exemplo, um livro. $\mathrm{O}$ recurso é identificado por um Uniform Resource Identifier (URI) que é usado como o nome do recurso.

O Predicado é utilizado como um nome para uma propriedade, ou seja, ele pode ser usado para descrever algum aspecto específico, atributo, característica ou relação de um determinado recurso.

O Objeto é um valor de tipo estabelecido ou um literal.

Um Grafo RDF é um conjunto de declarações em RDF. Uma declaração é uma tripla RDF. A Figura 3.3 mostra linhas de código RDF (em XML) e seu diagrama, respectivamente.

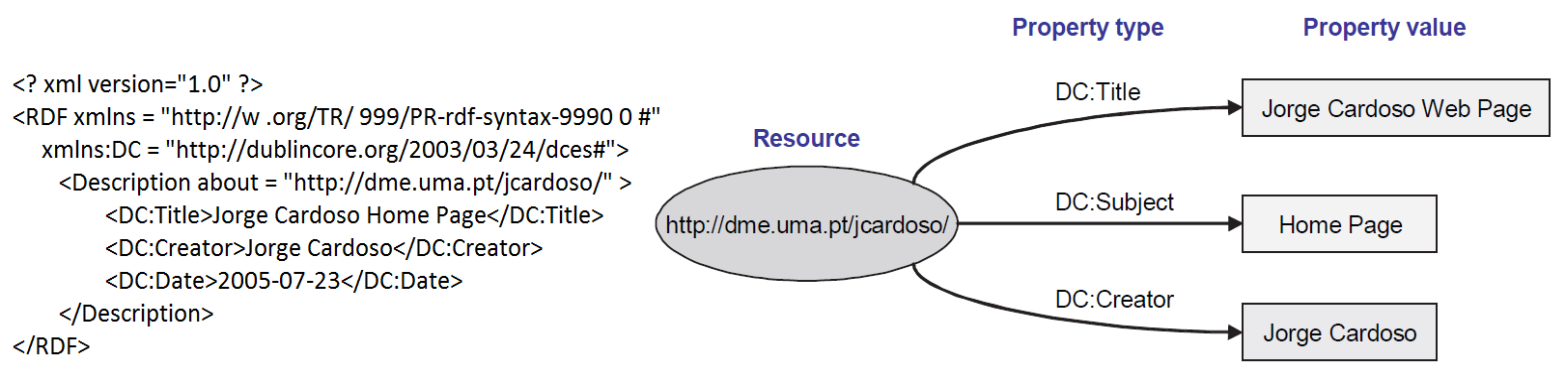

Figura 3.3: Conjunto de triplas RDF e seu diagrama representativo. 


\subsection{OWL (Web Ontology Language)}

O poder de expressividade do RDF é limitado. De fato, o Web Ontology Working Group do W3C identificou um número de casos de uso para a Web Semântica que exigiria muito mais expressividade do que o RDF (Antoniou e Harmelen, 2008). Surgiu, então, a linguagem OWL - definida para ser a linguagem padrão para ontologias e ser amplamente usada na Web Semântica. Ela permite suporte a raciocínio eficiente e conveniência de expressão de conceitos usando lógica descritiva (description logic), uma família de linguagens formais para a representação de conhecimento. A linguagem OWL está na versão 2, que foi considerada um passo substancial para a evolução da linguagem em relação às versões anteriores (Grau et al., 2008).

Ontologias em OWL foram desenvolvidas em várias áreas, como, medicina, biologia, geografia, astronomia, defesa nacional e nas indústrias automobilística e aeronáutica (Grau et al., 2008). As ontologias destinadas às áreas de medicina e biologia originaram as bioontologias.

\subsection{Bio-ontologias}

Cientistas da área biomédica desde cedo perceberam as diferentes maneiras que ontologias poderiam auxiliar em suas pesquisas. Eles já utilizavam artefatos ontológicos antes mesmo do surgimento da Web Semântica, daí o interesse do W3C. No início, os artefatos mais utilizados eram terminologias e vocabulários controlados, formando listas de conceitos e descrições textuais de seus significados. Eles foram criados principalmente para permitir que pesquisadores resolvessem alguns dos problemas relacionados à explosão de dados obtidos em seus trabalhos.

$\mathrm{Na}$ área de radiologia, a necessidade de indexar arquivos médicos para análise de patologias em imagens médicas coletadas originou o Índice ACR.

\section{6 Índice ACR e o Medical Imaging Resource Center}

Os radiologistas realizam seu trabalho analisando imagens em seus relatórios e registros médicos. Com o intuito de organizar melhor e recuperar esses dados analisados, eles necessitam de uma linguagem unificada com o uso de um léxico comum. 
O American College of Radiology (ACR) desenvolveu o Index for Radiological Diagnosis - conhecido como o Índice ACR - para servir de base para um sistema de indexação de arquivos para o ensino em radiologia. Inicialmente, esse índice foi utilizado para organização e categorização dos processos de indexação com base em imagens interessantes coletadas por radiologistas.

O Índice ACR tem o auxílio de códigos numéricos (separados por pontos). O primeiro conjunto numérico serve para a localização da anatomia e, o segundo (depois do ponto), para identificar a entidade patológica. Por exemplo, no código ACR 642.3212 o número 3212 corresponde a "primary adenocarcinoma" e 642 em "lingula" (Langlotz, 2006). Esses códigos referenciam terminologias. Esse processo de numeração permite que radiologistas se recordem dos códigos relativos a lugares anatômicos que, geralmente, são utilizados para categorização de suas bibliotecas de imagens pessoais.

Recentemente, os computadores facilitaram o gerenciamento e a organização de termos de índices e suas inter-relações. Dicionários online, por exemplo, são considerados ferramentas muito valiosas já que possuem milhares de registros.

Para contribuir com um melhor gerenciamento digital de imagens, o RSNA (Radiological Society of North America) desenvolveu o Medical Imaging Resource Center (MIRC) conjunto de ferramentas para usuários se conectarem a arquivos didáticos eletrônicos através da internet. O MIRC oferece também a possibilidade da criação de material didático e de outras formas de anotações em bibliotecas digitais pessoais.

A necessidade de sistemas de indexação informatizados mais modernos, levou a RSNA a desenvolver o RadLex (RSNA, 2011), como resposta às lacunas encontradas em outras terminologias radiológicas.

\subsection{RadLex}

RadLex é uma ontologia, instanciada em OWL (Web Ontology Language), que reúne, de forma unificada, os termos usados em radiologia (Langlotz, 2006). Ela consiste em uma terminologia controlada para a radiologia com mais de 68.000 elementos - uma fonte singular unificada de termos da prática, educação, e pesquisa na área. O RadLex satisfaz as necessidades de desenvolvedores de software, vendedores de sistemas e usuários de radiologia por meio da adoção das melhores características de sistemas de terminologia existentes, permitindo a produção de novos termos. A RSNA desenvolveu um navegador de termos (radlex.org) que permite a visualização da estrutura e conteúdo do RadLex de uma 
forma conveniente a usuários potenciais (RSNA, 2011). Por exemplo, o termo Ct device (dispositivo de tomografia computadorizada) faz parte da classe Imaging device (dispositivo de imagens), que consiste em um Medical device (dispositivo médico), que, por sua vez, é um Medical object (objeto médico) que é um Object (objeto).

A RSNA teve o apoio do ACR (American College of Radiology) para que os materiais de ensino de radiologia usassem os índices do RadLex. Além disso, houve apoio do College of American Pathologists na utilização de um subconjunto de termos estendidos do SNOMEDCT, como um ponto de partida para criação do RadLex. Outras cooperações com outras normas tornaram o RadLex mais abrangente, como a norma DICOM. Houve também o apoio de uma vasta gama de profissionais da área de radiologia (Langlotz, 2006). O RadLex está disponível para download no site Bioportal do National Center for Biomedical Ontologies ${ }^{2}$.

O RadLex é usado em anotações sobre imagens na ferramenta ePAD com o auxílio da infraestrutura oferecida pelo projeto AIM.

\subsection{Annotation and Image Markup (AIM)}

As imagens médicas modernas contêm uma grande quantidade de informações no formato padrão DICOM. A maior parte dessas informações está no conteúdo dos dados nos seus respectivos pixels. Esses dados contêm um rico conteúdo que não está explícito ou acessível às máquinas. Essas informações são interpretadas por observadores humanos, como os radiologistas, mas não são capturadas ou relacionadas às imagens usando uma forma mais estruturada de informação (Rubin et al., 2008a).

O projeto Annotation and Image Markup (AIM), em sua terceira versão, é o formato padronizado para armazenamento de informação quantitativa e qualitativa sobre imagens médicas. Ele também permite atingir os requisitos estabelecidos pela caBIG In Vivo Imaging Workspace (Rubin et al., 2008a). O caBIG (Cancer Biomedical Informatics) é um programa que foi criado em 2004 pelo National Cancer Institute (NCI) com a intenção de facilitar o compartilhamento de infraestrutura, dados e aplicações ao longo dos mais de 50 centros de câncer nos EUA (Prior et al., 2007). O projeto AIM consiste em um modelo de informação que oferece uma infraestrutura para a criação de coleções de anotações médicas sobre imagens. O projeto baseia-se no formato AIM XML de anotação e marcação em imagens

\footnotetext{
${ }^{2}$ http://bioportal.bioontology.org/ontologies/40885
} 
médicas em DICOM ou outros formatos. Essas anotações e marcações são consideradas como um objeto de informação sobre as imagens, que não está ligado fisicamente às mesmas.

O modelo de informação AIM (AIM schema) é descrito em (Rubin et al., 2008a) com o auxílio de um diagrama de classes UML. Ele é a base para expressar a captura de informações contidas nas imagens médicas através de anotações e marcações de informações relevantes. Uma anotação pode ser explicativa ou uma descrição de informação, gerada por seres humanos ou por máquinas, e é relacionada ao conteúdo de uma ou várias imagens. As anotações tornam-se uma coleção de descrições de conteúdo que podem ser usadas para fins de mineração de dados semânticos. A marcação de imagem é composta por símbolos gráficos ou descrições textuais associados à imagem. Isso auxilia na descrição de uma informação textual e das regiões de interesse visual. As informações são usadas para criar um documento, obedecendo o AIM schema, através de funções da biblioteca de software AIM. Usando-se o AIM schema é possível a geração de objetos DICOM SR, documentos AIM XML e documentos HL7 CDA.

De forma geral, o projeto AIM é constituído pelo modelo de informação AIM schema e por uma biblioteca (implementada em $\mathrm{C}++$ ) para criação de anotações no modelo AIM schema, AIM XML, DICOM e HL7 CDA.

\section{9 ePAD e AIM}

A Figura 3.4 mostra parte dos dados de uma anotação AIM que a ferramenta ePAD permite armazenar. As anotações descrevem os resultados de interpretação de imagem. Para estudos do câncer, elas incluem identificação da imagem, momento de obtenção da imagem, nome da lesão, localização anatômica, tipo de lesão, comprimento do segmento de marcação visual da lesão na imagem, entre outros. 


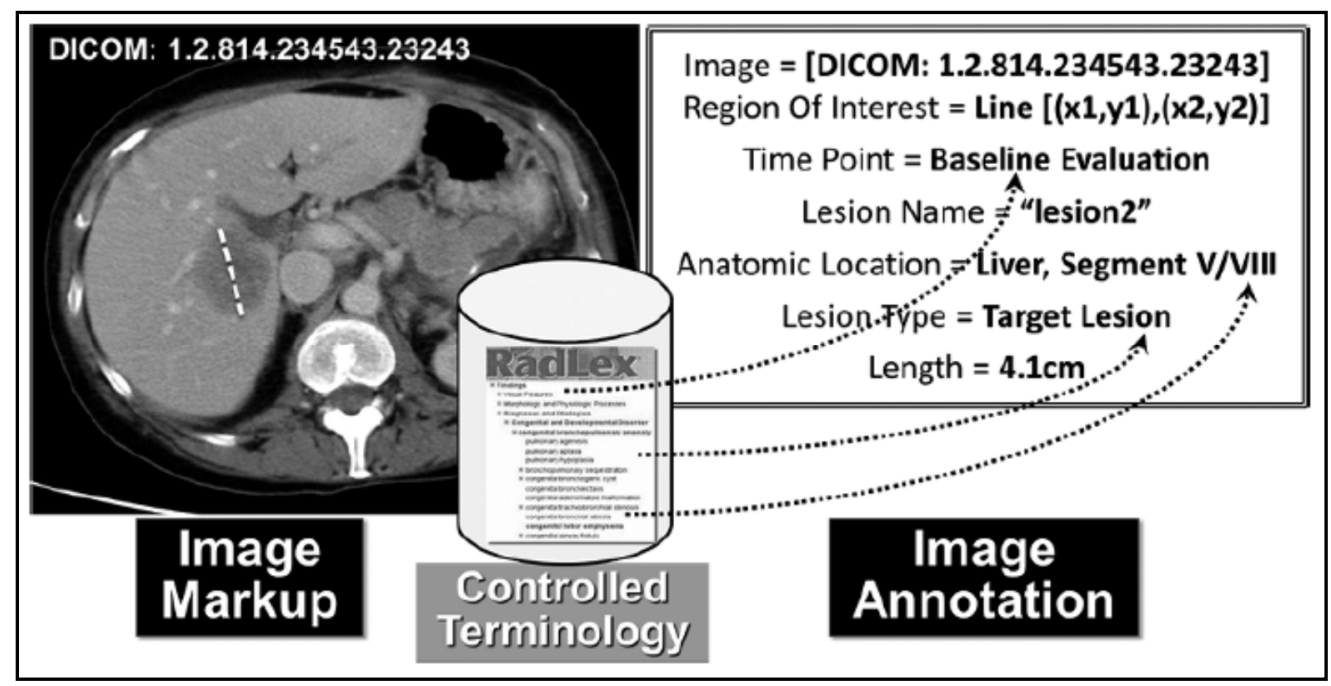

Figura 3.4: AIM. Anotações de imagem com medidas, localizações anatômicas e tipos de lesões.

O ePAD permite a marcação de lesões sobre imagens médicas e a associação de anotações AIM utilizando o RadLex. Essas anotações podem ser baseadas em templates, como a RECIST ${ }^{3}$ (Response Evaluation Criteria In Solid Tumors) um conjunto público de regras que definem quando pacientes de câncer melhoram ("respond"), ficam na mesma ("stable") ou pioram ("progression") durante tratamento.

Atualmente, não é possível ainda armazenar os dados gráficos das marcações em 3D devido à versão do AIM utilizada, AIM 3, não dar suporte. A versão 4 do AIM tornará possível o armazenamento dessas marcações juntamente com seus dados quantitativos e qualitativos.

\subsection{Considerações Finais}

A Web Semântica e suas tecnologias derivadas, como RDF e OWL, estão tornando o trabalho na área de saúde mais flexível, ágil e otimizado. Uma das dificuldades em concretizar o grande potencial das ontologias em pesquisa biomédica é o isolamento das várias comunidades envolvidas. Alguns pesquisadores dedicam uma considerável quantidade de tempo de suas carreiras desenvolvendo ontologias e ferramentas relacionadas enquanto poucos pesquisadores (biólogos e médicos) sabem como ontologias podem realmente acelerar suas pesquisas. Padrões médicos que utilizem tecnologias da Web Semântica, como o RadLex (disponível em OWL), tem o potencial de possibilitar a interoperabilidade e o uso de

\footnotetext{
${ }^{3}$ http://www.recist.com
} 
ferramentas (como o ePAD) auxiliando pesquisas médicas e biológicas permitindo a criação de melhores soluções com o apoio de computadores.

No caso da radiologia, padrões como o RadLex (OWL) e o AIM (XML) são utilizados por ferramentas, como o ePAD, para gerar relatórios médicos estruturados e diretamente processáveis por máquinas. 


\section{Ferramentas de Anotação Radiológicas}

Neste capítulo, são apresentadas ferramentas utilizadas por radiologistas para visualização de imagens médicas, marcação, criação e gerenciamento de anotações semânticas sobre as mesmas - algumas usando o padrão AIM. Depois de uma busca bibliográfica na literatura da área, não foi encontrada nenhuma ferramenta para marcação 3D e anotação radiológica que seguisse o formato AIM XML e que fosse baseada na Web (usando apenas um navegador), como o ePAD. Foi encontrada uma aplicação comercial, o syngo.via WebViewer da Siemens ${ }^{4}$, que pode apenas mostrar mas não anotar, nem realizar marcação 3D sobre imagens médicas via Web.

Foram encontradas duas ferramentas desktop que permitiam marcações $2 \mathrm{D}$ e anotações em imagens médicas baseadas no formato AIM XML: o AIM ClearCanvas Workstation e o OsiriX-iPad (OsiriX com iPad plugin). Uma terceira ferramenta desktop foi encontrada, chamada 3D Slicer, que permite marcações em três dimensões sobre imagens médicas, mas não no formato AIM XML.

$\mathrm{O}$ ePAD versão 1.x é a base para criação da solução desenvolvida neste trabalho. $\mathrm{O}$ ePAD usa tecnologias Web interativas, como RIA, GWT e WebGL, que serão discutidas na seção 4.5.

\section{1 caBIG Tools}

Em 2005, o caBIG, criou o projeto In Vivo Imaging Workspace para promover o uso de imagens médicas no estudo do câncer. O principal objetivo desse projeto é promover avanços no campo da informática radiológica através do desenvolvimento, otimização e validação de ferramentas computacionais para extrair conhecimentos, a partir de imagens médicas in vivo, e melhorar, dessa forma, os resultados dos pacientes com câncer (Prior et al., 2007).

Recentemente, o caBIG apoiou dois projetos de ferramentas para anotação semântica de imagens médicas no formato AIM XML: o AIM ClearCanvas Workstation e o OsiriX-iPAD (renomeado posteriormente para AIM ePAD).

\footnotetext{
${ }^{4} \mathrm{http}: / /$ healthcare.siemens.com/medical-imaging-it/syngoviaspecialtopics/syngovia-webviewer
} 


\subsubsection{AIM ClearCanvas Workstation}

O AIM ClearCanvas Workstation é um pacote de soluções de código aberto que inclui um servidor de imagens (PACS), um RIS, e um programa cliente para visualizar imagens médicas compatível com o sistema operacional Microsoft Windows (Serique et al., 2012). Essa ferramenta permite a busca por imagens e estudos médicos em PACS e também no National Biomedical Imaging Archive - um serviço aberto que oferece armazenamento, busca e identificação de imagens aos usuários. Ela também provê um conjunto de funcionalidades para criação, edição e visualização de anotações AIM:

- AIM TCGA (The Cancer Genome Atlas) Template Tool - permite anotações baseadas em questões e respostas capturadas.

- AIM Object Locator - lista todos os objetos AIM de um estudo (conjunto de imagens) sem precisar passar por todas as imagens.

- AIM Details Tool - oferece a visualização detalhada de informação de entidades anatômicas e de observações de imagens, quando o usuário seleciona uma marcação gráfica para anotação já existente.

- Line Measurement Tool - permite que o usuário meça o maior diâmetro da lesão e calcule seu tamanho aproximado.

As informações das anotações realizadas pelo usuário são salvas localmente no formato AIM XML. A imagem anotada permanece inalterada.

O formulário de anotação usado, baseado na AIM TCGA template tool, é exibido na Figura 4.1. O rótulo 1 mostra a localização do botão de ativação da ferramenta dentro do AIM ClearCanvas. O rótulo 2 fixa o pop-up de anotação na interface do AIM ClearCanvas. O rótulo 3 apresenta o formulário carregado a partir de um AIM TCGA template. 


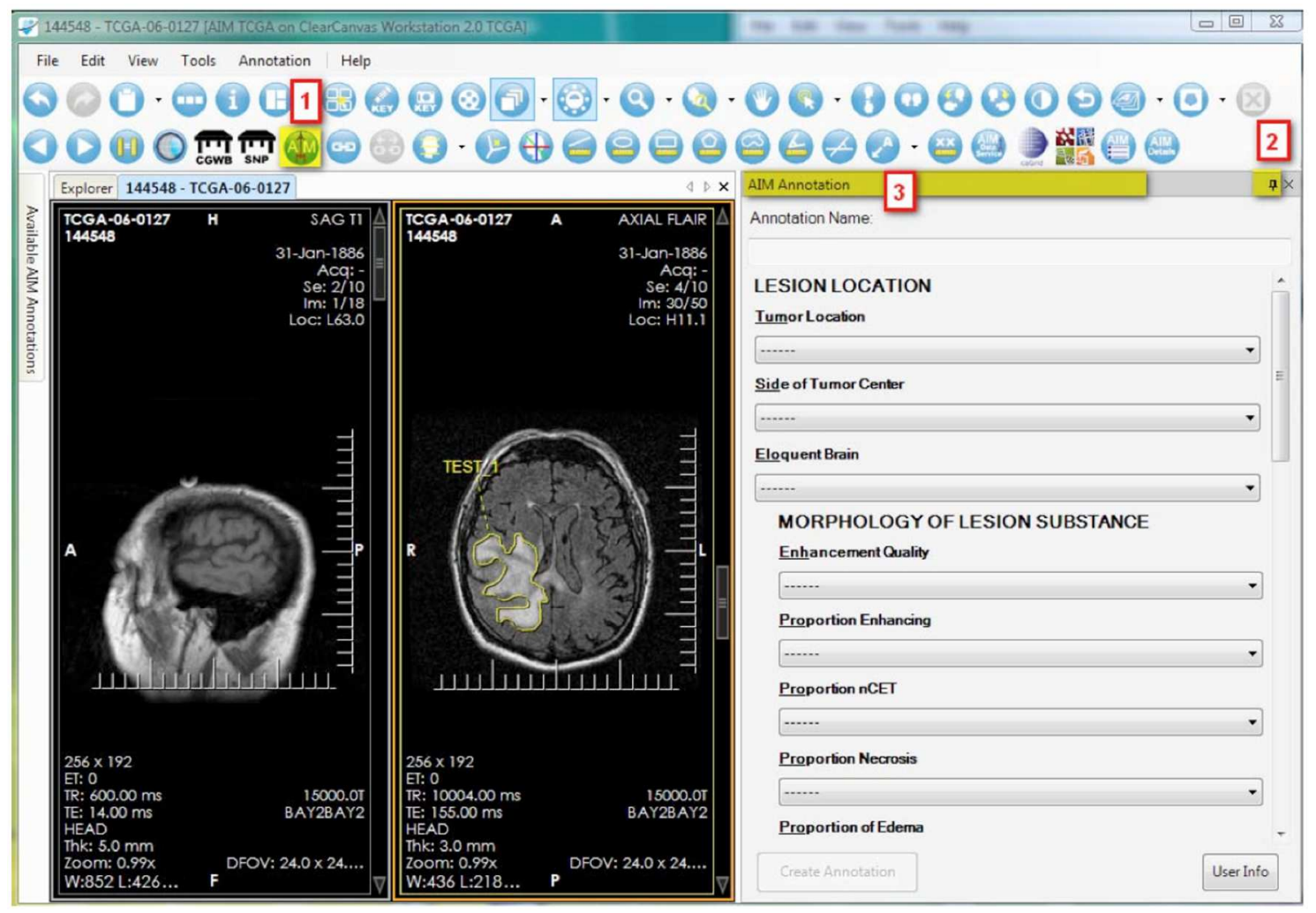

Figura 4.1: Anotação Semântica e marcação de imagem no AIM ClearCanvas

Os arquivos de anotação mantêm referências às imagens marcadas com dados dos ROIs (Regions of Interest), que são desenhos geométricos, criados pelo usuário, delimitando a região anotada nas imagens.

O AIM ClearCanvas Workstation - apoiado pela CaBIG - continua sendo desenvolvido. Mesmo em sua versão atual e com todas as características citadas anteriormente, essa solução ainda não fornece marcação de regiões de interesse 3D sobre imagens médicas e exige sua execução em um sistema operacional desktop específico.

\subsubsection{OsiriX-iPad}

O OsiriX-iPad é um plugin do OsiriX - software de navegação, apresentação e interpretação de grandes conjuntos de imagens DICOM multidimensionais e de várias modalidades (Rosset et al., 2004). O OsiriX é um aplicativo de código aberto e standalone para o sistema operacional Mac OS X. Ele inclui um banco de dados de imagens e oferece ferramentas de visualização e processamento para as mesmas, que podem ser obtidas de PACs. Ele também foi desenvolvido baseando-se em uma arquitetura de componentes de código aberto, mostrada na Figura 4.2. 


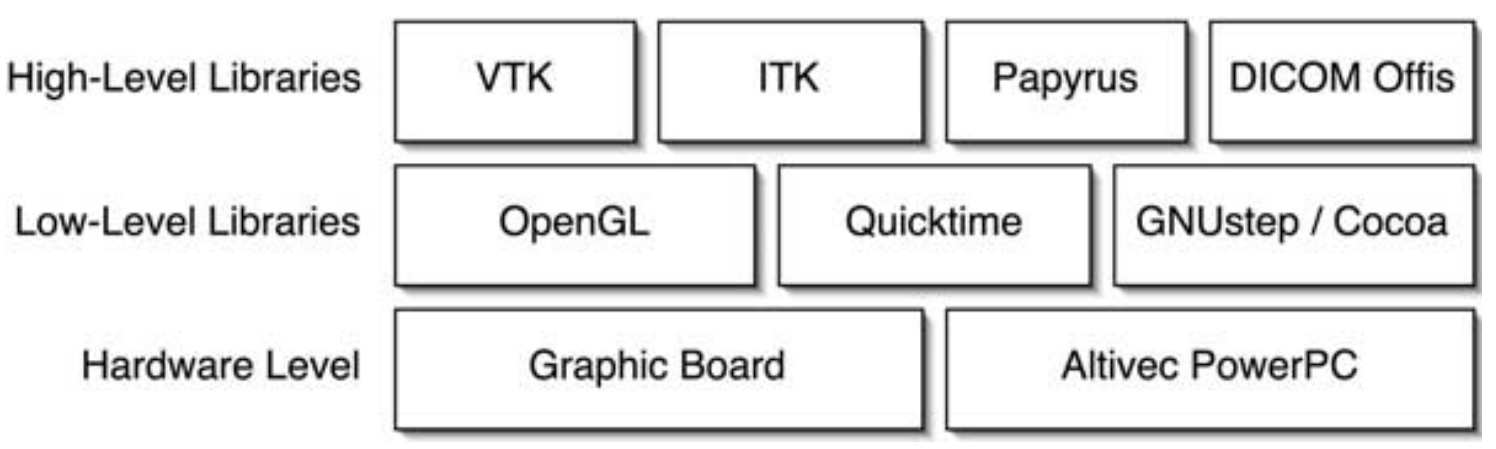

Figura 4.2: Arquitetura com os componentes do OsiriX-iPad (Rosset et al., 2006).

Os componentes principais da arquitetura do OsiriX (Figura 4.2) são:

As High-Level Libraries consistem em bibliotecas de alto nível muito usadas pela comunidade científica para processamento, visualização de imagens médicas em ambientes 2D e 3D, e gerência e suporta os arquivos DICOM e seus protocolos de comunicação.

As Low-Level Libraries correspondem às bibliotecas de baixo nível que utilizam padrão gráfico usado pela indústria de processamento de imagens em 3D (OpenGL), trocas de formatos de imagem (TIFF, Photoshop, JPEG, JPEG2000 e BMP) e exportação de sequência de slides de imagens em formatos de vídeo (AVI, MPEG, MPEG4 e outros).

No nível de hardware, encontram-se funções de baixo nível da plataforma PowerPC para a aceleração do processamento de sinais digitais, possibilitando um alto desempenho e interação em tempo real.

A arquitetura modular do OsiriX também facilita o desenvolvimento de plugins. Por isso, foi desenvolvido o OsiriX-iPad plugin, um tab-plugin de código aberto do software OsiriX (Rubin et al., 2008). Ele permite pesquisadores e clínicos realizarem anotações semânticas sobre imagens radiológicas.

O plugin também oferece uma orientação visual para os usuários enquanto esses gravam as informações, realizando feedback quanto ao conteúdo exigido por cada tipo de anotação semântica. Quando o usuário insere informações, o plugin sugere termos das ontologias RadLex e Foundational Model of Anatomy (FMA) ${ }^{5}$ a medida que o usuário digita o texto. Ele também fornece pistas visuais sobre a integralidade das descrições radiológicas.

A aplicação iPad plugin compreende três componentes:

1. Um modelo de informação para anotações semânticas de imagens;

2. Uma interface de usuário para coletar as anotações dos usuários;

\footnotetext{
${ }^{5}$ http://bioportal.bioontology.org/ontologies/FMA
} 
3. Um back-end de armazenamento para salvar as anotações como AIM XML e serializar os dados para outros padrões de formatos.

A tela do aplicativo OsiriX-iPad é mostrada na Figura 4.3. O usuário seleciona uma imagem a ser anotada e entra uma descrição usando uma sintaxe e gramática que é semelhante ao Inglês (por exemplo, "heterogeneous hypodense mass enhancing in right lobe of the liver", ou seja, "massa hipodensa heterogênea aumentando no lóbulo direito do fígado"). O OsiriXiPad simultaneamente fornece um feedback para o usuário com a validação do texto. Uma vez que o conteúdo da anotação seja válido, o OsiriX-iPad armazena as anotações e a descrição em um arquivo AIM XML, posteriormente serializado para uma variedade de padrões de formatos como o DICOM-SR ou HL7-CDA. A imagem em si continua separada da anotação, embora a anotação esteja ligada à ela através de um identificador exclusivo - DICOM UID.

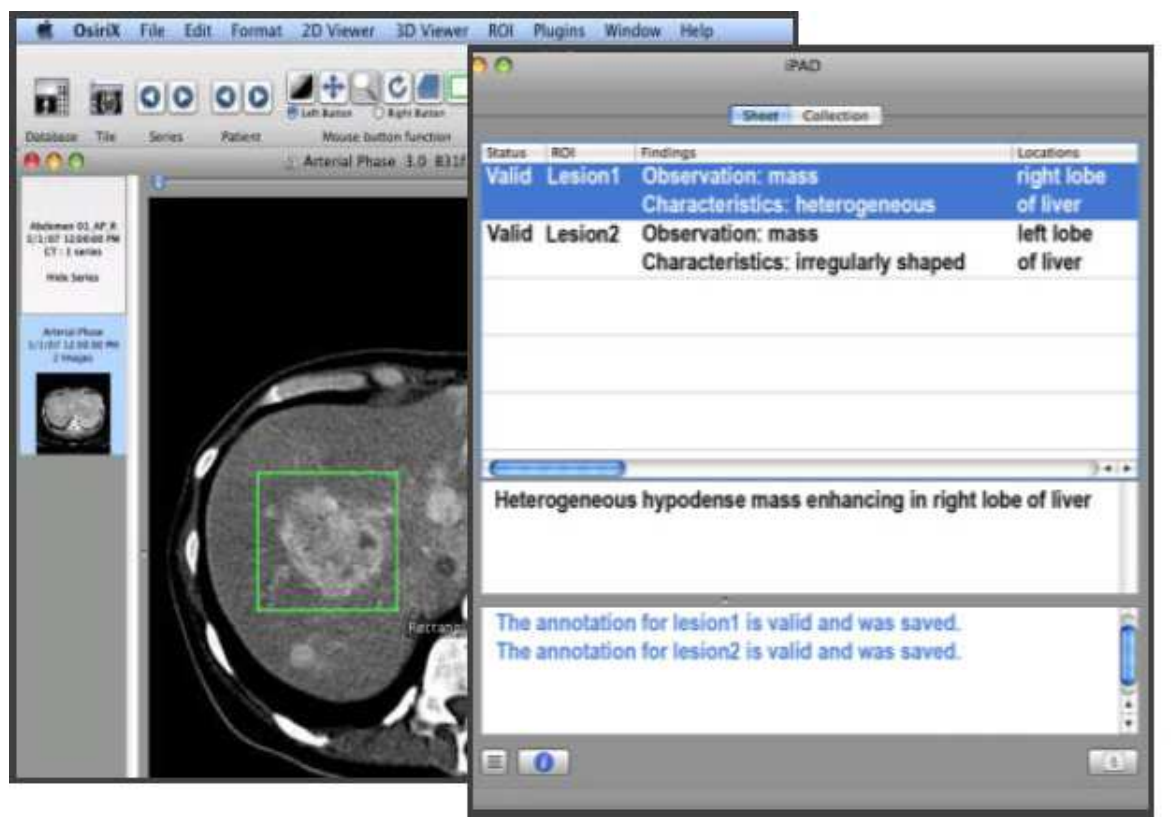

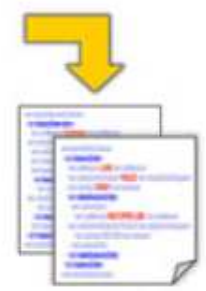

AIM annotations linked to images

Figura 4.3: Anotação semântica marcada com o OsiriX-iPad (Rubin et al., 2008).

O projeto Osirix-iPad dependente do sistema operacional Mac OS e permite marcação de regiões de interesse (ROIs) somente em 2D para anotações sobre imagens. Ele foi descontinuado e o projeto ePAD (electronic Physician Annotation Device) para a plataforma Web (discutido na seção 4.3) tomou o seu lugar. 


\subsection{D Slicer}

O 3D Slicer é uma ferramenta desktop desenvolvida na linguagem $\mathrm{C}++$ para análise e visualização de imagens de qualquer natureza. No caso de análise de imagens médicas, é permitido realizar visualização, marcação $2 \mathrm{D}$ e 3D, e anotação textual a partir de arquivos DICOM locais ou de PACS. A ferramenta é open source e funciona nos sistemas operacionais Linux, Mac OS e Windows. Ela faz parte do trabalho desenvolvido pela National Alliance for Medical Image Computing (NA-MIC) ${ }^{6}$, financiada pelos National Institutes of Health. O 3D Slicer permite também a instalação de plugins. Um desses plugins está sendo desenvolvido pela Universidade de Harvard para realização de anotações em formato AIM XML ${ }^{7}$ mas ainda não há resultados. Entretanto, não há menção sobre disponibilização de templates para auxílio no preenchimento de anotações com termos léxicos do RadLex. A Figura 4.4 mostra a ferramenta exibindo os 3 planos ortogonais de uma parte do corpo de um paciente.

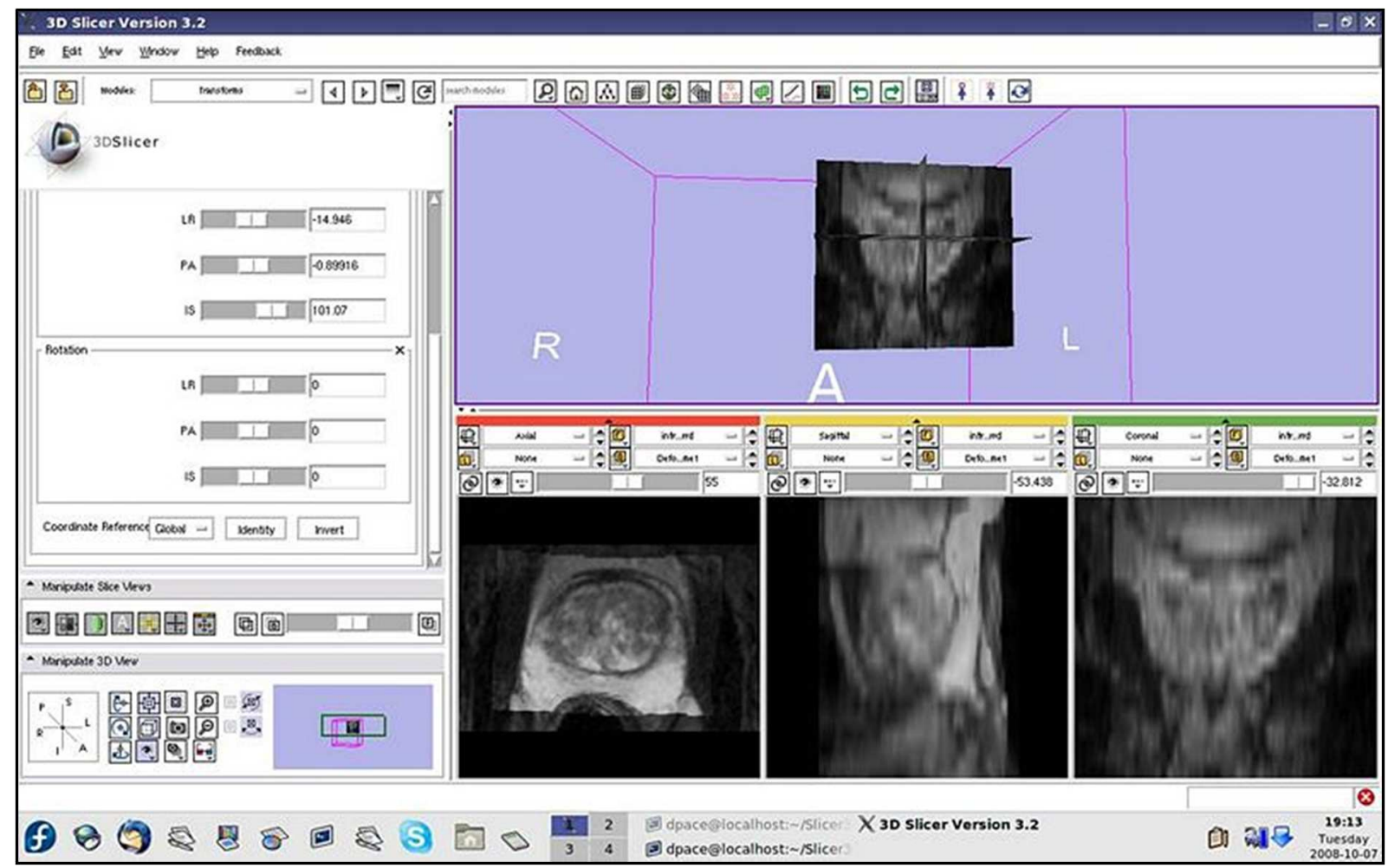

Figura 4.4: Tela do 3D Slicer.

Os três planos ortogonais, o Axial, Frontal e Sagital, são planos perpendiculares entre si usados em ferramentas de visualização de imagens médicas para mostrar pilhas de imagens 2D (plano Axial) com efeito tridimensional. Eles são ilustrados na Figura 4.5. As imagens

\footnotetext{
${ }^{6}$ http://www.na-mic.org/

${ }^{7}$ http://www.na-mic.org/Wiki/index.php/Projects:ARRA:SlicerUI
} 
mostradas nos planos Frontal e Sagital são calculadas, a partir das imagens do plano Axial, para dar a impressão que é possível obter imagens originais do paciente em qualquer dos planos. Isso melhora a percepção das estruturas 3D nas imagens (órgãos, lesões, etc.) pelos radiologistas.

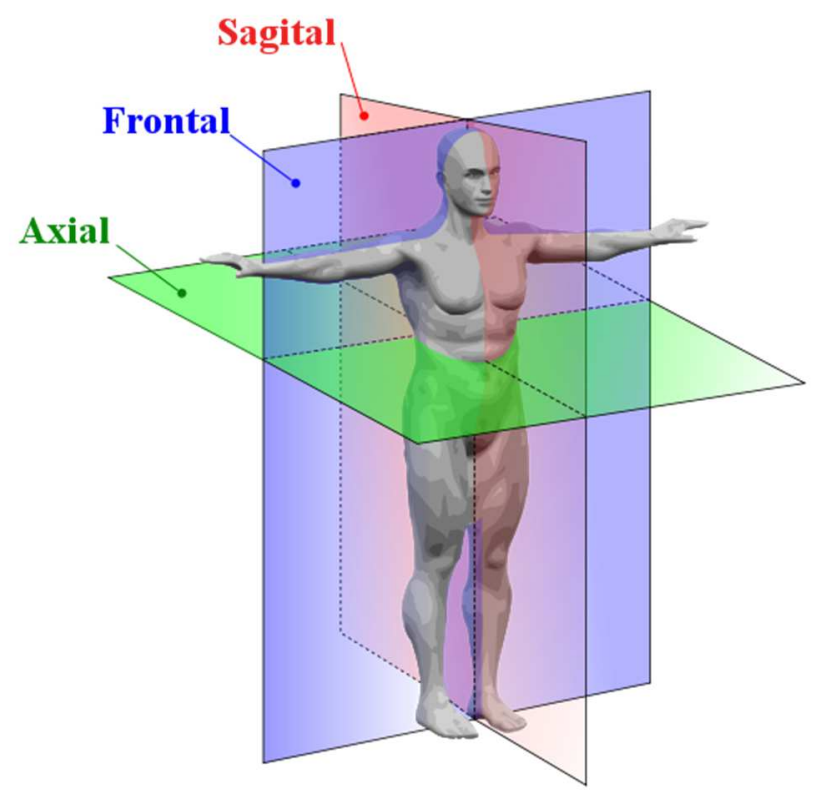

Figura 4.5: Planos ortogonais anatômicos (Axial, Frontal e Sagital) (YassineMrabet/CC-BYSA-3.0).

O $3 D$ Slicer (versão atual 4.3.0) é uma ferramenta capaz de ajudar profissionais na análise de imagens radiológicas com módulos de marcação em três dimensões por pontos de referência e anotação textual simples. Entretanto, não há independência do uso de sistema operacional e não possui estrutura para armazenamento da anotação em arquivo AIM XML como o ePAD oferece - marcação 3D intuitiva por meio de um cursor esférico sobre as fatias de imagens de modo simultâneo - e anotação no modelo AIM (AIM schema), que permite a compreensão das informações por computadores.

\section{3 ePAD}

Todas as ferramentas discutidas anteriormente são aplicativos desktop. Sentindo o amadurecimento de tecnologias Web interativas (como HTML5, WebGL e GWT), o Department of Radiology - Stanford University e o Grupo de Pesquisas em Web Interativa e Sistemas Multimídia (Intermídia) - USP decidiram desenvolver uma ferramenta Web para anotação de imagens médicas usando o modelo AIM (ao invés de continuar o desenvolvimento do OsiriX-iPAD). As vantagens de um aplicativo Web são várias, como não 
necessitar de instalação na máquina do cliente, estar disponível em qualquer máquina ligada à internet, menor custo de operação, etc.

O ePAD (electronic Physician Annotation Device), ferramenta de anotação semântica de imagens independente de plataforma e open source, surgiu dessa cooperação (a versão 1.0 contou também com a colaboração do ACR - American College of Radiology). Ele utiliza tecnologias RIA para plataforma Web.

$\mathrm{O}$ ePAD recupera imagens médicas de servidores PACs e permite a manipulação das mesmas através da interação por navegadores Web (Serique et al., 2012). Ele também suporta Templates (como a RECIST) para as anotações em formato AIM XML (que ficam separadas das imagens). A ligação entre essas informações é feita por identificadores únicos (DICOM UID). A tela do aplicativo é apresentada na Figura 4.6.

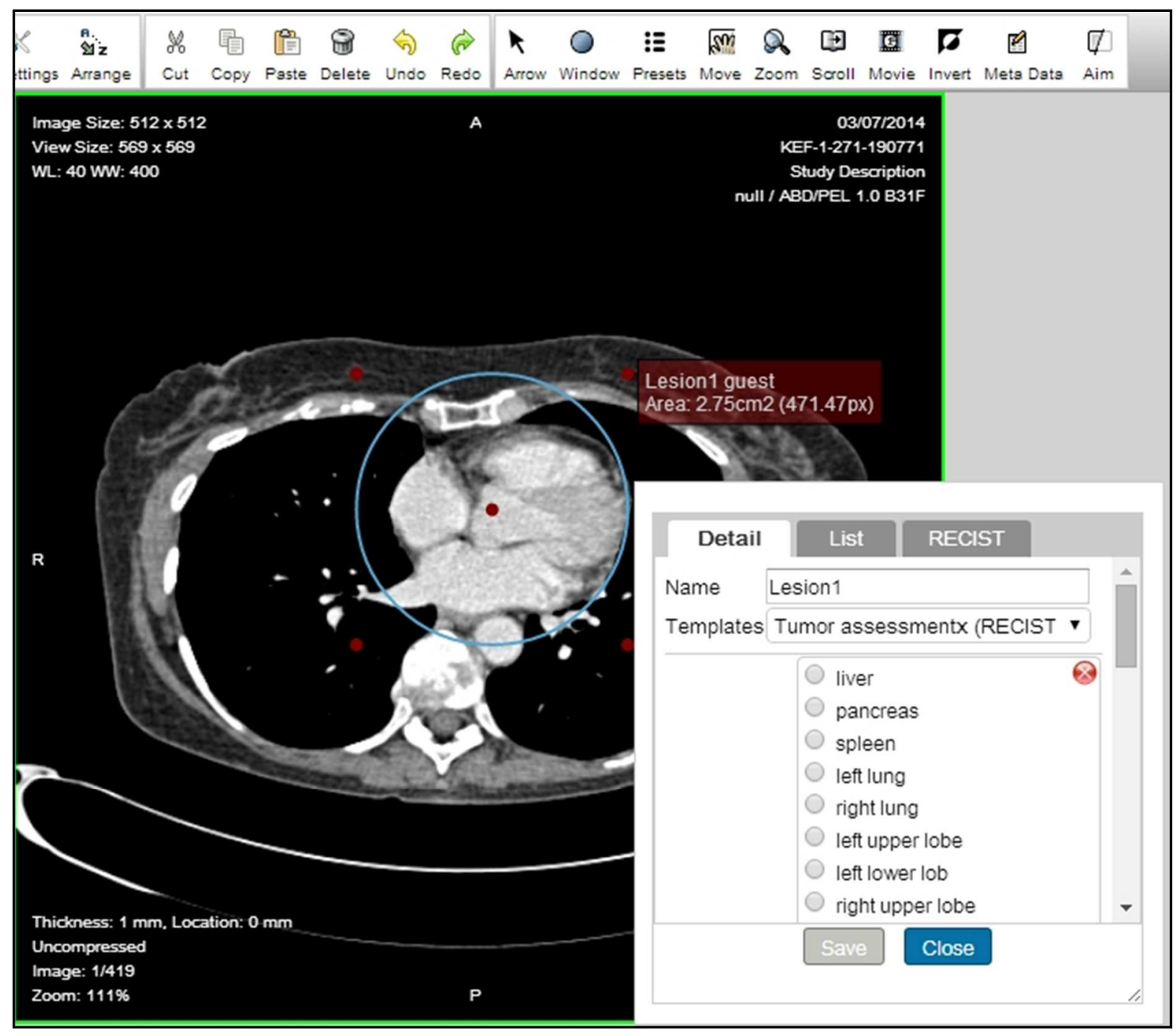

Figura 4.6: Tela da ferramenta ePAD. 
O usuário ePAD abre uma série de imagens médicas obtidas de um PACS, realiza marcações de ROIs (Regions of Interest) com ferramentas de desenhos geométricos 2D (linhas, polígonos, etc.) e anota essas marcações com termos do RadLex em formato AIM XML. O sistema ePAD pode recuperar imagens médicas diretamente de sistemas PACS.

\subsection{A versão 3D do ePAD}

Um dos objetivos deste trabalho é criar uma solução $W e b$ para a criação e visualização de anotações semânticas sobre regiões 3D para lesões em imagens radiológicas, que fará parte de uma futura versão do ePAD. Como pode ser visto na Tabela 2, nenhuma das ferramentas pesquisadas é capaz de fazer marcações 3D e anotá-las usando o padrão AIM XML. Em adição a isso, a versão 3D do ePAD ainda é capaz de executar em um navegador Web.

Tabela 2. Comparação das Ferramentas.

\begin{tabular}{|c|c|c|c|}
\hline & Anotação AIM XML & $\begin{array}{c}\text { Plataforma Desktop / } \\
\text { Web }\end{array}$ & Marcação 3D \\
\hline $\begin{array}{c}\text { AIM ClearCanvas } \\
\text { Workstation }\end{array}$ & Sim & Desktop & Não \\
\hline OsiriX-iPad & Sim & Desktop & Não \\
\hline $3 D$ Slicer & Não & Desktop & Sim \\
\hline ePAD (v 1.0) & Sim & Web & Não \\
\hline
\end{tabular}

Essa nova versão do ePAD deve ser facilmente usada por radiologistas, permitindo a escolha de modos de processamento das anotações como cálculos de maior diâmetro, de volume, e de posição de lesões, por exemplo. Ela deve ser uma extensão do ePAD atual e, por isso, também deverá estar disponível na plataforma Web (sem a necessidade de instalação de software na máquina dos usuários), por isso foi decidido implementá-la como uma aplicação Web com AJAX e WebGL. Além das tecnologias já usadas pelo ePAD (AJAX, GWT), escolhemos incluir o uso de WebGL (Web Graphics Library): uma API JavaScript para renderização de gráficos 3D que usa diretamente programas na GPU (Graphics Processing Unit) do computador. Programas gráficos em WebGL são muito mais rápidos que em JavaScript, que simplesmente não teriam a rapidez necessária para mostrar interações em 3D. 
O processo de desenvolvimento da versão 3D do ePAD - incluindo mockups da interface com auxílio de simulações em vídeo, pesquisa de usabilidade, consistência, visibilidade, e criação de um protótipo funcional - é detalhado no capítulo 5. O restante deste capítulo, discute as tecnologias usadas no projeto.

\subsection{Rich Internet Applications}

Rich Internet Applications (RIAs) são aplicações Web com características das de desktop. Basicamente, RIAs são aplicações que têm a aparência de uma aplicação desktop clássica, mas que são carregadas, e não instaladas, na máquina cliente através da internet.

O ePAD foi desenvolvido como uma RIA, pois esse é o tipo de funcionalidade que usuários da radiologia exigem e estão acostumados. Existem várias maneiras de se implementar RIAs, como a máquina virtual Java (através de applets), JavaScript, Adobe Flash e, mais recentemente, o Microsoft Silverlight (Shah, 2008). Mas apenas aplicações baseadas em JavaScript não precisam da instalação de nenhum software na máquina do usuário. Isso diminui em muito os custos de administração e problemas de instalação e upgrade. RIAs em JavaScript tornaram-se possíveis a partir do surgimento do Ajax: o Asynchronous JavaScript and XML (Ajax) é uma metodologia que emprega o uso das tecnologias JavaScript e XML, para fazer requisições assíncronas de informações a servidores a partir de programas JavaScript (rodando no navegador). A finalidade do Ajax é tornar as páginas Web mais interativas. O Ajax deu origem a uma interação mais dinâmica, o Web 2.0.

\subsection{Web 2.0}

Embora existam muitas definições para Web 2.0, a maioria parece concordar com a ideia de usar a "Web como plataforma" na qual todos os aplicativos são executados em um navegador, ao invés de serem pré-instalados no desktop (Kereki, 2011).

A Web 2.0 combina muitas tecnologias. Essas tecnologias residem em diferentes camadas, e são mostradas na Figura 4.7.

O Client Layer é essencialmente o lado do navegador Web. As tecnologias de Web 2.0 criaram uma revolução nesta camada, utilizando a combinação de várias tecnologias para criar uma excelente experiência interativa para o usuário.

Protocol layer é onde os novos protocolos, baseados em HTTP, se encontram. Eles foram criados para suportar as novas tecnologias de cliente e servidor. 
Structure layer é a camada que contém ingredientes para criação de canais de comunicação. Anteriormente, era utilizada apenas pelo HTML, agora na Web 2.0, novos protocolos, mais sofisticados, são utilizados nessa camada.

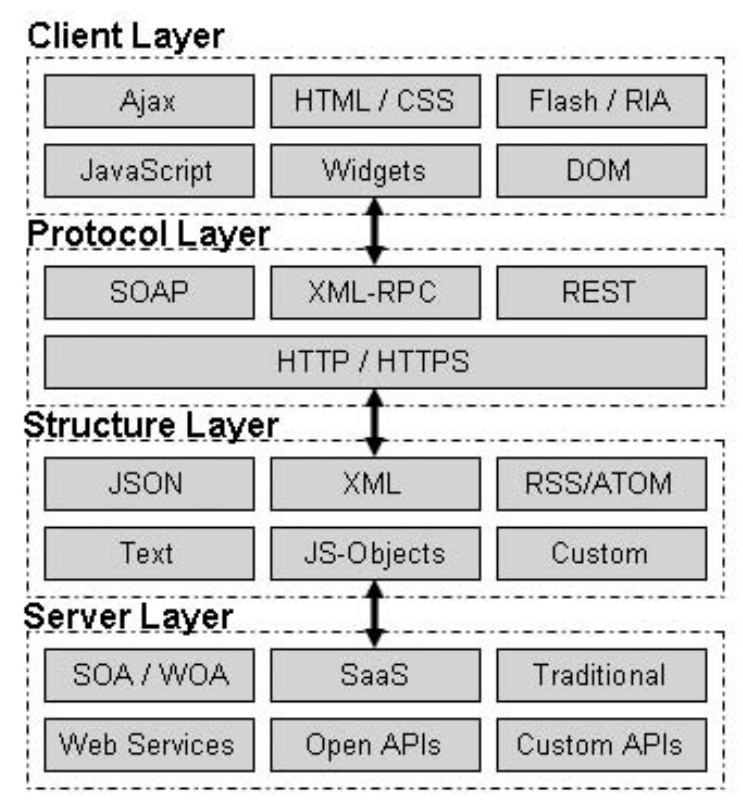

Figura 4.7: Web 2.0, camadas de tecnologias (Shah, 2008).

Server Layer é a camada servidora. A Web 2.0 introduziu novas tecnologias nessa camada para capacitar a rede como uma plataforma e apoiar a troca de informações de uma aplicação para outra.

Para implementar o ePAD como uma aplicação RIA/Web 2.0, foram usadas duas tecnologias principais, GWT e WebGL.

\subsection{Google Web Toolkit (GWT)}

O Google Web Toolkit (GWT) é uma ferramenta que permite aos desenvolvedores Web a criação de aplicações com níveis de interatividade similares de uma aplicação desktop, usando a linguagem Java. O desenvolvedor codifica em Java e compila seu código para JavaScript, que é executado no navegador Web. O resultado disso é um código final otimizado, em JavaScript, compatível com as peculiaridades de cada navegador Web, pois o GWT gera um código específico para os navegadores Web mais populares (Chrome, Internet Explorer, Firefox e Safari), tirando essa tarefa nada trivial das mãos dos desenvolvedores. A Figura 4.8 ilustra as fases do processo de compilação de uma aplicação implementada com GWT. 


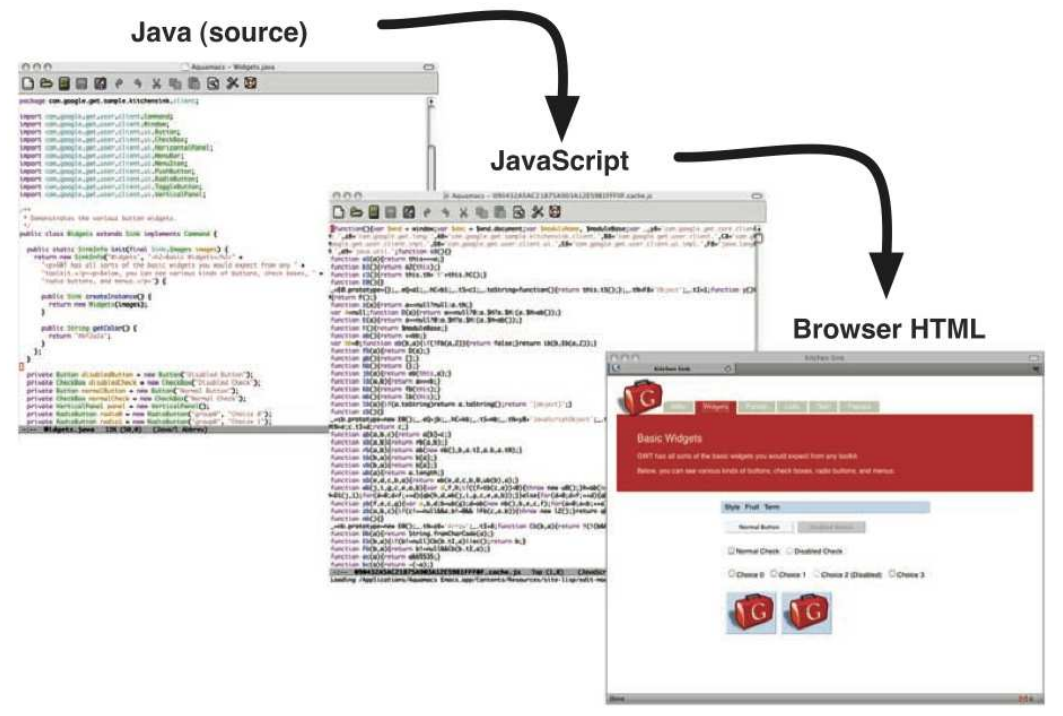

Figura 4.8: Visão geral da compilação de um programa em GWT.

A principal vantagem do GWT, em relação às demais tecnologias de desenvolvimento de RIA, é que ele é baseado em JavaScript e Ajax e requer apenas um navegador Web padrão para ser executado (não há a necessidade de se instalar plugins, como o Flash). Como o GWT utiliza apenas HTML/JavaScript, programas escritos usando GWT podem rodar em diferentes plataformas, sem alteração.

O GWT também oferece um conjunto de ferramentas de teste, incluindo um debugging shell, permitindo que desenvolvedores testem e depurem o código enquanto interagem com a aplicação em um navegador Web.

\subsection{Web Graphics Library - WebGL}

A Web Graphics Library $\left(\mathrm{WebGL}^{8}\right.$ ) consiste numa API (application programming interface) JavaScript para criação de gráficos 2D e 3D para a plataforma Web, que é baseada na OpenGL (Open Graphics Library) Embedded Systems 2.0 e faz parte da especificação do HTML5 $^{9}$. OpenGL é uma API multiplataforma para renderização de gráficos 2D e 3D em ambientes desktop. OpenGL Embedded Systems ${ }^{10} 2.0$ faz parte de um subconjunto da API da biblioteca OpenGL e é o padrão de aceleração de gráficos 2D e 3D para sistemas embarcados. O objetivo da WebGL, por sua vez, é permitir o acesso dos navegadores às Unidades de

\footnotetext{
${ }^{8}$ https://www.khronos.org/webgl/

${ }^{9}$ http://www.w3.org/TR/html5/

${ }^{10} \mathrm{https}: / /$ www.khronos.org/opengles/
} 
Processamento Gráficas (GPUs), possibilitando visualização e interação com objetos em três dimensões (Cantor e Brandon, 2012).

Além da vantagem da portabilidade entre sistema operacionais, a WebGL também está disponível em navegadores de dispositivos móveis como tablets e smartphones. Não é exigida a instalação de qualquer software para o uso dessa tecnologia, já que WebGL é parte do padrão HTML5 e a maioria dos navegadores suportam sua execução. São eles: Google Chrome, Firefox, Safari (a partir do OSX 10.6, mas é necessário ativar) e Opera. O Internet Explorer promete rodar o WebGL a partir da versão 11.

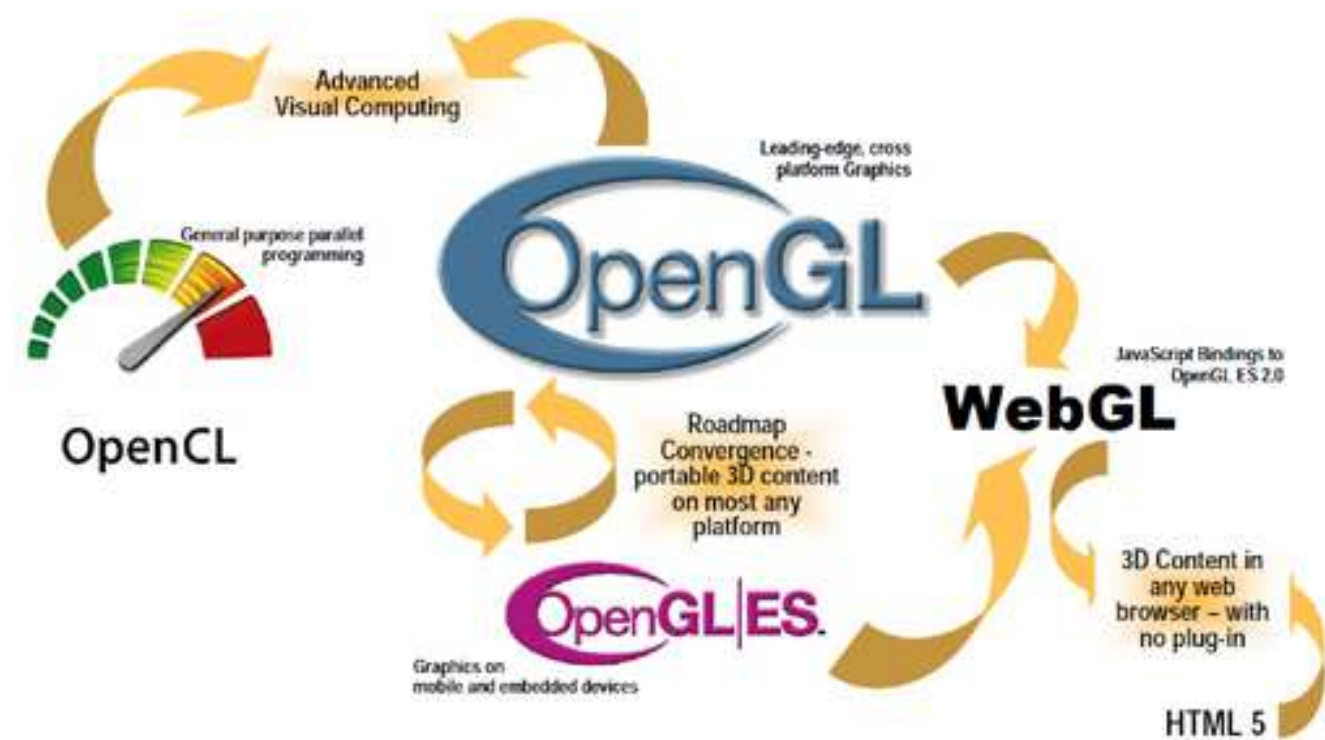

Figura 4.9: Ecossistema relacionado à OpenGL (Khronos, 2008).

A Figura 4.9 mostra o ecossistema relacionado à OpenGL (Khronos, 2008). Nela, é possível perceber que, ao acessar uma aplicação WebGL, o conteúdo parte do navegador (HTML5), que traduz código JavaScript para linguagem OpenGL ES 2.0 com auxílio da biblioteca WebGL, sendo executado na unidade de processamento gráfico (GPU - Graphics Processing Unit). A figura ilustra que o fluxo de informação pode partir de dispositivos móveis seguindo o mesmo destino, utilizando unidades aceleradoras gráficas embarcadas.

O fato de a WebGL utilizar a GPU, faz com que os cálculos para manipulação de dados das imagens médicas na versão 3D do ePAD - como exibição, zoom, translação e marcação de regiões de interesse - sejam realizados com mais rapidez, sendo realizados por processadores gráficos dedicados.

A WebGL possui uma abordagem de renderização baseada no cliente: os elementos que fazem parte do cenário 3D são baixados de um servidor, mas o processamento exigido para se obter uma imagem é realizado localmente, do lado do cliente. Em comparação com outras 
tecnologias (como Java 3D, Flash, The Unity Web Player Plugin) a WebGL oferece várias vantagens (Cantor e Brandon, 2012):

1. Programação JavaScript: trabalhar com JavaScript permite o acesso a todas as partes do DOM (Document Object Model) e a comunicação entre elementos com maior facilidade comparado a um applet. É também mais fácil integrar o WebGL com outras bibliotecas JavaScript, como o GWT.

2. Gerenciamento automático de memória: diferente da OpenGL, a qual exige operações manuais para alocar e desalocar. A regra de escopo de variáveis em JavaScript é obedecida e a memória é desalocada automaticamente, quando não é mais necessária.

3. Pervasividade: graças aos avanços tecnológicos, navegadores com JavaScript encontram-se instalados em smartphones e tablets.

4. Performance: a performance de aplicações WebGL é comparável a aplicações standalone, graças à habilidade de acesso ao hardware acelerador gráfico local (GPU).

5. Compilação zero: dado que WebGL é escrita em JavaScript, não é necessário compilar o código antes de executá-lo no navegador.

\subsubsection{Estrutura de uma aplicação WebGL}

Como em qualquer biblioteca para gráficos 3D, certos componentes são necessários para se criar um cenário 3D. Esses elementos fundamentais, no caso da WebGL, são:

- Canvas: o elemento que armazena o cenário a ser renderizado. É um elemento padronizado do HTML5 e, assim, pode ser acessado utilizando o Document Object Model (DOM) por meio do JavaScript.

- Objetos: as entidades 3D que fazem parte do cenário. Eles são compostos de triângulos formados por vértices e índices.

- Iluminação: nada em um mundo 3D pode ser visto se não há iluminação, incluindo efeitos de reflexão e absorção de luz.

- Câmera: o canvas atua como ponto de acesso ao mundo 3D. Pode-se ver e explorar um cenário 3D, por meio dele, com perspectivas de visualização diferentes. 
Vértices são pontos que definem objetos 3D. Cada vértice é representado por três números de ponto flutuante que correspondem às coordenadas $\mathrm{x}, \mathrm{y}$ e $\mathrm{z}$. Todos os vértices são armazenados em um array JavaScript para, depois, construir um buffer de vértices.

Índices são rótulos numéricos para os vértices dados em um cenário 3D. Eles permitem a WebGL conectar os vértices para produzir uma superfície. Os índices também são armazenados em um array JavaScript que é passado ao pipeline de renderização WebGL - o buffer de índices.

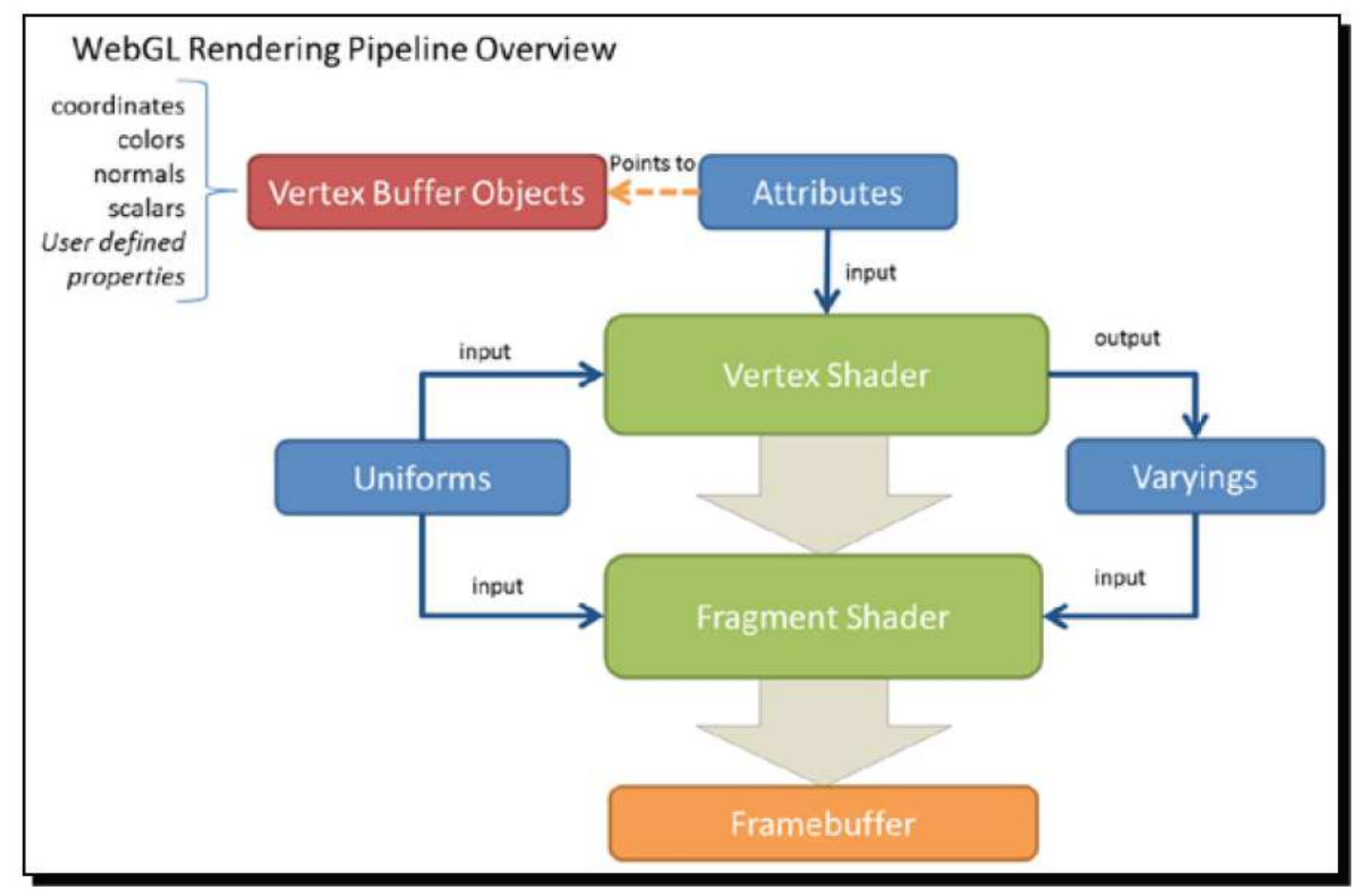

Figura 4.10: Pipeline de renderização WebGL (Cantor e Brandon, 2012).

A Figura 4.10 ilustra o pipeline de renderização WebGL de forma simplificada. Ele utiliza os elementos fundamentais citados anteriormente. As entidades da figura são descritas a seguir:

- Vertex Buffer Objects (VBOs): contêm dados que a WebGL exige para descrever a geometria a ser renderizada. Há vários elementos de dados, como normais de vértices, cores, coordenadas de textura e outros, que podem ser modelados como VBOs.

- Vertex shader: esse é chamado a processar cada vértice e manipula dados como coordenadas, normais e cores de vértices, e coordenadas de textura. Esses dados são representados por atributos no vertex shader. Cada atributo aponta a um VBO de onde os dados do vértice são lidos. 
- Fragment shader: cada conjunto de três vértices define um triângulo e cada elemento na superfície desse triângulo precisa ter uma cor associada, senão a superfície seria transparente. Cada elemento da superfície é chamado de fragmento (fragment ou pixel). O objetivo principal do fragment shader é calcular a cor de pixels individuais. A Figura 4.11 ilustra essa ideia.

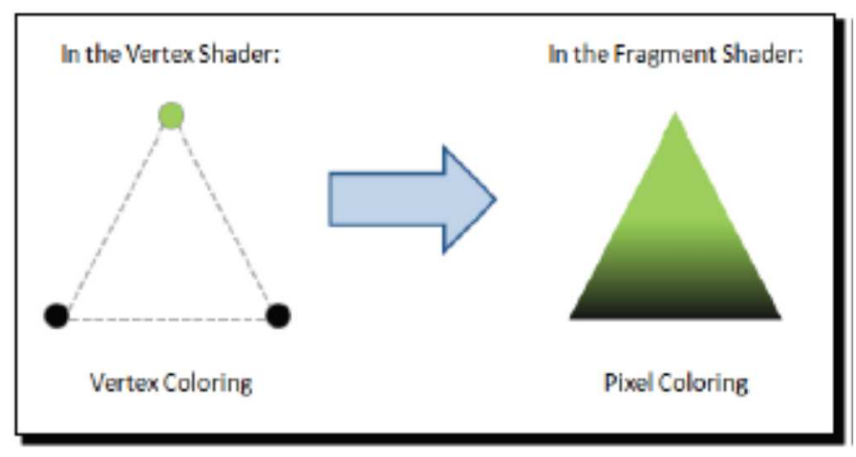

Figura 4.11: Cálculo das cores de pixels individuais (Cantor e Brandon, 2012).

- Framebuffer: é um buffer (memória intermediária) que contém os fragmentos processados pelo fragment shader. Depois de todos os fragmentos terem sido processados, uma imagem $2 \mathrm{D}$ é formada e exibida na tela. O framebuffer é o destino final do pipeline de renderização.

- Atributos, uniformes e varyings: são os três tipos diferentes de variáveis que podem ser encontrados na programação com shaders. Atributos são variáveis de entrada usados no vertex shader como, por exemplo, coordenadas ou cores de vértices, etc. Uniformes são variáveis de entrada disponíveis para os vertex shader e fragment shader, seus valores não se modificam durante um ciclo de renderização. Como exemplo temos a posição de pontos de luz. Varyings são usadas para passagem de dados entre vertex shader e ofragment shader.

Os dois shaders (vertex e fragment) rodam programas paralelos na GPU usando a linguagem GLSL - visto a seguir. A renderização de objetos em WebGL ocorre por geometria definida com a ajuda de arrays JavaScript. O buffer de vértices (VBO) é criado e um atributo do vertex shader é apontado ao VBO, que armazena coordenadas de vértices. O buffer de índices (IBO), que contêm dados de índices que determinam como os dados de coordenadas são processados para renderização de objetos geométricos, é utilizado para realizar a renderização (Figura 4.12): 


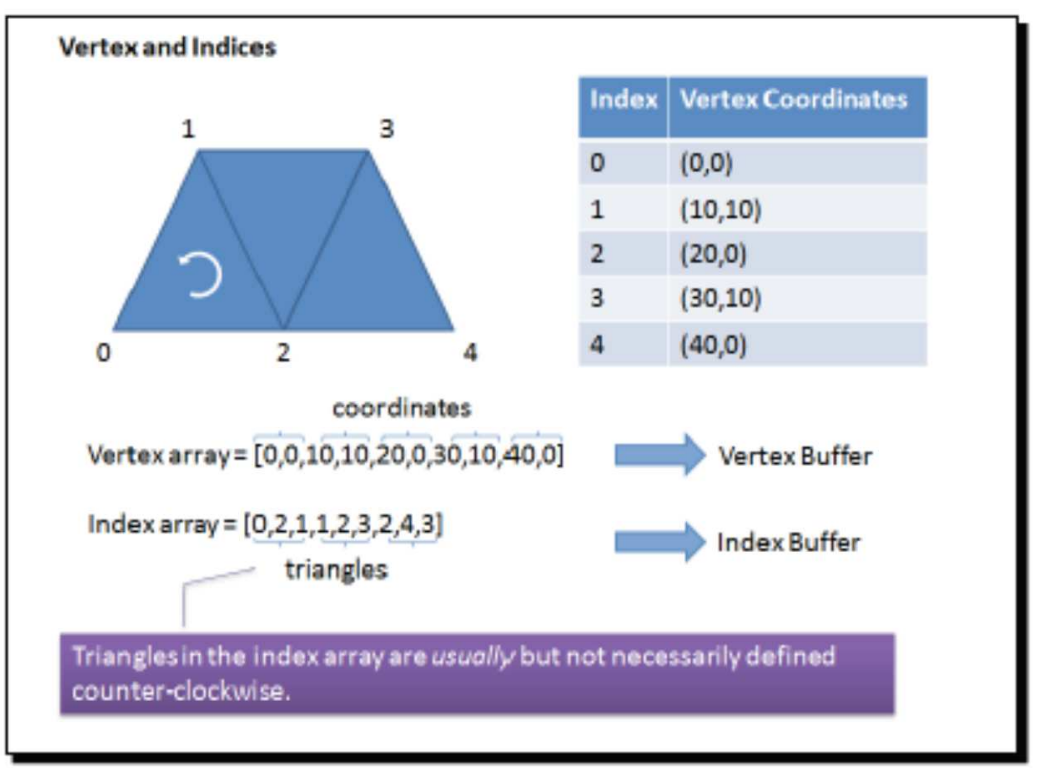

Figura 4.12: Renderização de objetos 3D por vértices e índices (Cantor e Brandon, 2012).

É possível perceber que as coordenadas foram colocadas sequencialmente no array de vértices e o array de índices dita como essas coordenadas são utilizadas para desenhar um trapézio. Portanto, o primeiro triângulo é definido pelos vértices (com índices) 0 , 1 e 2; o segundo triângulo pelos vértices 1,2 e 3; e, finalmente, o terceiro triângulo pelos vértices 2, 3 e 4. Esse procedimento é obedecido para todas as possíveis figuras geométricas a serem desenhadas.

No caso deste projeto, as imagens radiológicas são renderizadas em texturas retangulares que são armazenadas no framebuffer para visualização.

Este trabalho focou no processamento pelo fragment shader referente ao tipo de interpolação realizada para obtenção da cor final de cada fragmento da imagem radiológica e da marcação no cenário. A linguagem para sua manipulação é chamada de GLSL ES (OpenGL ES Shading Language).

\subsubsection{GLSL ES (OpenGL ES Shading Language)}

OpenGL ES Shading Language $e^{11}$ é a linguagem na qual se programa os shaders e é incorporada no código HTML, criando uma ligação com a aplicação WebGL em JavaScript. Sua sintaxe e semântica são muito similares ao C. Ela oferece tipos e funções que facilitam

\footnotetext{
${ }^{11}$ http://www.khronos.org/registry/gles/specs/2.0/GLSL_ES_Specification_1.0.17.pdf
} 
manipulação paralela de vetores e matrizes - utilizados para processamento dos objetos no cenário como, por exemplo, as imagens radiológicas e as ROIs deste projeto.

As operações são realizadas sobre vetores de 4 componentes (red, green, blue, alpha vermelho, verde, azul, opacidade) de ponto flutuante (valores de 0 a 1) que armazenam os pixels das imagens radiológicas e das ROIs.

\subsection{Considerações Finais}

O OsiriX-iPad, o AIM ClearCanvas Workstation, o 3D Slicer e o ePAD são todos programas que oferecem visualização de imagens radiológicas e criação de anotações semânticas, com o uso do padrão AIM (exceto o 3D Slicer). Com a exceção do ePAD, esses programas são aplicações desktop, exigindo instalação local e configuração para serem utilizadas. Outro fator a se considerar é que o OsiriX-iPad tem que ser executado em sistemas Mac OS e o AIM ClearCanvas Workstation em Microsoft Windows (o 3D Slicer não tem anotação das imagens no modelo AIM), restringindo o número de usuários possíveis do sistema. O ePAD, por sua vez, soluciona esses problemas mas, atualmente, apenas possibilita a manipulação de imagens em duas dimensões. Um sistema de visualização em 3D, baseado em tecnologias Web (RIA, GWT e WebGL), não oferece problemas de compatibilidade de plataformas desktop ou instalação local e possibilita maior portabilidade e facilidade de uso. 


\section{5. ePAD em 3D}

Neste capítulo, são apresentados a arquitetura geral do ePAD, o desenvolvimento do protótipo para marcações em três dimensões e os resultados obtidos. O protótipo foi implementado com base nas necessidades de radiologistas no seu processo de trabalho num ambiente clínico padrão. Ele é um cliente, desenvolvido com tecnologias RIA, que recupera imagens médicas de servidores PACS num plano ortogonal anatômico de visualização 2D (o plano Axial - vide Figura 4.5), gera dois planos ortogonais de visualização (os planos Frontal e Sagital), e possibilita a criação de marcações em 3D (ROIs) em cada um dos planos ortogonais. Os usuários podem interagir com o programa utilizando um navegador Web padrão dispensando a instalação de software e plugins adicionais.

Para a criação da interface deste novo ePAD, foram realizadas reuniões e avaliações elaboradas pelo autor deste trabalho com usuários finais da área de radiologia da Stanford University. O protótipo inicial consistiu na geração dos três planos ortogonais de visualização 3D - criado pelo grupo de pesquisa do ICMC-USP. A partir disso, foi incorporada a implementação do cursor esférico pelo autor para marcação de regiões de interesse. Foram apresentados formulários online com possíveis interfaces em vídeos narrados (protótipos de vídeo) legendados em português e inglês, incluindo a interface com o cursor esférico de marcação. Essa interface teve seu desenvolvimento adequado às necessidades detectadas. Alguns resultados preliminares foram publicados num artigo científico (Rubin et al, 2014) juntamente com o grupo de pesquisa de Stanford.

Os usuários-alvo do novo sistema de marcação 3D sobre imagens médicas são radiologistas e estudantes de radiologia. Nos testes realizados, foram usados pesquisadores do Department of Radiology - Stanford University e professores da Faculdade de Medicina da Universidade de São Paulo - Campus Ribeirão Preto (FMRP-USP). Outro objetivo, foi tornar a arquitetura do ePAD mais flexível para o desenvolvimento. Como havia a necessidade de conciliar a nova funcionalidade 3D com o editor 2D já existente, foi escolhida uma arquitetura baseada num framework com suporte a plugins para novas funcionalidades. Essa nova arquitetura também abre a possibilidade de novos módulos para o ePAD, como, por exemplo, um módulo para visualização de imagens de exames patológicos (doenças em geral). 


\subsection{Arquitetura geral do ePAD}

A comunicação entre o ePAD e o servidor PACS ocorre com o auxílio de Web Services. Eles realizam requisições, quando necessário, integrando o sistema ePAD com os PACS. A Figura 5.1 ilustra a arquitetura geral do ePAD: o sistema conecta-se a ambientes clínicos por intermédio de servidores PACS.

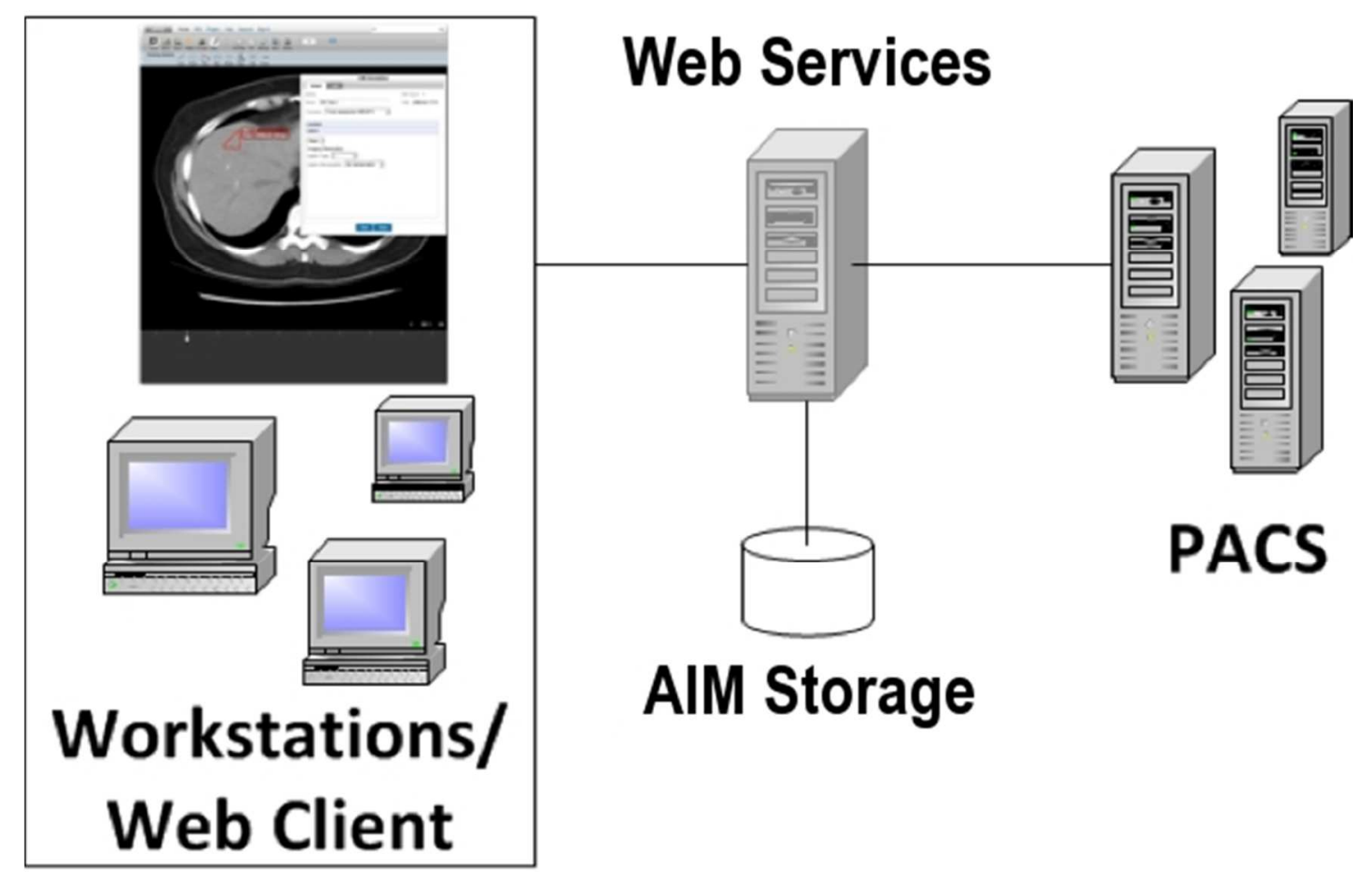

Figura 5.1: Arquitetura geral do ePAD.

O ePAD divide-se em parte servidora - uma aplicação Java executada em um servidor Web, e em parte cliente - aplicação GWT (Google Web Toolkit) e WebGL executado em um navegador Web utilizando apenas HTML5, JavaScript e WebGL.

A parte servidora é constituída pelos Web services de comunicação com a parte cliente. $\mathrm{O}$ papel dos Web Services é realizar comunicação diretamente com os servidores PACS para recuperar as informações de imagens, sua ordem e seus metadados. A parte servidora cria um cache das imagens para facilitar o tratamento e transferência das mesmas entre a parte servidora para a parte cliente (Web Client) do ePAD.

O Web Client foi implementado em sua maior parte em GWT e WebGL. As séries (conjuntos) de imagens, anotações e demais informações são obtidas por requisições HTTP realizadas aos Web Services. 


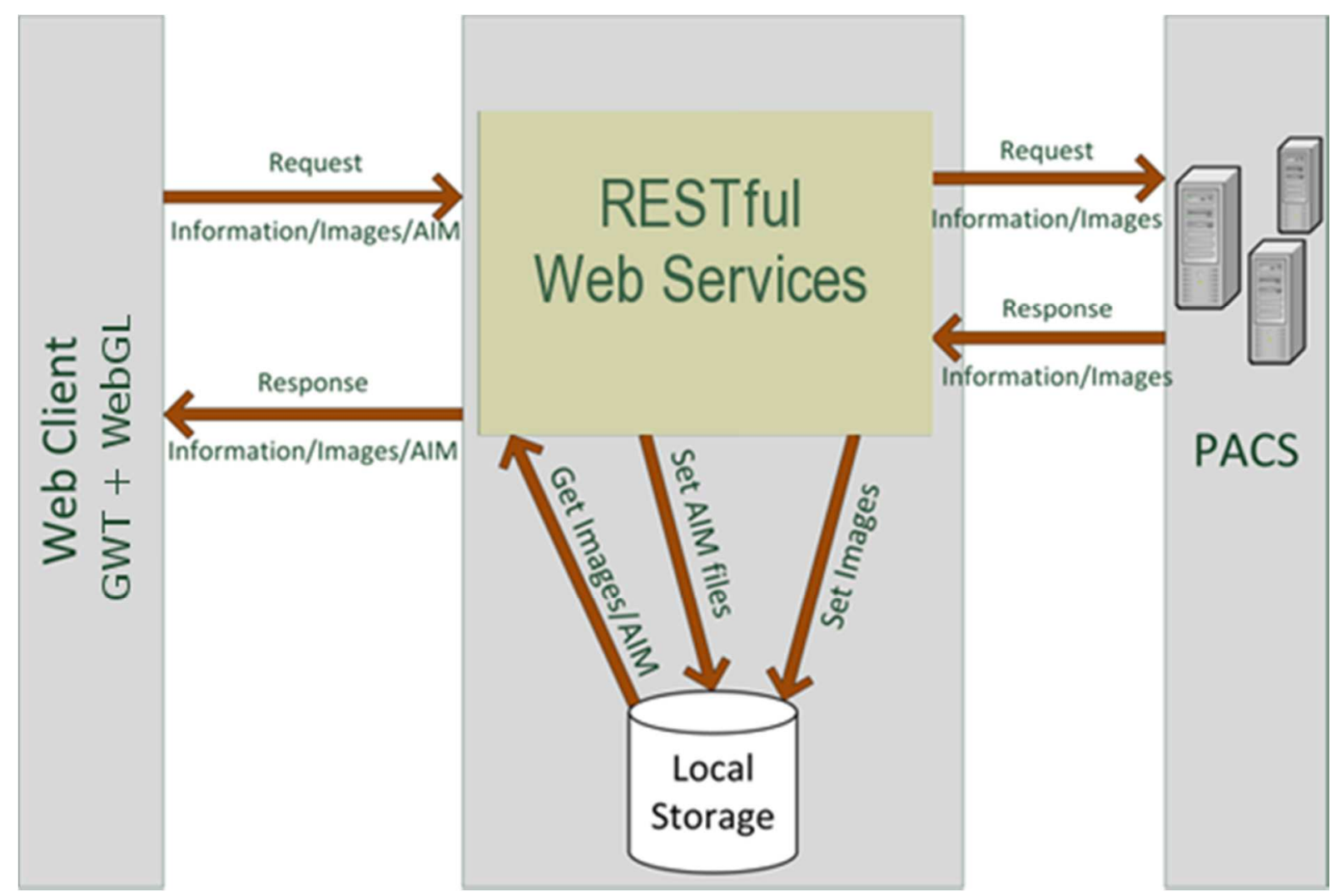

Figura 5.2: Arquitetura da parte servidora do ePAD.

\subsubsection{Parte servidora}

A Figura 5.2 ilustra a arquitetura de fluxo de dados da parte servidora do ePAD. Esta camada comunica-se com os PACS por protocolos WADO ou HL7, dependendo de qual deles esteja implementado no PACS. O cliente comunica-se com os serviços RESTful implementados em servlets. Servlets recuperam imagens e anotações armazenadas localmente. Os protocolos e as formas de comunicação entre os Web Services e os PACS estão sendo desenvolvidos pela equipe do Department of Radiology da Stanford University.

A parte servidora utiliza um Local Storage que serve para armazenar os arquivos AIM e as imagens provenientes dos PACS. Estas imagens são passadas para a parte cliente por chamadas RESTful. 


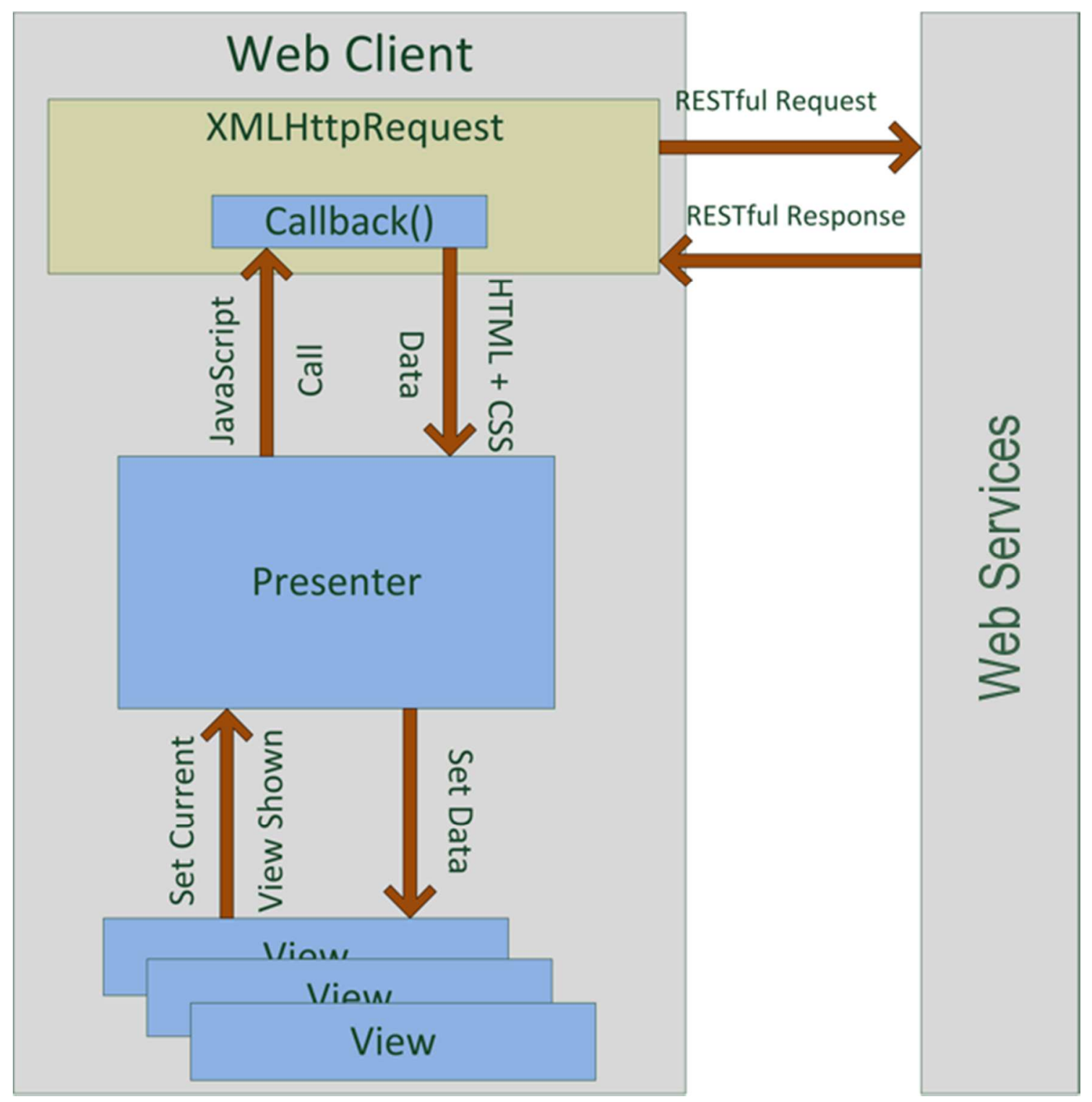

Figura 5.3: Arquitetura do cliente ePAD.

\subsubsection{Web Client}

A Figura 5.3 apresenta a arquitetura do cliente ePAD. Ele se comunica com o lado servidor por requisições RESTful para recuperação das imagens médicas e anotações AIM XML. O Web Client foi implementado usando o GWT e WebGL.

\subsubsection{Recuperação de Imagens no Cliente}

As imagens médicas são armazenadas no formato DICOM nos PACS, mas, como navegadores não são capazes de processar esse formato, elas são convertidas para o formato PNG (Portable Network Graphics). Essa conversão não é direta. Imagens DICOM têm como valor de cada pixel a intensidade de radiação emitida pelo volume que aquele pixel representa, 
sendo que as coordenadas $\mathrm{x}$ e $\mathrm{y}$ do pixel e a coordenada $\mathrm{z}$ da imagem representam a coordenada $\mathrm{x}, \mathrm{y}$ e $\mathrm{z}$ do centro do volume (o pixel também tem largura e altura e a imagem grossura, thickness, formando um cubo, ou seja, um voxel). O tipo de radiação emitida varia com o tipo de exame, raios-X para Tomografia Computadorizada (CT), ondas de rádio para Ressonância Magnética (MRI) e fótons gama para emissão de pósitrons (PET). O valor de radiação é codificado em valores inteiros de 12 ou 16 bits.

Para converter as imagens DICOM para PNG, foi escolhido pelo autor o formato de 32 bits por pixel (PNG permite vários formatos de codificação por pixel ${ }^{12}$ ), um byte para vermelho, um para verde, um para azul e um para alfa (alfa representa a transparência do pixel). Foram usados 2 bytes (vermelho e verde) para armazenar os valores DICOM em 16 bits. Foram deixados os valores de azul e alfa como 0 para uso futuro, isso não implica em imagens maiores já que o PNG comprime esses valores não usados.

O formato JPG não foi usado porque enquanto o PNG permite o armazenamento com compressão de dados sem perda (lossless), ou seja, o resultado da descompressão dos dados é igual aos dados originais, o JPG apresenta mudança de valores (o que não é admissível em se tratando de imagens médicas). Além de converter as imagens DICOM para PNG, elas são reunidas numa imagem maior para serem enviadas aos clientes. Cada imagem recebida pelo cliente é constituída por um conjunto de 16 imagens (4 linhas por 4 colunas de imagens) ilustrado na Figura 5.4. Desse modo, ocorre uma otimização na transferência das imagens na rede, em seu carregamento e na utilização da memória e do processador da unidade de processamento gráfico (GPU). As imagens são descomprimidas por rotinas já existentes no navegador (para o formato PNG) e são manipuladas sempre na GPU (usando WebGL). Essa manipulação inclui a geração dos planos ortogonais de visualização, marcações, zoom, translação, etc. O uso da GPU (Graphics Processing Unit), aumentando o desempenho em cálculos e projeções gráficas, permite uma velocidade de interação com os objetos gráficos que torna o ePAD usável. Se as mesmas operações fossem realizadas usando apenas JavaScript o programa seria muito lento e inviável.

\footnotetext{
${ }^{12}$ http://www.w3.org/TR/PNG/
} 


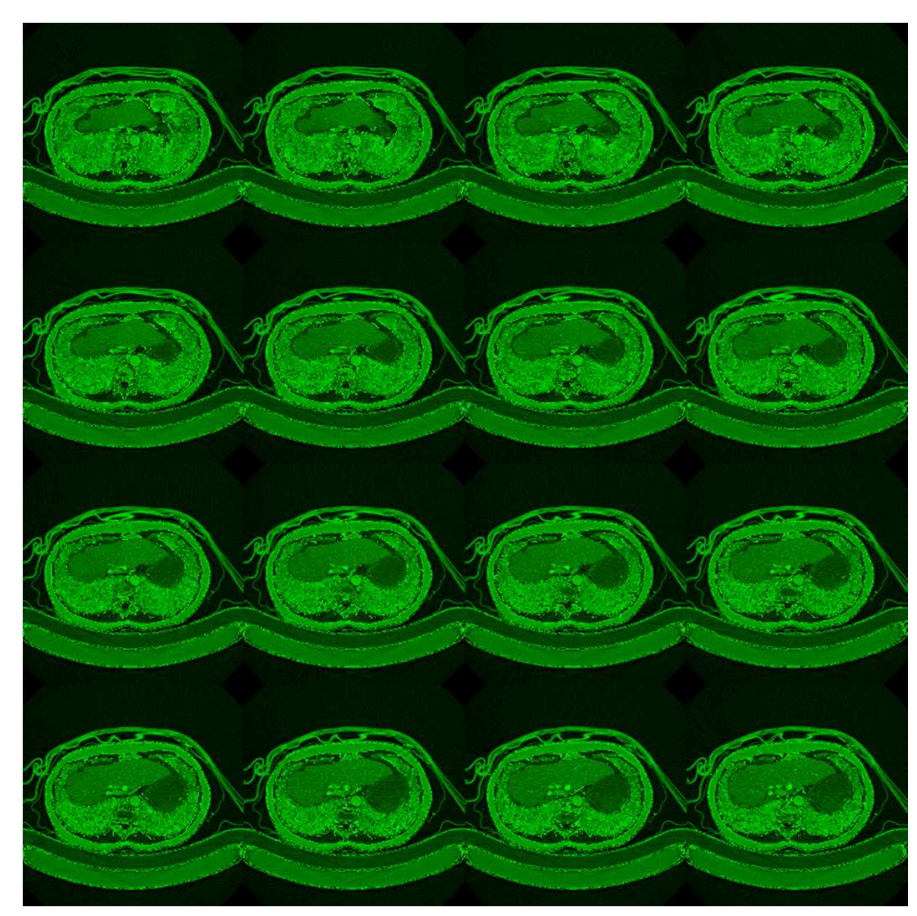

Figura 5.4: 16 imagens (4 linhas por 4 colunas de imagens).

\subsubsection{Features do Cliente}

A versão cliente deste protótipo pode realizar:

- Geração dos planos ortogonais de visualização das slices das imagens DICOM (Axial, Frontal e Sagital);

- Navegação na pilha de imagens em cada plano de visualização;

- Alterar o window/level, ou seja, o janelamento usual das imagens em todos os planos no lado cliente;

- Zoom e deslocamento das imagens visualizadas em todos os planos;

- Criar Regiões de Interesse (ROI) utilizando um cursor esférico em todos os planos de visualização;

- Exibição das projeções do ROI de cada slice das imagens em cada plano de visualização;

- Otimização de transferência de imagens por rede, de uso de memória, de processador da GPU e de processamento de ROIs. 


\subsection{Protótipo Funcional da Visualização 3D}

Para a criação da interface de visualização 3D foram realizadas reuniões e avaliações com pesquisadores e usuários finais da área de radiologia da Stanford University. Foram definidas as necessidades básicas para um ambiente de marcação em 3 dimensões e, a partir disso, uma interface foi implementada para mostrar os três planos ortogonais (Axial, Frontal e Sagital). Ela foi modelada com base nas interfaces 3D já existentes em ferramentas para visualização de imagens radiológicas em planos, como o OsiriX.

A partir do sistema ePAD original, desenvolvido para anotações $2 \mathrm{D}$ em imagens médicas, um protótipo de visualizador foi implementado em GWT utilizando as tecnologias HTML5 e WebGL. O principal objetivo desse protótipo foi servir de prova de conceito, apresentando as funcionalidades a usuários finais.

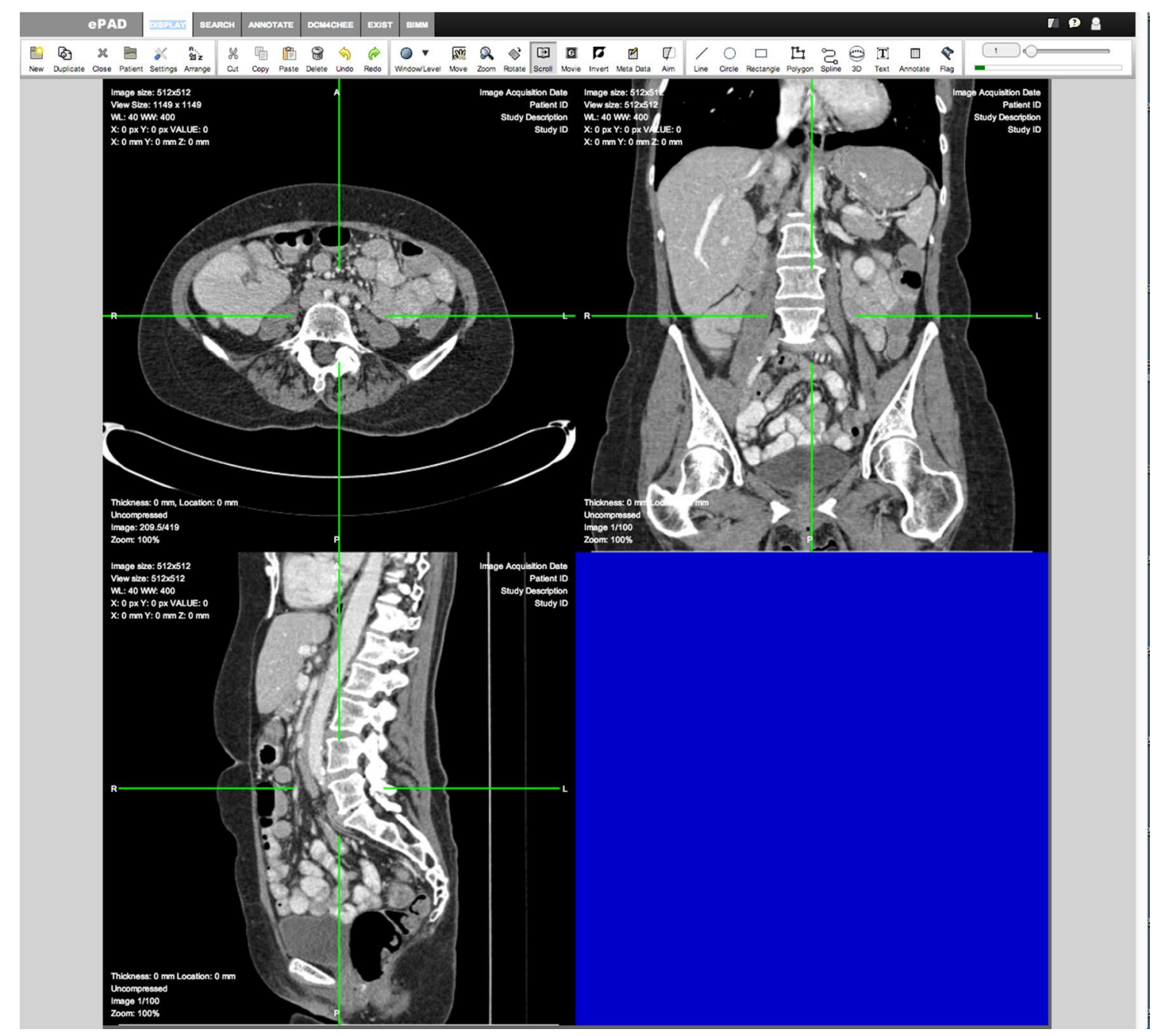

Figura 5.5: Interface do protótipo. 


\subsubsection{Interface Gráfica do Protótipo}

A Figura 5.5 apresenta a interface gráfica do protótipo. No canto superior, encontra-se a barra superior de menus, exibida na Figura 5.6. Ela possui o logotipo do sistema ePAD e, em seguida, o conjunto de menus: visualização, edição e manipulação de imagens médicas (DISPLAY), busca de estudos de pacientes (SEARCH), acesso às anotações de estudos de pacientes (ANNOTATE), servidor PACS (DCM4CHEE), repositório de imagens médicas (EXIST) e gerenciador de metadados de imagens biomédicas (BIMM).

\section{ePAD}

\section{gEARCH ANNOTATE DCMACHEE}

I 98

Figura 5.6: Barra superior de menus.

A próxima barra horizontal, na Figura 5.7, consiste em controles de visualização, edição e manipulação das imagens e, à direita dela, temos também o controle de navegação das imagens (slices) do plano Axial. Nessa barra, o usuário pode mudar opções de visualização, criar e editar Regiões de Interesse (ROIs) e manipular as informações de imagens médicas. Na Tabela 3, as funcionalidades dessa barra são listadas e discutidas, por se tratar de um protótipo, nem todas as funcionalidades foram implementadas como, por exemplo, abertura de uma janela popup para navegação direta a ROIs de lesões anotadas, undo, redo, e outros indicados na tabela mencionada.

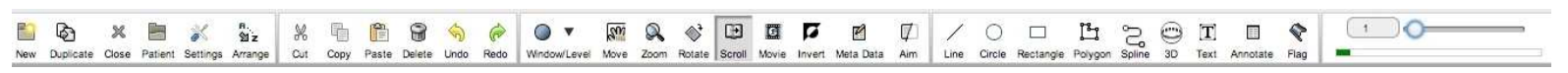

Figura 5.7: Barra de ferramentas do ePAD.

Tabela 3: Lista de funcionalidades da barra de ferramentas.

\begin{tabular}{|c|l|l|}
\hline Ícone & \multicolumn{1}{|c|}{ Função/Descrição } & Implementado \\
\hline New & $\begin{array}{l}\text { New: permite a criação de novo projeto de estudo de } \\
\text { paciente. }\end{array}$ & Sim \\
\hline $\begin{array}{c}\text { Duplicate } \\
\text { \& }\end{array}$ & $\begin{array}{l}\text { Duplicate: permite a visualização duplicada do mesmo } \\
\text { estudo de paciente. }\end{array}$ & Sim \\
\hline Close & Close fecha o estudo que está sendo visualizado. & Sim \\
\hline
\end{tabular}




\begin{tabular}{|c|c|c|}
\hline Patient & $\begin{array}{l}\text { Patient Jacket: permite abrir uma janela popup para } \\
\text { navegação direta a ROIs de lesões anotadas no estudo do } \\
\text { paciente. }\end{array}$ & Não \\
\hline Settings & $\begin{array}{l}\text { Settings: permite a ativação/desativação de } \\
\text { funcionalidades e modos de visualização (2D para 3D e } \\
\text { vice-versa) }\end{array}$ & Sim \\
\hline $\begin{array}{l}\text { Av. } \\
\text { Avrange }\end{array}$ & Arrange: permite rearranjar os planos de visualização. & Não \\
\hline $\begin{array}{l}\text { So } \\
\text { cut }\end{array}$ & $\begin{array}{l}\text { Cut: permite recortar um ROI, ou seja, removê-lo para } \\
\text { colagem posterior. }\end{array}$ & Não \\
\hline $\begin{array}{l}\text { 眲 } \\
\text { Copy }\end{array}$ & Copy: permite copiar um ROI para colagem posterior. & Não \\
\hline Delete & Delete: permite excluir um ROI. & Sim \\
\hline $\begin{array}{l}\text { (n) } \\
\text { Undo }\end{array}$ & Undo: permite desfazer a edição de um ROI. & Não \\
\hline$\Leftrightarrow$ & Redo: permite refazer a edição de um ROI. & Não \\
\hline$\underset{\text { Windowlevel }}{\mathbf{v}^{-1}}$ & $\begin{array}{l}\text { Window/Level: a mudança de Window/Level da imagem. O } \\
\text { usuário deve pressionar o botão direito do mouse e arrastar } \\
\text { na horizontal e vertical, trocando os valores de } \\
\text { Window/Level da imagem. }\end{array}$ & Sim \\
\hline $\begin{array}{l}\sqrt{\text { SM }^{2}} \\
\text { Move }\end{array}$ & $\begin{array}{l}\text { Move: permite a movimentação da imagem na tela do } \\
\text { sistema. O usuário deve pressionar o botão esquerdo do } \\
\text { mouse e arrastar para a posição desejada. }\end{array}$ & Sim \\
\hline Zoom & $\begin{array}{l}\text { Zoom: permite o aumento ou diminuição da imagem. O } \\
\text { usuário deve clicar e arrastar na imagem para aumentar ou } \\
\text { diminuir o tamanho da mesma. }\end{array}$ & Sim \\
\hline$\diamond_{\text {Rotate }}^{7}$ & $\begin{array}{l}\text { Rotate: permite rotacionar a imagem. O usuário deve clicar } \\
\text { no botão para acrescentar } 90^{\circ} \text { de rotação a imagem. }\end{array}$ & Não \\
\hline Scroll & $\begin{array}{l}\text { Scroll: permite navegar pelo conjunto de imagens. O } \\
\text { usuário deve girar o botão scroll do mouse. }\end{array}$ & Sim \\
\hline
\end{tabular}




\begin{tabular}{|c|c|c|}
\hline $\begin{array}{l}\text { 賈 } \\
\text { Movie }\end{array}$ & $\begin{array}{l}\text { Play Movie: permite visualizar uma animação das } \\
\text { imagens. Quando o usuário clica essa opção, as imagens } \\
\text { são passadas, intercalando um curto período de tempo, } \\
\text { dando assim um efeito de filme pelas camadas da série de } \\
\text { imagens. }\end{array}$ & Não \\
\hline$\underset{\text { Invert }}{\boldsymbol{\varnothing}}$ & Invert: permite inverter os valores dos pixels da imagem. & Não \\
\hline Meta Data & $\begin{array}{l}\text { Meta Data: permite visualizar os metadados do estudo do } \\
\text { paciente. }\end{array}$ & Não \\
\hline (7) & $\begin{array}{l}\text { Aim: permite visualizar a lista de anotações realizadas no } \\
\text { estudo do paciente. }\end{array}$ & Sim \\
\hline Line & $\begin{array}{l}\text { Line: permite desenhar segmentos de reta para formação } \\
\text { de ROI. }\end{array}$ & Sim \\
\hline Circle & Circle: permite desenhar círculos para formação de ROI. & Sim \\
\hline $\begin{array}{l}\square \\
\text { Rectangle }\end{array}$ & $\begin{array}{l}\text { Rectangle: permite desenhar retângulos para formação de } \\
\text { ROI. }\end{array}$ & Não \\
\hline Polygon & $\begin{array}{l}\text { Polígono: permite desenhar polígonos para formação de } \\
\text { ROI. }\end{array}$ & Não \\
\hline$\underset{\text { Spline }}{\overbrace{0}^{\infty}}$ & Spline: permite desenhar curvas para formação de ROI. & Sim \\
\hline$\underbrace{}_{30}$ & $\begin{array}{l}\text { 3D Draw: permite usar uma esfera como cursor 3D para } \\
\text { edição de ROIs em 3D. }\end{array}$ & Sim \\
\hline Text & Text: permite adicionar texto com comentários. & Não \\
\hline $\begin{array}{c}\text { 围 } \\
\text { Annotate }\end{array}$ & $\begin{array}{l}\text { Annotate: permite a criação e visualização das anotações } \\
\text { AIM. O sistema apresenta o formulário de criação de } \\
\text { anotações AIM para os ROIs desenhados pelo usuário. }\end{array}$ & Sim \\
\hline Flag & $\begin{array}{l}\text { Flag Image: permite marcar uma imagem para análise } \\
\text { posterior. }\end{array}$ & Não \\
\hline
\end{tabular}




\subsubsection{Utilizando o Protótipo}

Para usar o protótipo, um usuário inicia uma interação pela busca e abertura de uma série de imagens de um estudo sobre um paciente. A tela da Figura 5.8 exibe o resultado da busca no ePAD: a primeira coluna ao lado direito do menu de Folders (pastas) e Search (busca) apresenta o nome do projeto (Project), na sublista o nome do paciente (Patient) com número de séries (Series) - ou seja, de conjuntos de imagens - e, em sua sublista, sua descrição (Description).

\begin{tabular}{|c|c|c|c|c|c|c|}
\hline ePAD & SEARCH ANNOTATE DCMACHEE EXIST & XNAT & & & 7 $7 ?$ & 8 \\
\hline \multicolumn{7}{|c|}{ New Project | Add to Project | Connect | Delete | } \\
\hline Download & \multicolumn{6}{|l|}{ Open } \\
\hline Folders & \multirow[t]{2}{*}{ Project/ Patient (\#Series) / Description } & $\begin{array}{l}\text { \#lmages / } \\
\text { Slice\# }\end{array}$ & \multirow{2}{*}{$\begin{array}{l}\text { Exam / } \\
\text { Template } \\
\text { Type }\end{array}$} & Series / Annotation Date & Patient/ Annotation Identifier & Ready \\
\hline 3D_USP & & & & & & \\
\hline Unassigned & \multicolumn{6}{|l|}{ V 3D_USP } \\
\hline \multirow[t]{2}{*}{ Eearch } & \multicolumn{3}{|l|}{ COMBINED LUT PSTATE TEST (1) } & \multicolumn{3}{|c|}{ XLUT_Pnn } \\
\hline & \multicolumn{3}{|l|}{ COMBINED LUT TEST (1) } & \multicolumn{3}{|c|}{ XLUT_nn } \\
\hline \multirow{4}{*}{$\begin{array}{l}\text { Filter by } \\
\square \text { Annotations } \\
\quad{ }_{\text {with }} \bigcirc_{\text {without }} \\
\square \text { Patient }\end{array}$} & \multicolumn{3}{|l|}{ COMPLEX COMBINATION TEST (1) } & \multicolumn{3}{|c|}{ CPLX_Pnn } \\
\hline & \multicolumn{3}{|l|}{ DISPLAY SHUTTER TEST (1) } & \multicolumn{3}{|c|}{ DISH_Pnn } \\
\hline & \multicolumn{3}{|l|}{ DISPLAYED AREA TEST (1) } & \multicolumn{3}{|c|}{ DISA_Pnn } \\
\hline & \multicolumn{3}{|l|}{ GRAPHIC ANNOTATION TEST (1) } & \multicolumn{3}{|c|}{ GRAN_Pnn } \\
\hline patient name & \multicolumn{3}{|l|}{ KEF-1-271-190771 (1) } & \multicolumn{3}{|c|}{$190771426051643995806366280644 \ldots$} \\
\hline$\square$ Modality & $\nabla$ THORAX CAP (ADULT) (1) & 419 & CT & $3 / 7 / 14$ & 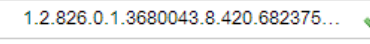 & $\checkmark$ \\
\hline \multirow[t]{2}{*}{ modality } & ABD/PEL 1.0 B31F & 419 & ст & $3 / 7 / 14$ & & $\checkmark$ \\
\hline & MODALITY LUT PSTATE TEST (1) & & & & MLUT_Pnn & \\
\hline \multirow{7}{*}{$\begin{array}{l}\text { Sort by } \\
\text { Patient } \\
\text { Study Date }\end{array}$} & MODALITY LUT TEST (1) & & & & MLUT_nn & \\
\hline & OVERLAY TEST (1) & & & & OVLY_Pnn & \\
\hline & PRESENTATION LUT PSTATE TE... & & & & PLUT_Pnn & \\
\hline & SPATIAL TRANSFORMATION TES.. & & & & SPAT_Pnn & \\
\hline & TEXT ANNOTATION TEST (1) & & & & TEAN_Pnn & \\
\hline & VOI LUT PSTATE TEST (1) & & & & VLUT_Pnn & \\
\hline & VOI LUT TEST (1) & & & & VLUT_nn & \\
\hline
\end{tabular}

Figura 5.8: Tela de resultado de busca do ePAD.

A próxima coluna da tela, na sequência, consiste no número de imagens ou slices (fatias) da série de imagens. A coluna mais à direita mostra o tipo de exame realizado: CT (Tomografia Computadorizada), por exemplo. A próxima coluna à direita exibe a data da criação da série de imagens. A próxima coluna, na sequência, apresenta os códigos (UID DICOM) dos estudos encontrados do paciente selecionado na primeira coluna.

Para abrir a série de imagens, o usuário seleciona o estudo do paciente e clica no botão Open. Todo o procedimento descrito até aqui ocorre da mesma maneira desde a versão 1.0 do ePAD. A partir deste momento, as novas funcionalidades do protótipo são apresentadas.

A tela de visualização (Display), Figura 5.9, é exibida com o conjunto de imagens aberto no primeiro plano ortogonal (nesse caso, Axial). A partir disso, os outros dois planos ortogonais apresentarão, logo em seguida, os conjuntos de imagens respectivos (no caso, 
Frontal e Sagital). O usuário pode utilizar as ferramentas de visualização em cada plano para melhorar sua compreensão sobre as imagens como, por exemplo, alterando os níveis de window/level, movendo as próprias imagens ou realizando zoom. As opções mencionadas estão destacadas com um retângulo em laranja na Figura 5.9.

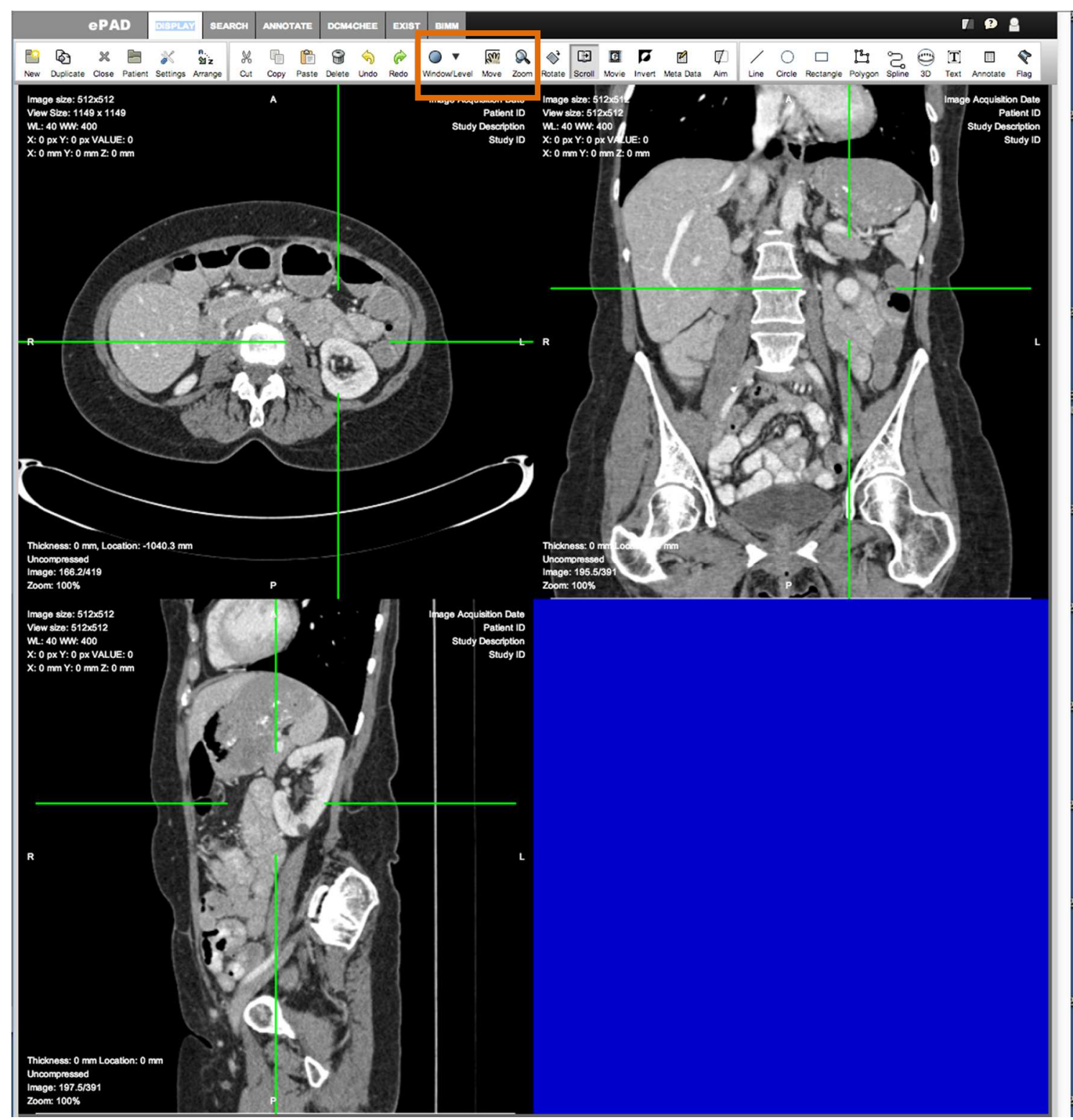

Figura 5.9: Tela de visualização de imagem do ePAD (Display).

Após a localização da lesão na imagem, o usuário pode clicar na posição da lesão em um dos planos para que o sistema navegue até as fatias correspondentes nos outros dois planos. A partir disso, os cruzamentos das réguas (rulers) perpendiculares e de cor verde são centralizados na posição selecionada e nas posições correspondentes nos outros planos, focalizando a região a ser marcada - ilustrado pela Figura 5.10. O mesmo procedimento pode ser realizado posicionando-se o cursor do mouse sobre um dos planos e acionando-se a 
rolagem do botão scroll. Dessa maneira, a navegação pelas fatias é feita enquanto as fatias correspondentes nos outros dois planos são apresentadas. Esses procedimentos mostram a navegação por um conjunto de imagens para se localizar as lesões de interesse, a marcação dessas lesões será mostrada na seção 5.4.

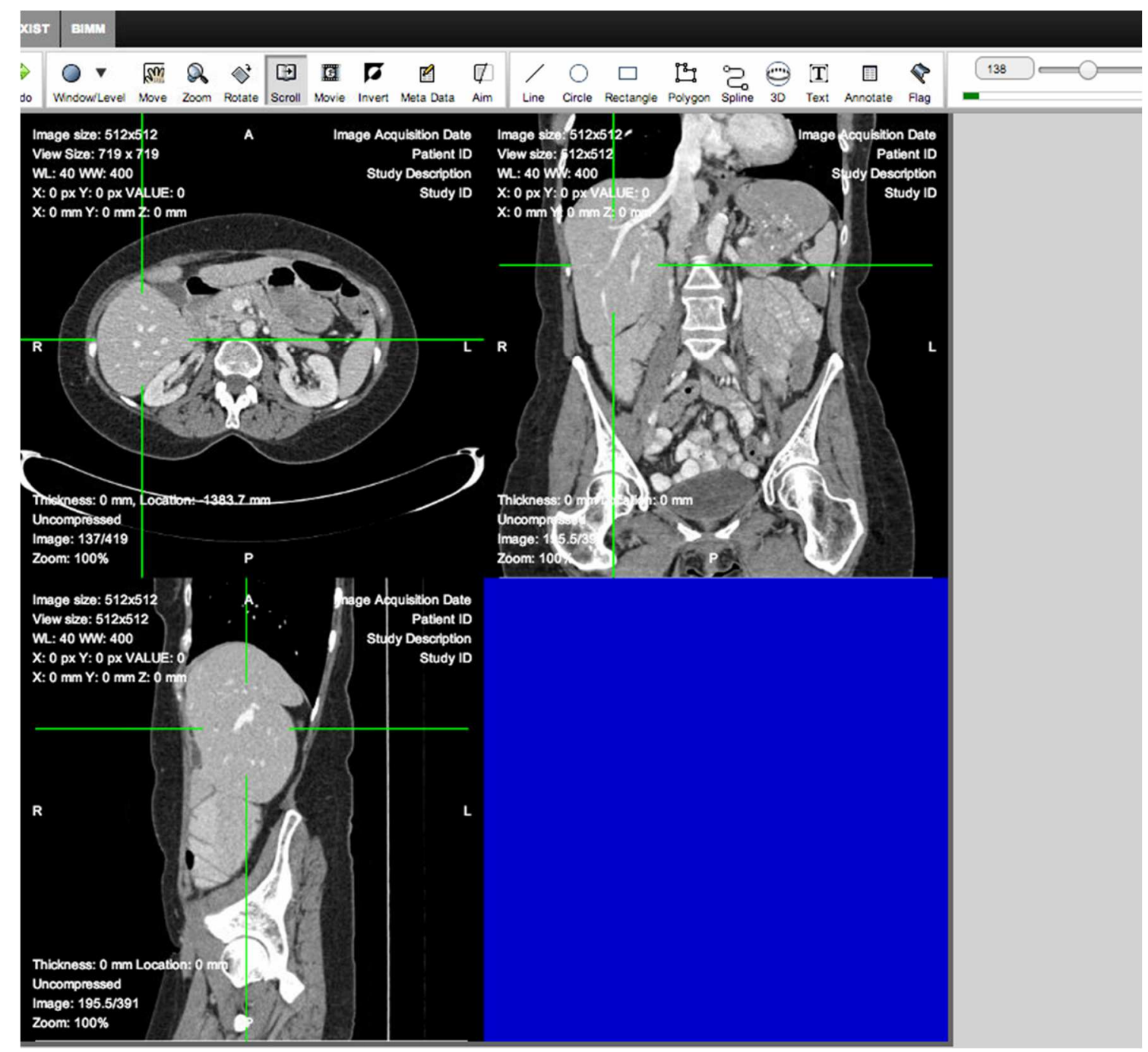

Figura 5.10: Usuário seleciona posição em que se encontra a lesão a ser marcada.

\subsection{Projeto das Interfaces de Marcação 3D}

Ao contrário da interface de visualização 3D, para a marcação de regiões de interesse (ROIs) 3D, ainda não existem interfaces consagradas na área. Assim, depois de discussões com radiologistas de Stanford, decidiu-se implementar protótipos em vídeo de três opções de interfaces para selecionar regiões 3D:

- cursor esférico - onde o usuário pinta a região 3D com uma esfera, 
- similaridade de cores de pixels - onde o usuário seleciona uma região 3D que tem pixels com valores de intensidade semelhantes, e

- detecção de bordas - onde a região selecionada está entre bordas detectadas pelo programa.

Os protótipos possuem narração, legendas e exibem a interação de um usuário realizando marcações nos três planos de visualização com cada opção. Eles foram construídos utilizandose a interface do protótipo do ePAD para visualização dos três planos, que serviu de background, e animações feitas com Flash tão próximas quanto o possível da realidade. Os três vídeos são apresentados a seguir, eles se iniciam depois que uma série de imagens de um paciente é aberta pelo usuário e é possível ver os 3 planos: o Axial, o Frontal e o Sagital.

\subsubsection{Cursor Esférico 3D}

No vídeo apresentado na Figura 5.11, a marcação 3D é realizada pelo cursor esférico, projetando um conjunto de ROIs circulares com raios correspondentes à cada fatia do conjunto de imagens.

Inicialmente, foi aberta uma série de imagens de um paciente e o botão de cursor 3D foi acionado. Com o cursor do mouse no plano Axial, se o botão de rolagem do mouse for movido para cima ou para baixo, as fatias anteriores ou posteriores na série serão exibidas no mesmo plano. O mesmo efeito pode ser visualizado no plano Frontal ao mover o botão de rolagem do mouse e também no plano Sagital. O botão esquerdo do mouse, quando pressionado, é utilizado para selecionar uma região 3D que é projetada simultaneamente nos planos Axial, Frontal e Sagital. É como se houvesse um pincel circular com um certo diâmetro desenhando sobre um plano e extrapolando a ideia para uma esfera que desenha um objeto 3D cujas projeções aparecem simultaneamente nos 3 planos. 


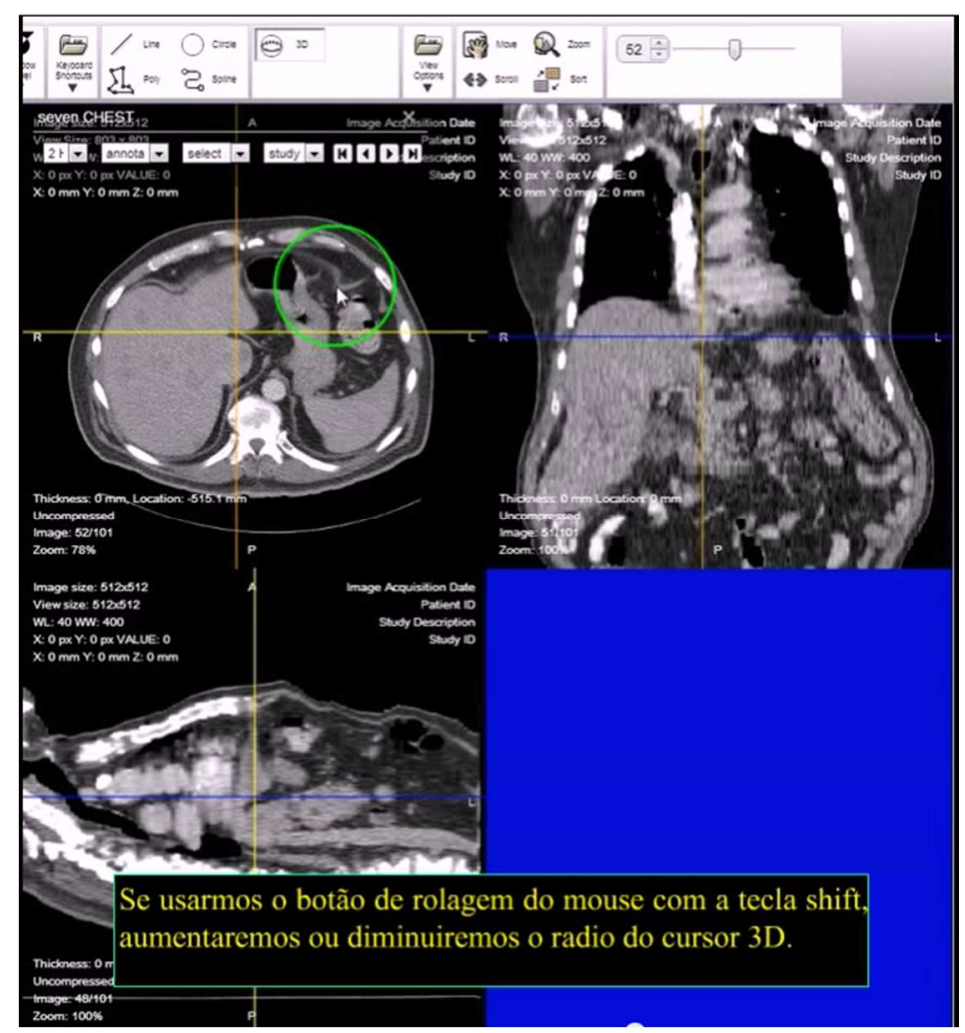

Figura 5.11: Vídeo de simulação ROI 3D.

\subsubsection{Similaridades de Cores de Pixels}

No vídeo ilustrado pela Figura 5.12, algo chamado de variação de similaridade de cores de pixel é utilizado. Ao ter a série de imagens do paciente aberto e o cursor sobre o plano Axial, o usuário escolhe um ponto sobre a imagem e um intervalo predefinido de valores numéricos para os pixels. Uma área da imagem é selecionada na qual as cores dos pixels estão dentro desse intervalo de valores.

Se o botão de rolagem do mouse for movido para cima com a tecla shift, o intervalo de valores aumenta e, com ele, a área selecionada aumenta de acordo com o aumento da variação de cores dos pixels e vice-versa. 


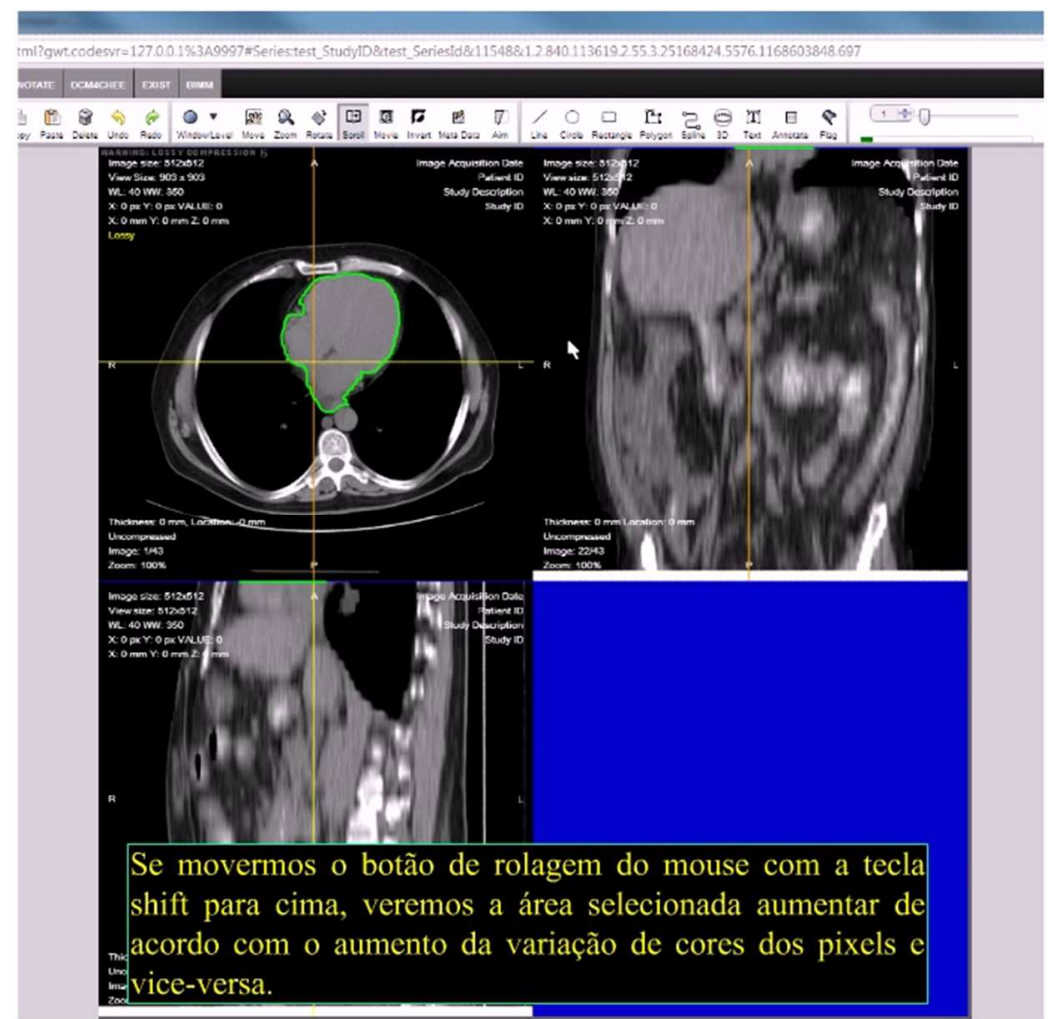

Figura 5.12: Vídeo de similaridades de cores de pixels.

\subsubsection{Detecção de Bordas}

Este vídeo é semelhante ao anterior, mas, neste caso, um algoritmo de detecção de bordas é utilizado para marcar os limites de uma região de interesse. Na Figura 5.13, um zoom foi realizado na fatia e uma região específica foi selecionada. As bordas foram detectadas, mas a área selecionada não foi fechada, nesse caso de simulação. Foi percebido, em testes de softwares de detecção de bordas, que é possível obter regiões não fechadas. Para isso, uma cruz amarela, no centro do cursor circular, é utilizada como um cursor de desenho livre para fechar a área selecionada. $\mathrm{O}$ cursor pode ser visto na mesma figura. 


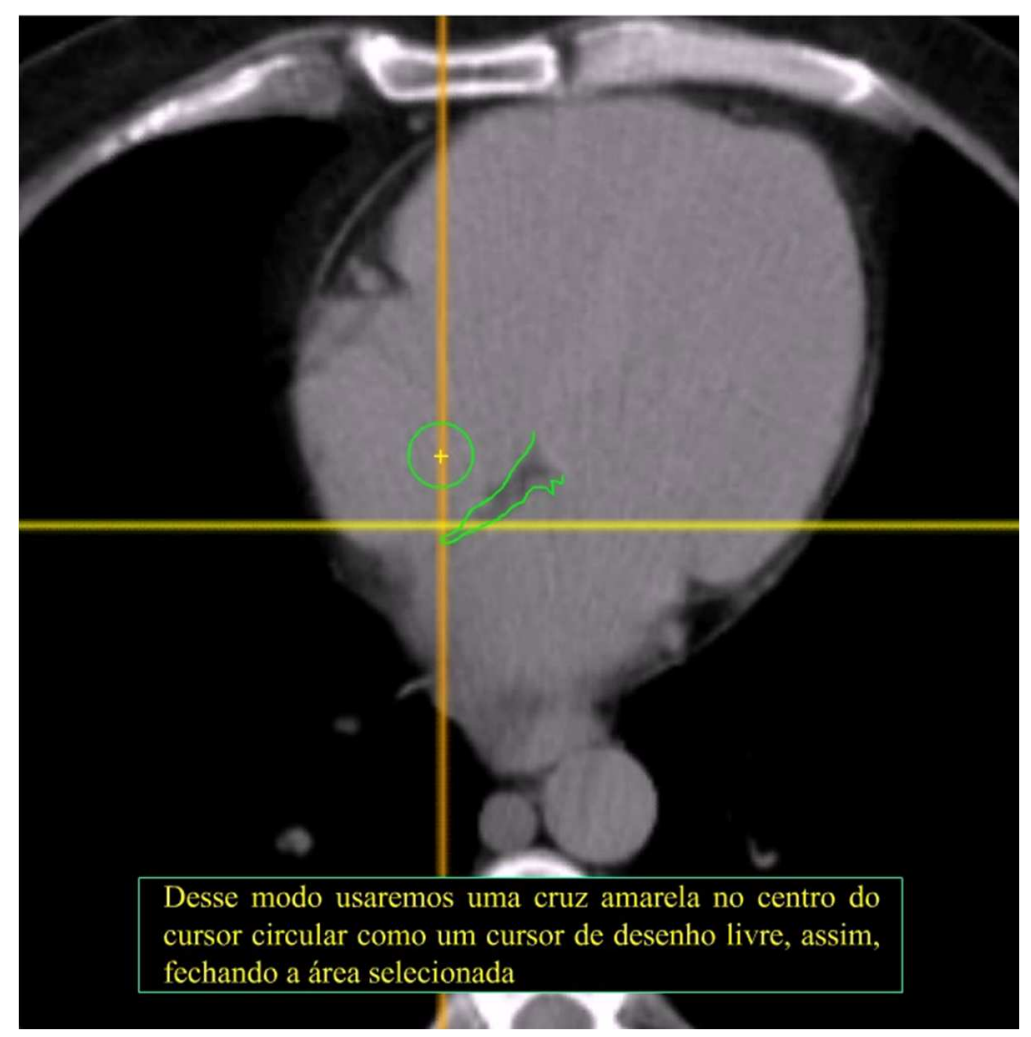

Figura 5.13: Vídeo de detecção de bordas.

\subsubsection{Questionário}

Depois da criação dos protótipos de vídeo, foram realizadas reuniões presenciais com professores de radiologia do Hospital das Clínicas da USP de Ribeirão Preto com a apresentação dos três protótipos de marcação 3D sobre imagens com a obtenção de opiniões e observações. Também foram feitas reuniões virtuais com radiologistas da Stanford University School of Medicine e eles também nos deram opiniões e observações. Em seguida, foi aplicado um questionário on-line (disponível no Anexo A) sobre esses vídeos com perguntas sobre usabilidade, consistência e visibilidade específicas para cada abordagem - ilustrado na Figura 5.14. A seguir, são apresentados os participantes e os resultados obtidos. 


\title{
Pesquisa ePad - Desenhando Regiões de Interesse (ROI)
}

\author{
Tempo estimado: 10 minutos (aproximadamente) \\ O ePad (electronic Physician device ou dispositivo eletrônico Médico) é uma ferramenta online, \\ independente de sistema operacional, para anotações semânticas e está sendo desenvolvido por \\ nosso grupo de pesquisa no ICMC-USP em conjunto com o Imaging Informatics Lab (LII) Dept. de \\ Radiologia - Stanford University. \\ ePad é de uso gratuito. \\ Esta pesquisa é feita de maneira confidencial e nenhuma identifação será requisitada. \\ Esta pesquisa refere-se a diferentes maneiras de se desenhar Regiōes de Interesse (ROI) em \\ imagens radiológicas usando o ePad. O objetivo é obter opiniōes e sugestōes para as diferentes \\ abordagens em desenho de ROls. 3 simulações em video exibem as diferentes abordagens. \\ Agradecemos por suas respostas. Estas serão consideradas para desenvolvimentos futuros para 0 \\ ePad. \\ Os vídeos devem ser tocados na máxima qualidade e em tela cheia para melhor visualização.

$\begin{array}{ll}\text { Continue » } & 7 \% \text { completed } \\ \text { Powered by } & \text { This content is neither created nor endorsed by Google. } \\ \text { R Google Forms } & \text { Report Abuse - Terms of Service - Additional Terms }\end{array}$

Figura 5.14: Questionário on-line de usabilidade, consistência e visibilidade.

\subsubsection{Resultados do Questionário on-line}

Os resultados do questionário on-line com os protótipos em vídeo foram obtidos de respostas enviadas por dois médicos radiologistas da Stanford University School of Medicine, por feedback informal através de e-mails de um professor e um pesquisador da mesma universidade (ambos radiologistas), e em entrevistas presenciais com dois professores de radiologia da Faculdade de Medicina da USP - Campus Ribeirão Preto. O total de participantes nessa pesquisa foi de seis pessoas - todas prováveis futuras usuárias do sistema proposto neste trabalho. A maioria deles já possui experiência na atividade de marcação e anotação de imagens radiológicas. O número reduzido de usuários já era esperado devido a grande dificuldade de encontrar usuários tão especializados dispostos a contribuir com seu tempo para pesquisas desse gênero.

Baseando-se nas respostas, obtivemos que:

- Quatro usuários já terminaram o período de residência em radiologia.

- Dois usuários estão no primeiro ano de fellowship.

- Nenhum dos usuários teve contato com software que permite marcações em três dimensões sobre imagens radiológicas.

- Todos conseguiram visualizar as simulações sem qualquer problema. 
- Três acharam as abordagens de marcação intuitivas, mas com ressalvas de que cada abordagem seria mais adequada para diferentes tipos de lesões, das características destas, e do propósito do estudo.

A partir da análise das respostas obtidas, foi decidido, em comum acordo com nossos parceiros da Stanford University, que a interface com cursor esférico 3D seria implementada. Essa decisão levou em conta o tipo variado de lesões que esse tipo de cursor pode ser usado, o fato de essas lesões incluírem as que nossos usuários alvo atuais - radiologistas trabalhando com clinical trials sobre drogas para câncer - trabalham, bem como na facilidade de implementação do cursor esférico. No futuro, outros tipos de cursor poderão ser implementados e testados.

A concepção de marcação por um cursor esférico sobre um conjunto de imagens em um plano ortogonal (Axial, por exemplo) é melhor ilustrada na Figura 5.15.

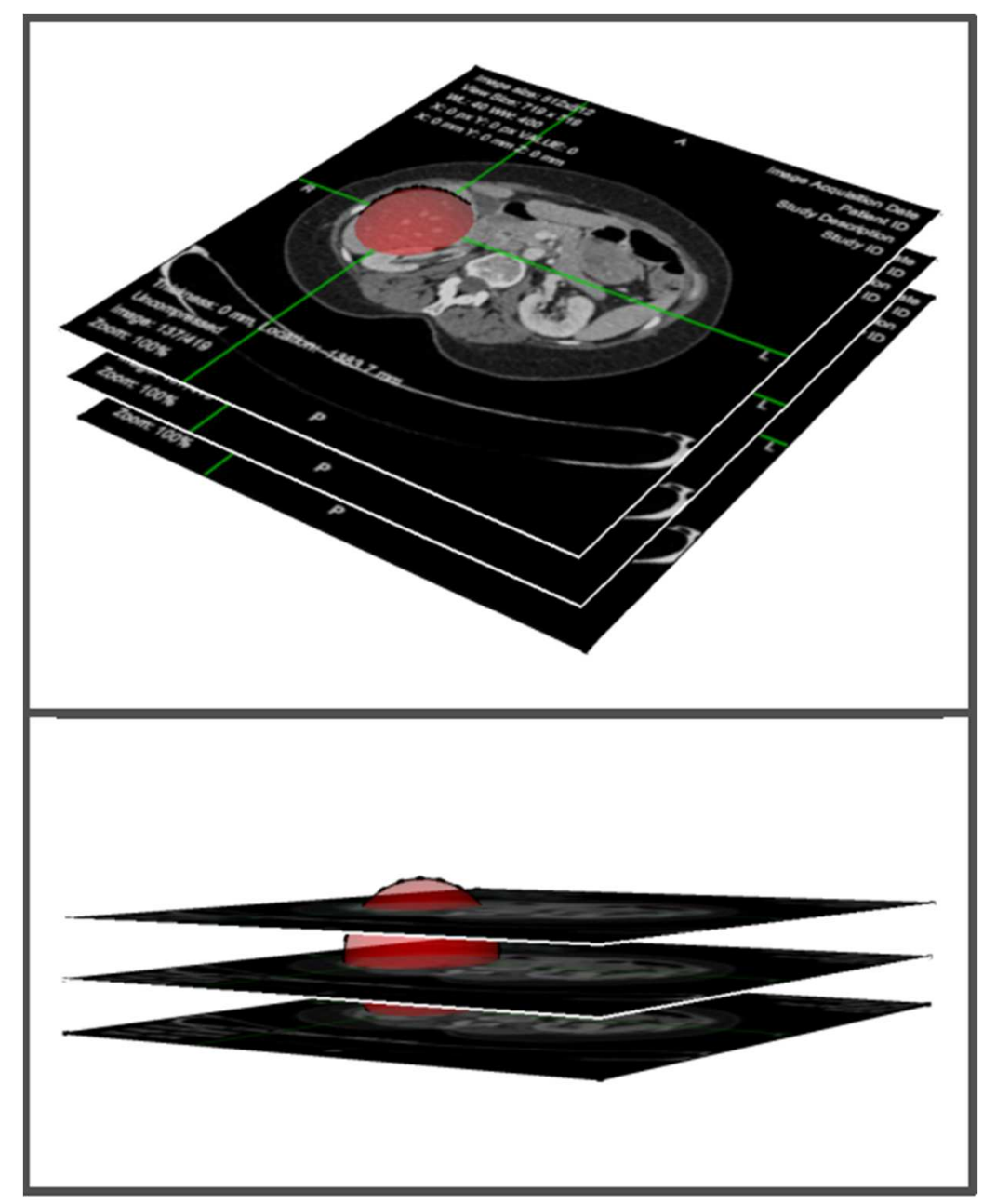

Figura 5.15: Marcação por cursor esférico (em vermelho) sobre imagens (Axial). 
Na mesma figura, podemos ver o curso esférico em 3D, representado em vermelho, e as camadas de imagens do plano Axial. O cursor pode ser movimentado pelo usuário nos eixos x, y e z e o ePAD mostra a projeção do cursor nos 3 planos (Axial, Frontal e Sagital). Caso o usuário pressione o botão esquerdo do mouse, o cursor passa a "pintar" todos os voxels por onde passar. $\mathrm{Ou}$, como os voxels são representados pelos pixels nas imagens do plano axial, ele "pinta" todos os pixels do axial por onde suas projeções passarem.

Esses voxels "pintados" formarão o ROI em 3D e também terão suas projeções mostradas nos 3 planos.

As funcionalidades que o sistema possui encontram-se a seguir:

- O cursor de marcação 3D deve ser uma esfera de raio escolhido pelo usuário por um atalho de teclado e/ou mouse.

- Ao ser realizada a marcação em uma das imagens de um plano de visualização, uma circunferência deve indicar a projeção do cursor esférico nos outros planos.

- A esfera resultante da marcação deve aparecer como "fatias" nas diversas camadas mostradas nos planos de visualização. O resultado da marcação é um ROI (Region of Interest).

- Ao se mover a esfera, ela "pinta" todos os pixels (ou voxels) por onde ela passar nas diversas camadas de imagens, podendo resultar em marcações de bordas irregulares.

- O sistema deve oferecer desempenho satisfatório nas operações de pinturas dos pixels com a esfera.

- A navegação pelo conjunto de imagens, em cada plano de visualização, deve apresentar as respectivas projeções da marcação 3D no plano.

Um protótipo funcional do cursor esférico foi implementado seguindo esses requisitos. Ele foi baseado no protótipo do visualizador 3D e avaliado pelos usuários especialistas do Departament of Radiology da Stanford University e será apresentado na seção 5.4.

O desenvolvimento do protótipo contou com feedback de nossos parceiros da Stanford University através de reuniões semanais por vídeo conferência e inúmeros e-mails. Ferramentas como wiki para gerenciamento de requisitos, documentação de código, pautas de reuniões, resultados de avaliações com usuários especialistas, e a ferramenta de gerenciamento de tarefas, JIRA, foram também utilizadas. 


\subsection{Marcação 3D por Cursor Esférico}

$\mathrm{Na}$ implementação do protótipo do ePAD, as imagens radiológicas são renderizadas usando-se texturas retangulares que armazenam 4 linhas por 4 colunas de imagens, resultando em 16 imagens por textura $(4 \times 4)$ que são processadas paralelamente na GPU. Este número foi decidido pela quantidade disponível de memória na maioria das placas aceleradoras e pelo fato de as imagens de CTs e PETs serem da ordem de 512x512 pixels. O processamento das operações do cursor esférico 3D, que incluem cálculos sobre as projeções do cursor e das marcações nos três planos, também é feito usando-se essas texturas e a GPU. Este fator foi influente sobre o modo como as imagens devem ser produzidas, transmitidas do servidor para o cliente, diminuindo o tempo de espera da transferência de imagens pela rede e otimizando o processamento pela GPU (lado cliente).

As marcações, os pixels "pintados" pelo cursor esférico, são também renderizados em texturas $4 \mathrm{x} 4$ para processamento paralelo usando 1 bit por ROI. Assim podemos dizer se um pixel faz parte ou não (foi pintado ou não) de um ROI. Atualmente, o protótipo usa uma textura ativa para as marcações e outra para as imagens radiológicas. Como cada pixel, em uma textura WebGL, tem 32 bits ( 8 bits para r, g, b e alfa), o protótipo pode mostrar ao mesmo tempo 32 ROIs diferentes por série de imagens, o que foi considerado adequado pelos especialistas. 


\subsubsection{Utilizando a Marcação 3D}

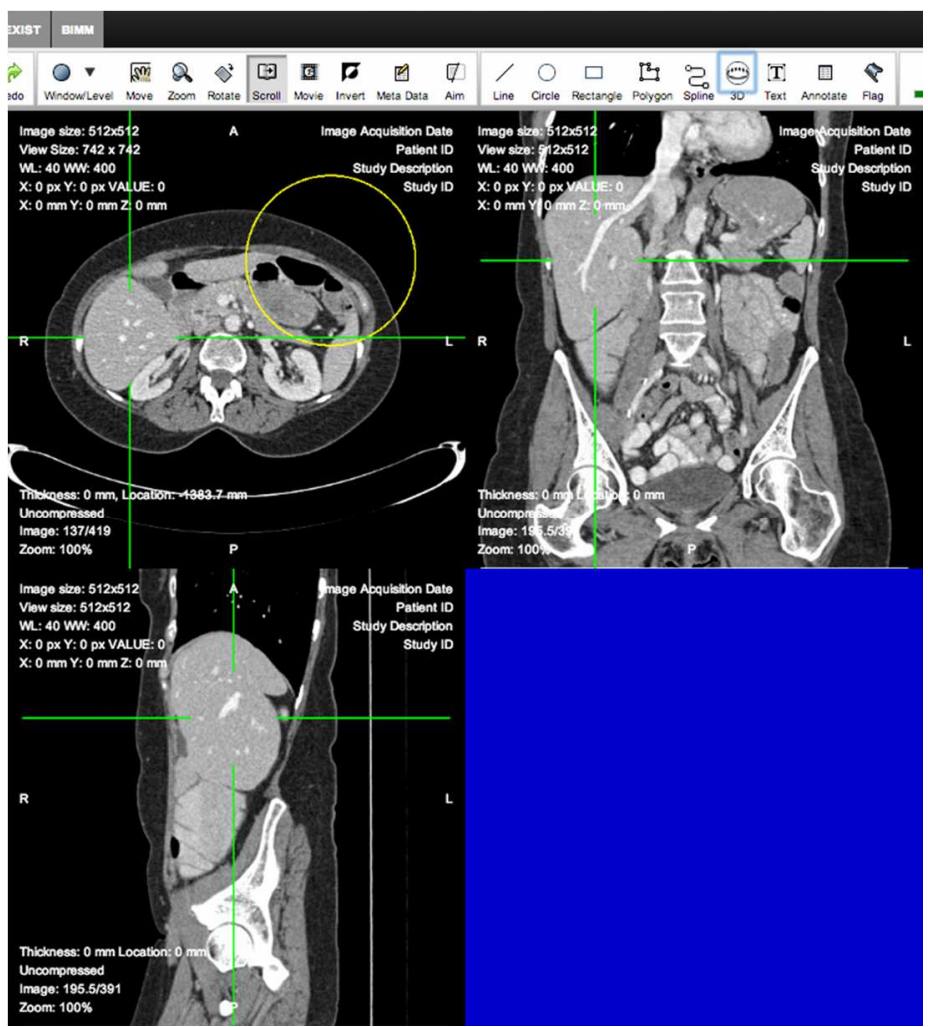

Figura 5.16: Cursor esférico projetado no plano Axial na cor amarela.

Para usar a marcação com o cursor 3D, o usuário primeiro encontra a lesão, como explicado na seção 5.2.2. Ao acionar o botão 3D na barra de ferramentas, o cursor esférico aparece em amarelo (Figura 5.16). Nessa figura, o cursor está posicionado sobre o cruzamento das réguas no plano Axial (Figura 5.17). Com a tecla shift pressionada, o botão de rolamento do mouse pode ser usado para alterar o raio da esfera. Por exemplo, rolando o botão para cima, o raio do cursor é redimensionado, resultando numa esfera menor e um círculo projetado de menor raio (Figura 5.18). 


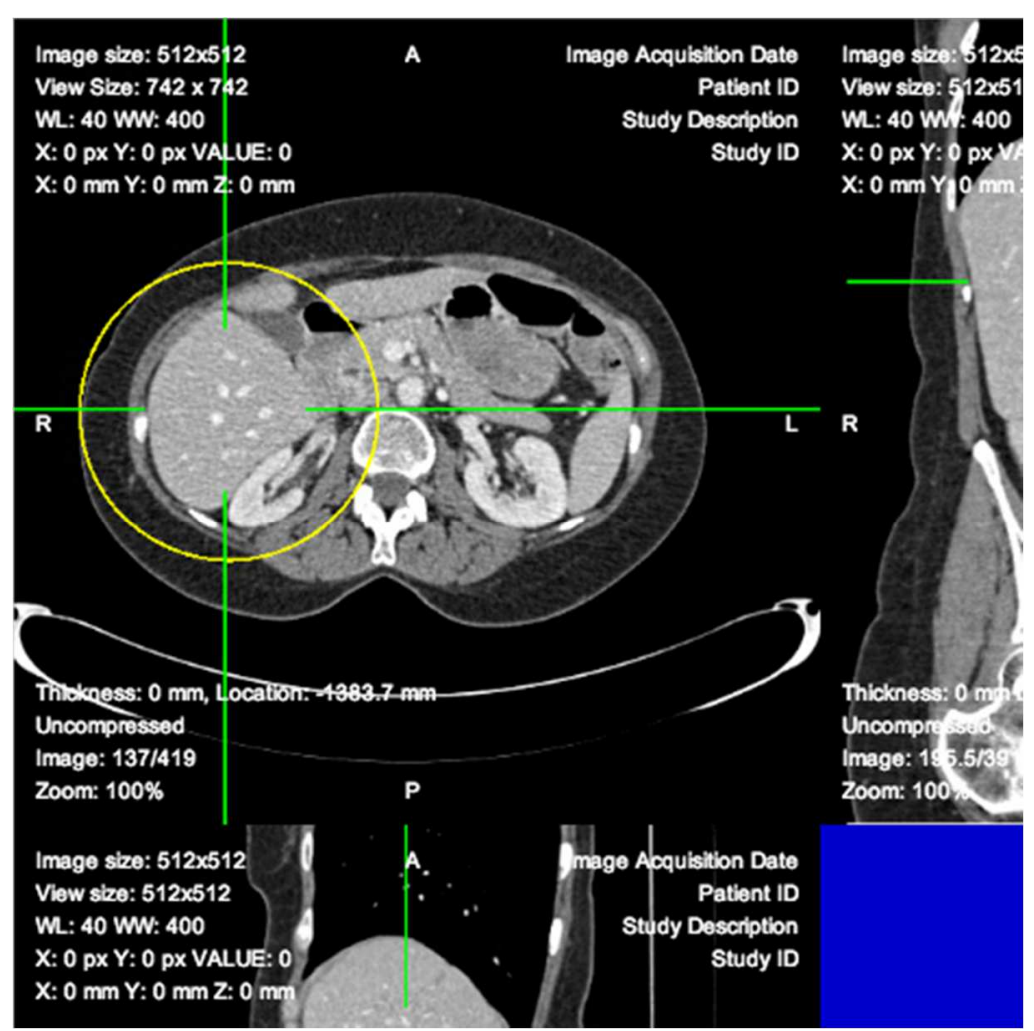

Figura 5.17: Cursor posicionado sobre o cruzamento das réguas.

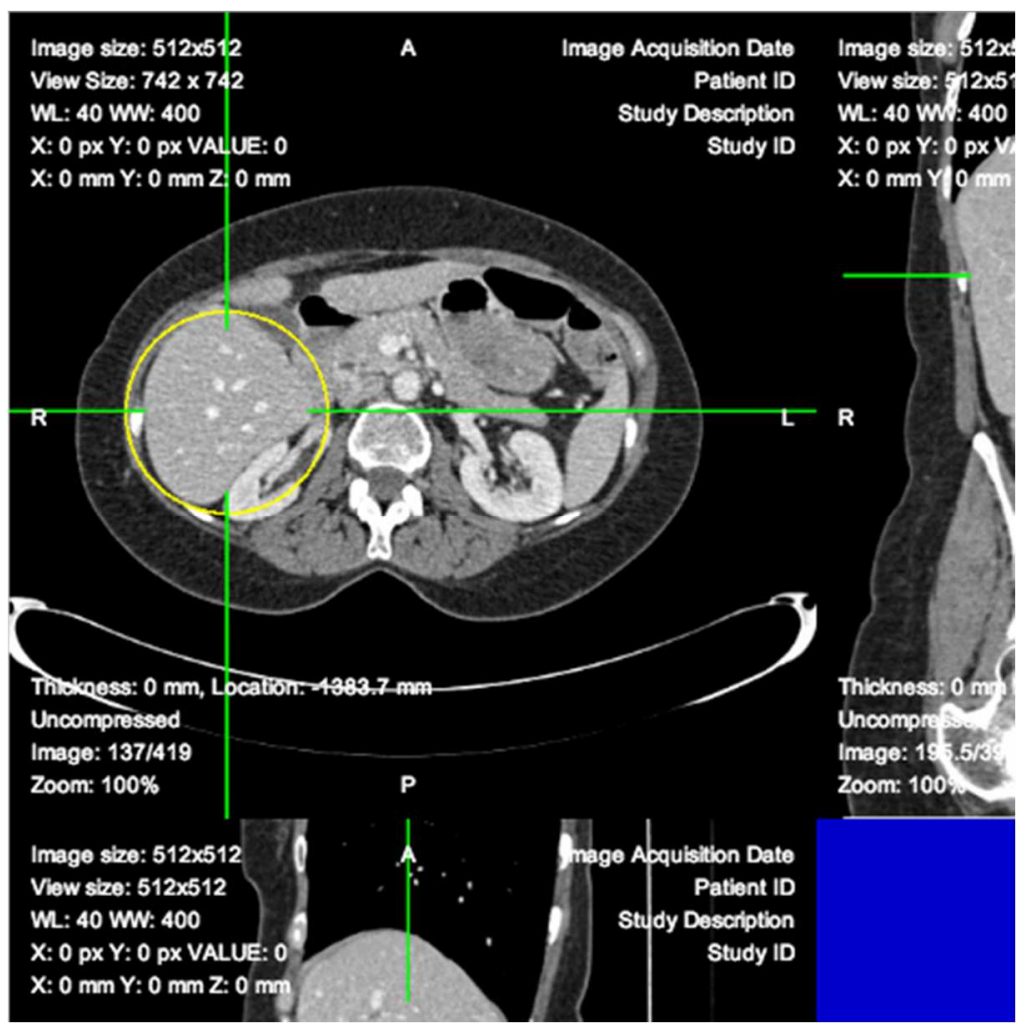

Figura 5.18: Cursor redimensionado com a tecla shift e botão de rolamento do mouse.

Para se marcar os pixels, o botão esquerdo do mouse é pressionado. Após isso, é possível ver os voxels marcados, formando uma esfera, com projeções no plano selecionado (Axial) e nos outros dois planos ortogonais (em vermelho na Figura 5.19). Caso se mude a camada que 
está sendo mostrada nos planos, a projeção vai mudar de forma a depender de onde o plano da imagem intersecta a esfera. Como resultado, se obtém um conjunto de círculos demarcados de cor vermelha em cada fatia (slice), dentro da região volumétrica do cursor esférico, em cada fatia em cada plano de visualização.

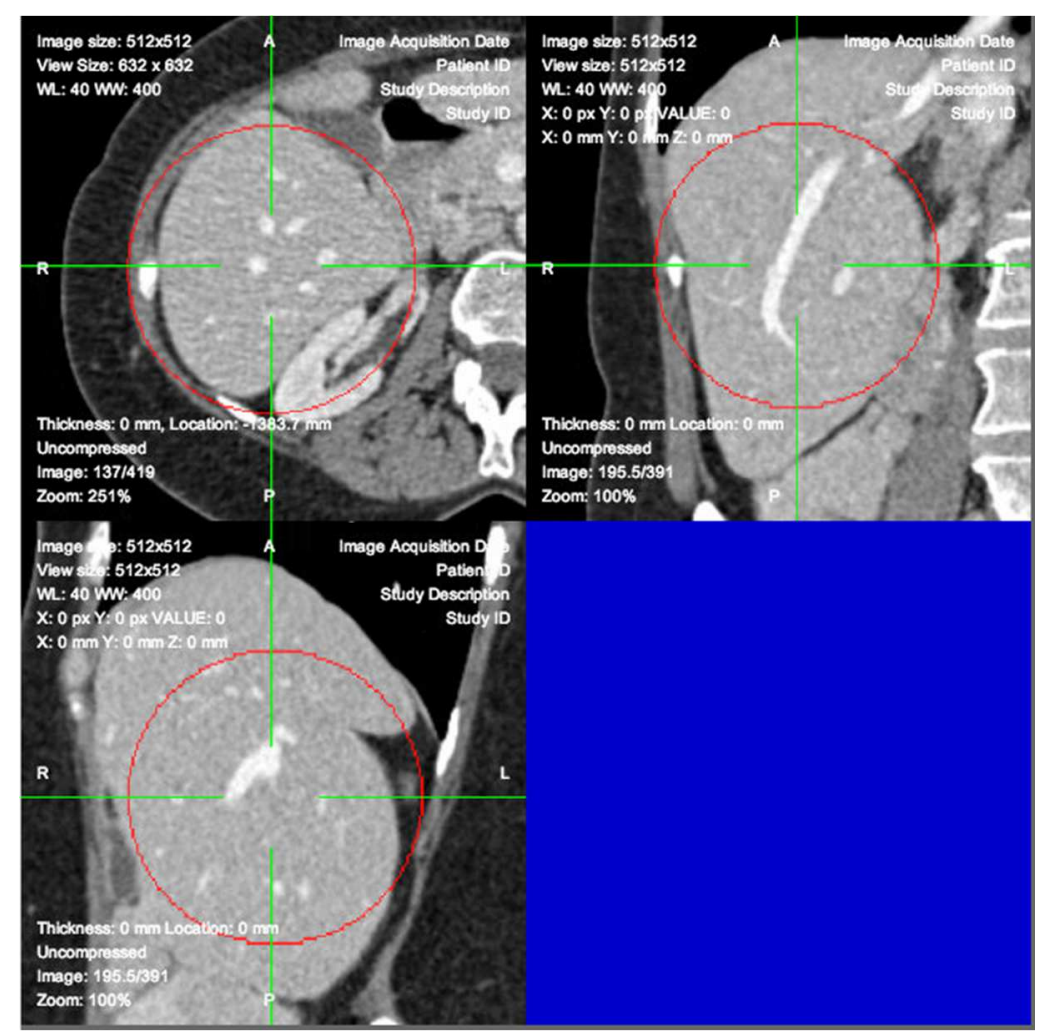

Figura 5.19: Marcação simultânea nos três planos ortogonais (círculos de cor vermelha).

O usuário pode analisar apenas um dos planos ortogonais executando duplo clique com botão esquerdo do mouse sobre a imagem da fatia visualizada - ilustrado na Figura 5.20. Nessa figura, é mostrada a imagem do plano Axial com a marcação realizada em vermelho. 


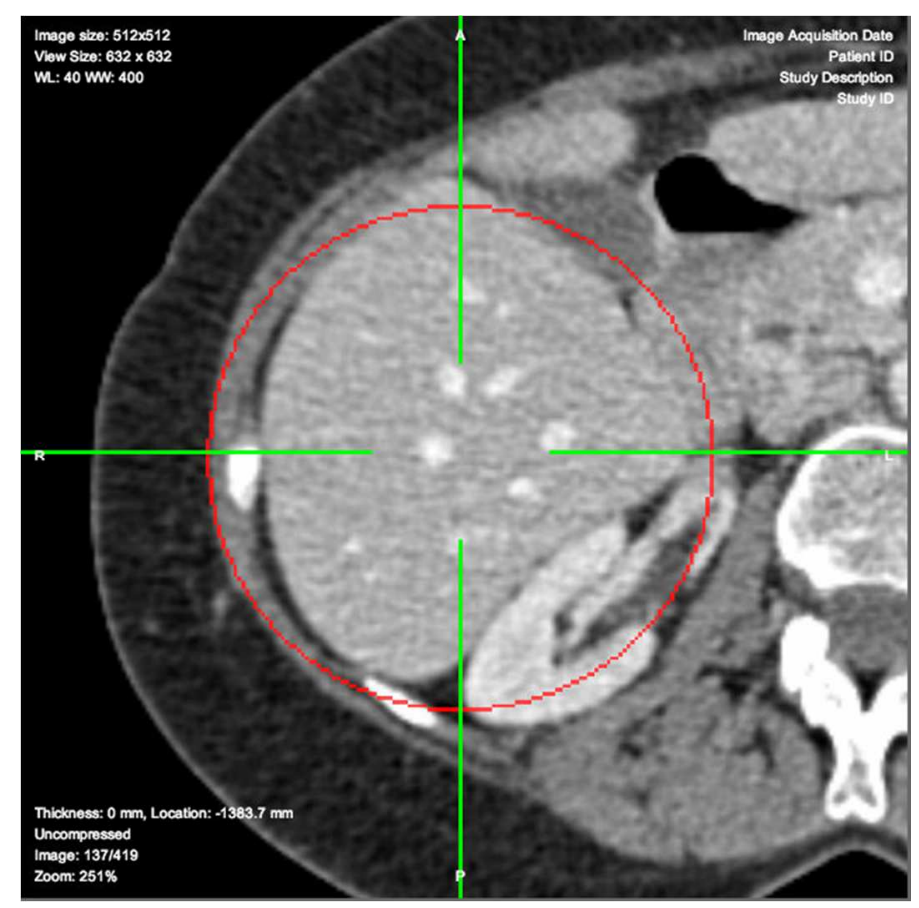

Figura 5.20: Imagem ampliada com marcação em vermelho.

Em seguida, foi realizada a navegação, mudança da imagem (camada) mostrada, para o início do conjunto de imagens marcadas do plano Axial. A navegação é executada pela rolagem do botão scroll do mouse (para cima ou para baixo) sobre o plano em que se encontra o cursor. É verificado que a marcação circular em vermelho no plano Axial possui dimensões menores, o cruzamento de réguas no plano Frontal está mais próximo do topo da projeção da esfera de marcação. O mesmo é verificado no plano Sagital - Figura 5.21, mostrando que o tamanho da projeção da esfera muda de acordo com a distância da camada ao centro da esfera. 


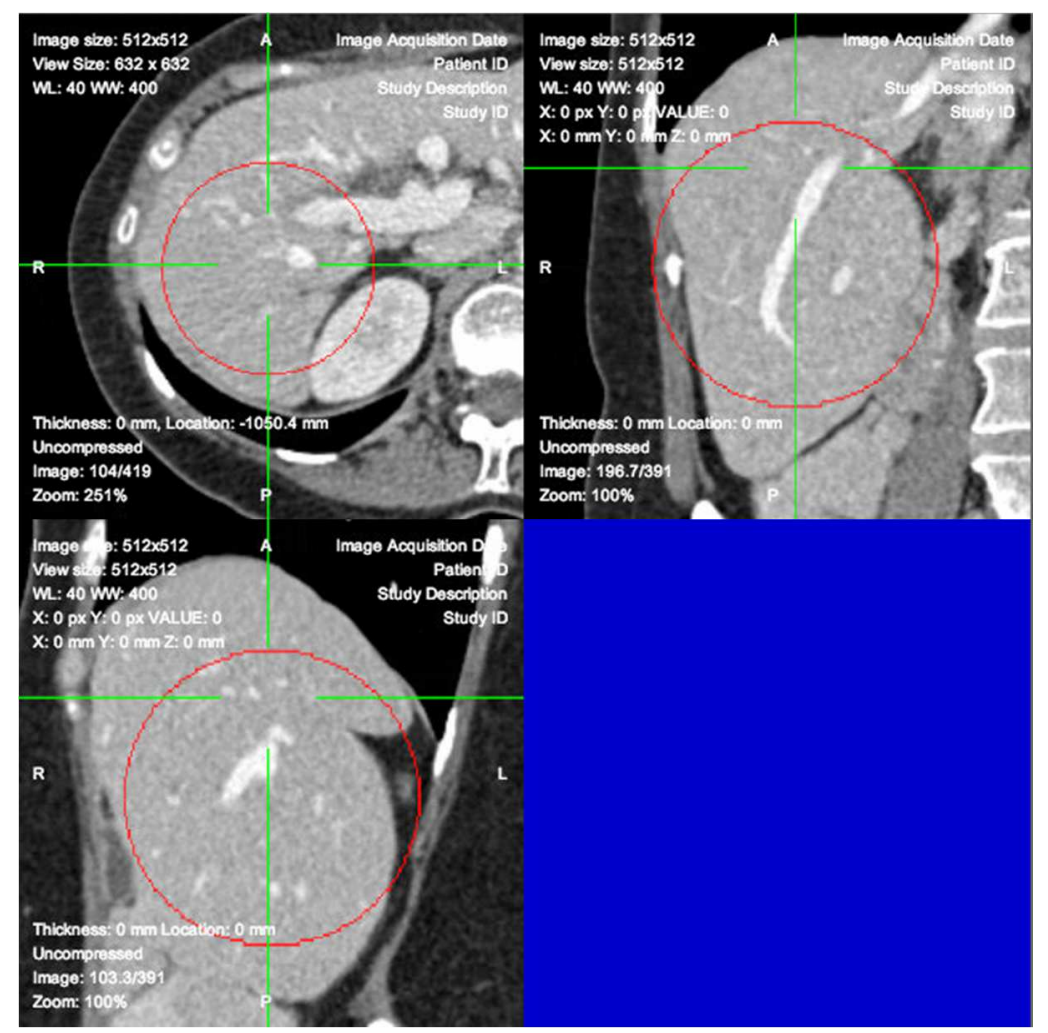

Figura 5.21: navegação pelo conjunto inicial de fatias da região volumétrica marcada.

No caso da navegação no plano Frontal (superior direito) em direção à coluna vertebral do paciente, é mostrada a área circular de marcação correspondente sobre cada fatia visualizada (Figura 5.22). A navegação no plano Sagital acontece de forma similar.

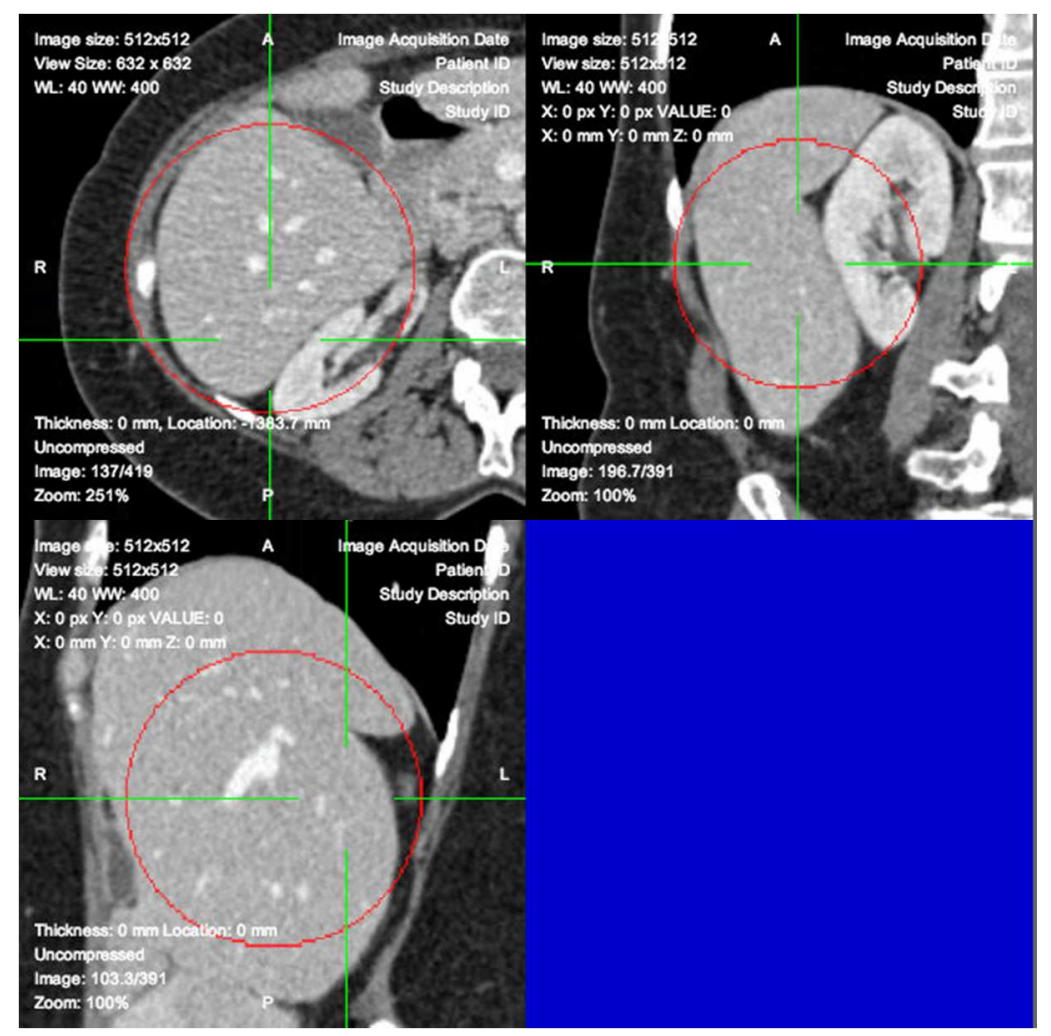

Figura 5.22: Navegação em direção à coluna vertebral do paciente (plano Frontal). 
No caso da navegação no plano Sagital (inferior esquerdo) em direção ao lado direito do paciente, é mostrada a área circular de marcação correspondente sobre cada fatia visualizada (Figura 5.23).

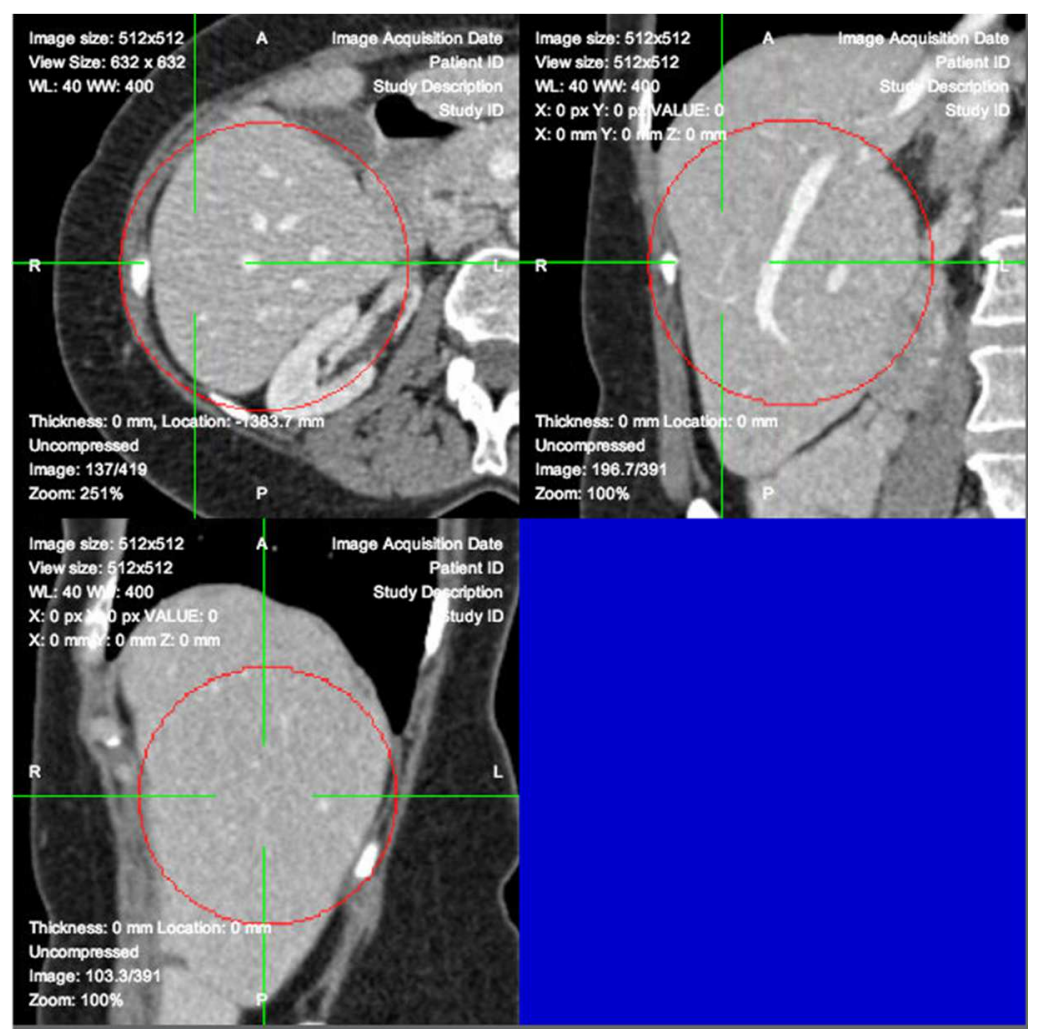

Figura 5.23: Navegação em direção ao lado direito do paciente (plano Sagital).

O usuário, em seguida, continuou a selecionar com o cursor esférico, no plano Axial, regiões próximas às margens da marcação original. Desse modo, essas regiões foram incorporadas ao volume anterior, e suas projeções nos três planos formam as áreas irregulares marcadas (Figura 5.24). 


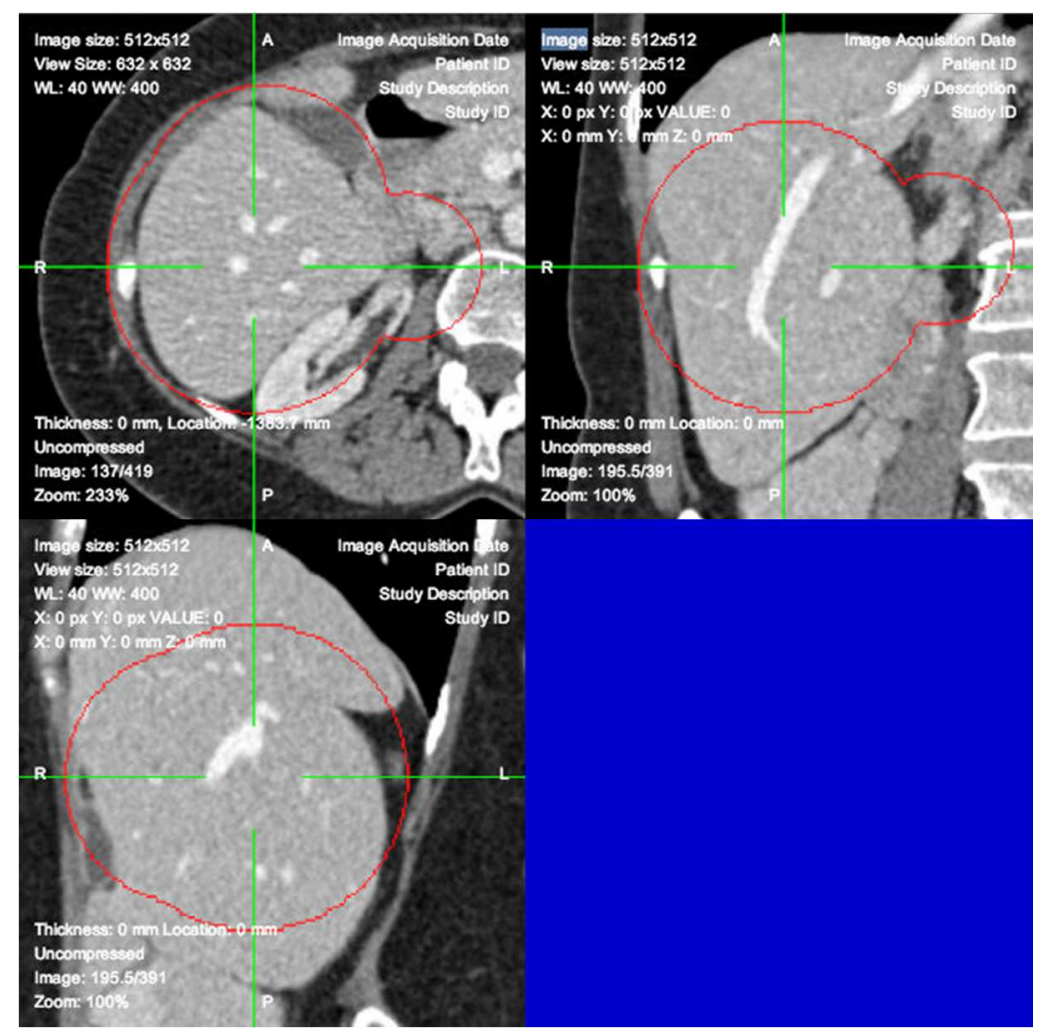

Figura 5.24: Áreas marcadas de forma irregular em todos os planos.

Na Figura 5.25, foi realizado o duplo clique com botão esquerdo sobre a imagem do plano Axial para melhor visualização.

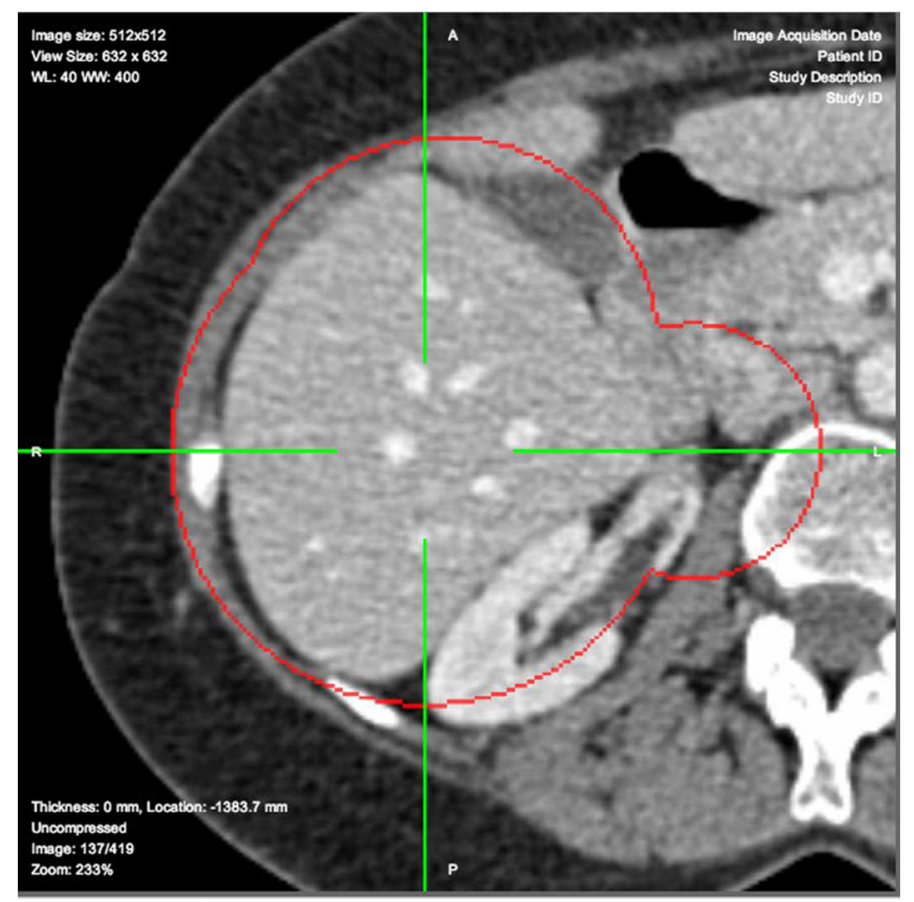

Figura 5.25: Imagem ampliada com marcação de área irregular.

A imagem ampliada com marcação irregular pode ser vista no plano Frontal (Figura 


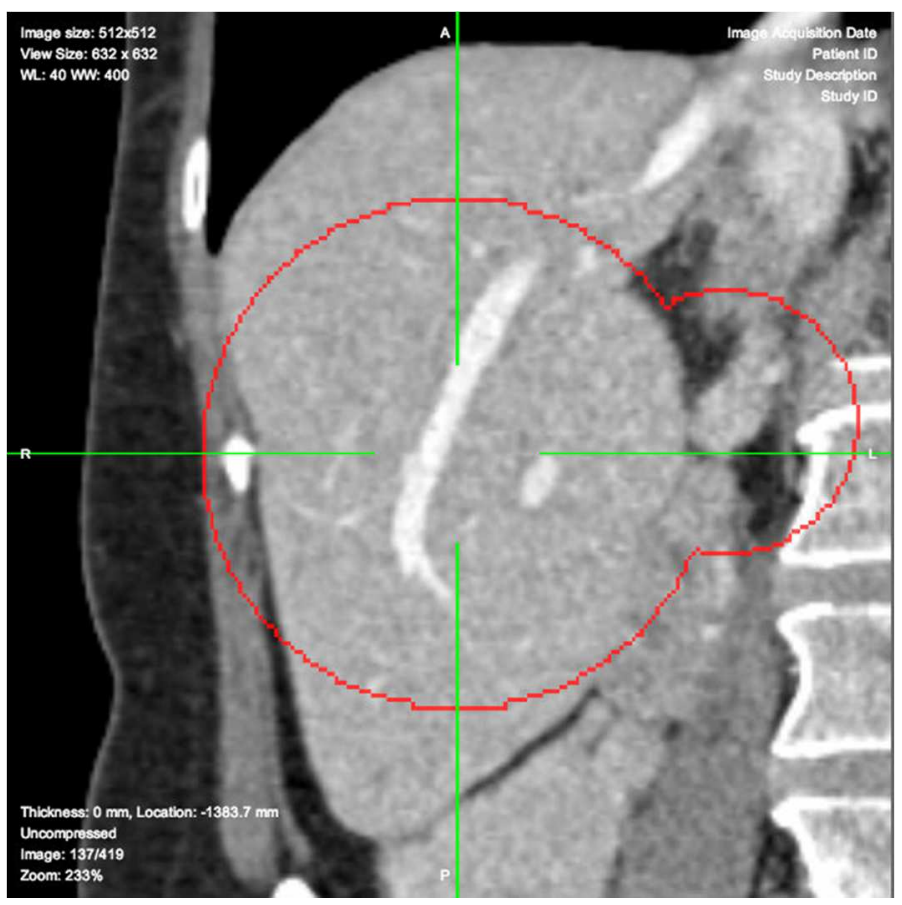

Figura 5.26: Imagem ampliada com marcação irregular no plano Frontal.

A imagem ampliada com marcação irregular pode ser vista no plano Sagital (Figura $5.27)$.

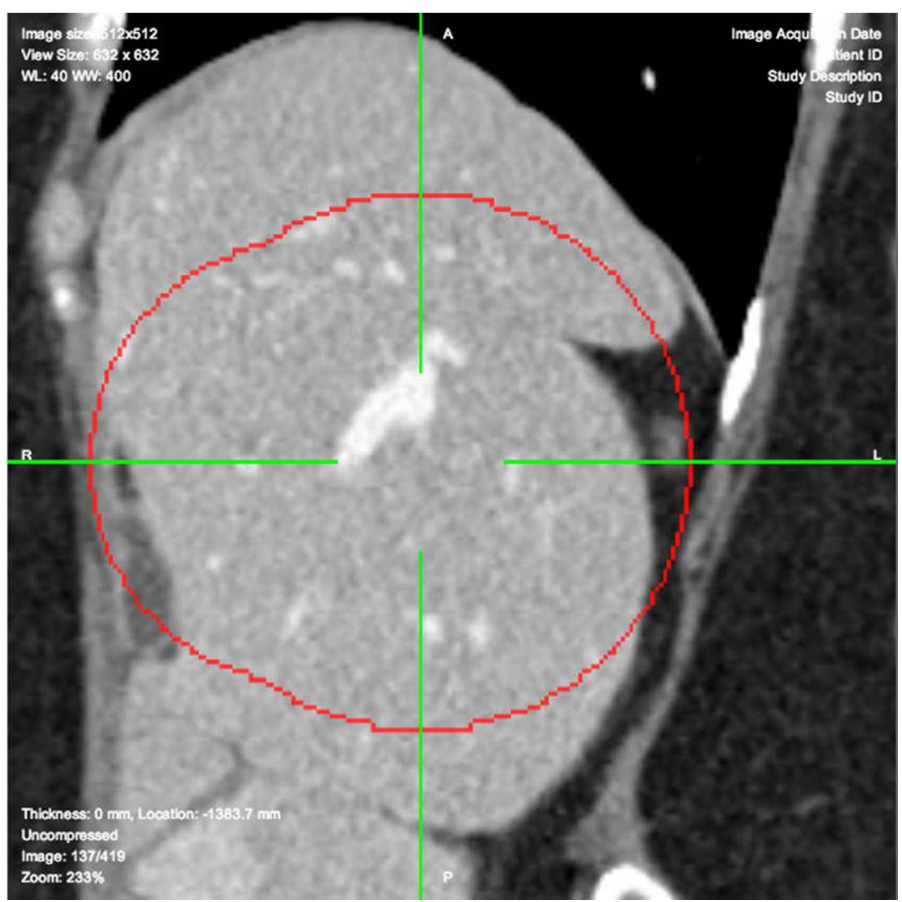

Figura 5.27: Imagem ampliada com marcação irregular no plano Sagital.

O usuário pode retocar ainda mais seu ROI 3D usando a mesma operação anterior em qualquer dos três planos. Ao terminar de marcar o ROI, o usuário deve editar as anotações semânticas sobre a imagem usando o RadLex e alguma template, como o RECIST (como explicado na seção 3.9). A anotação semântica da lesão não faz parte deste trabalho mas a 
Figura 5.28 mostra uma simulação de como o popup de edição deverá aparecer. Essa parte está sendo desenvolvido pelo grupo de pesquisa do Department of Radiology da Stanford University e está aguardando a integração do protótipo desenvolvido à nova versão do ePAD. Essa integração está dependendo do desenvolvimento da arquitetura de plug-ins do ePAD, que está em progresso.

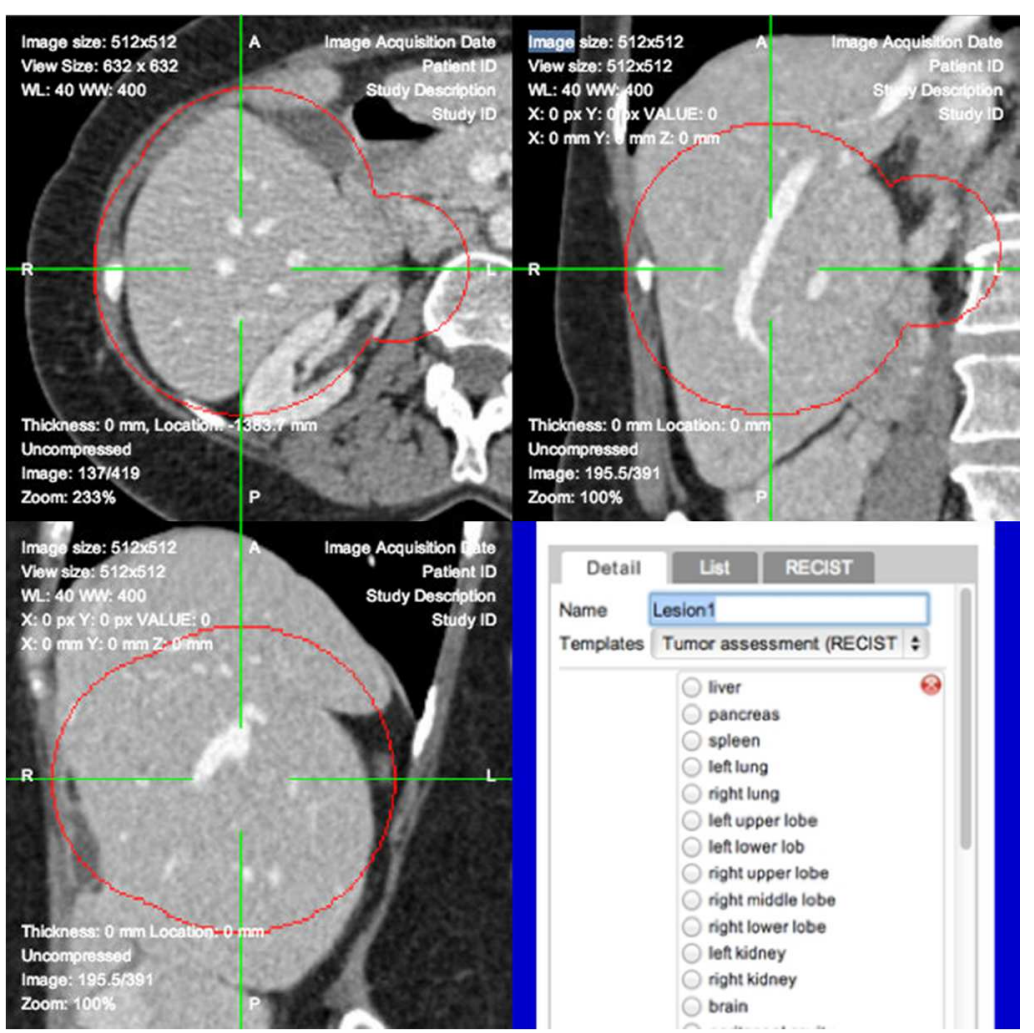

Figura 5.28: Anotação com termos léxicos para armazenamento em AIM XML.

\subsubsection{Arquitetura de plug-ins}

Está em desenvolvimento (mas não é parte deste trabalho) uma arquitetura baseada em plug-ins para o ePAD - onde cada plug-in tem funcionalidades específicas à uma aplicação. Por exemplo, um plug-in está em desenvolvimento como uma ferramenta para reconstrução multiplanar das imagens, oferecendo navegação pelo corpo do paciente em 3D mostrando as ROIs marcadas. Esse módulo será desenvolvido com bibliotecas como a XTK ${ }^{13}$ e poderá ser visualizado no plano inferior direito (mostrado na cor azul na Figura 5.24).

\footnotetext{
${ }^{13}$ https://github.com/xtk/X\#readme
} 


\subsection{Feedback: RSNA 2013}

No $99^{\text {th }}$ Scientific Assembly and Annual Meeting of the Radiology Society of North America (RSNA), em 2013 em Chicago, os grupos de pesquisa do ICMC-USP e do Department of Radiology - Stanford University disponibilizaram uma versão do protótipo ePAD (com geração dos três planos ortogonais de visualização, mas sem a marcação 3D) para avaliação por visitantes da área de radiologia em um stand da Stanford University. Entrevistas foram feitas com estes visitantes para obtenção de feedback visando melhorias futuras. A seguir, algumas das sugestões mais importantes obtidas das avaliações e entrevistas:

Imagens de maior resolução ficaram cortadas para uma usuária que estuda imagens de ossos. Suas imagens tinham $3700 \times 3000$ pixels

É necessário ter a capacidade de suportar tipos de arquivos adicionais por estudo

Algumas imagens parecem estar cortadas devido ao recálculo das medidas da imagem para ser encaixada no plano de visualização

É necessário melhorar o layout da interface gráfica e o logo da aplicação

O formato JPEG para imagens não é adequado para visualização devido à perda de informações após compactação e descompactação (ele é usado para mandar um rascunho das imagens, enquanto as imagens principais não chegam)

Necessário haver uma aba na qual é possível adicionar, editar e remover usuários

Alguns dos itens mencionados anteriormente e outros percebidos durante o processo de trabalho de pesquisa foram trabalhados e corrigidos como:

- Os cálculos das imagens dos outros planos ortogonais de visualização foram refeitos de maneira que as imagens sejam proporcionais, permitindo a visualização correta;

- Botões foram rearranjados para melhor visualização da interface gráfica da aplicação ePAD;

- Implementação de maior segurança de acesso aos dados durante todo o processo de execução da aplicação ePAD através de sessão;

- Apresentação correta de dois estudos de pacientes ao mesmo tempo; 


\subsection{Considerações Finais}

Neste capítulo foram apresentadas as contribuições mais relevantes deste trabalho: a visualização 3D, o estudo sobre qual interface de marcação 3D seria a melhor e o protótipo do cliente ePAD com marcação 3D. Durante todo o processo de desenvolvimento dos protótipos e interfaces, as suas funcionalidades e desempenho foram continuamente melhorados e adaptados seguindo decisões obtidas por constantes interações com usuários e reuniões entre nosso grupo de pesquisa do ICMC-USP, e o grupo da Stanford University, além de entrevistas com os médicos do HC da USP em Ribeirão Preto. Através do feedback dos usuários de maneiras formal (através de questionário) e informal (entrevistas e e-mails), foi possível constatar que as interfaces atendiam as expectativas e necessidades dos mesmos.

As avaliações (formais e informais) com usuários finais dos grupos de pesquisa da Stanford University e da Faculdade de Medicina da Universidade de São Paulo foram de suma importância para melhorias no projeto como um todo e para execução do plano de trabalho para a próxima versão do ePAD marcada para Agosto de 2014.

O próximo capítulo conclui a dissertação consolidando os resultados obtidos nas avaliações e ressaltando as principais contribuições e limitações desta pesquisa, além de sugerir trabalhos futuros. 


\section{Conclusões}

Nesta dissertação de mestrado foi desenvolvido um novo cliente Web para o sistema ePAD que é capaz de criar e apresentar marcação 3D. Esse cliente foi criado usando o GWT e funciona em navegadores Web sem a necessidade de instalação de plug-ins. Para sua criação, foi primeiro desenvolvido um protótipo de visualização de imagens radiológicas em 3D usando os três planos de projeção ortogonais, os planos Axial, Frontal e Sagital. Em seguida, foram propostas três interfaces para edição das anotações 3D e criados protótipos de vídeo mostrando cada uma delas. Usuários especialistas, médicos radiologistas (pesquisadores e profissionais da área), viram os três protótipos e deram suas opiniões através de questionários e entrevistas ao vivo e via internet. A partir das opiniões desses especialistas, foi escolhido o modelo com um cursor esférico 3D e o protótipo final do cliente foi implementado.

As várias versões dos protótipos foram avaliadas por profissionais da área e consideradas adequadas para o uso na marcação de lesões em um ambiente profissional. Em adição a isso, durante este trabalho, o sistema ePAD foi testado como um todo usando uma versão anterior da interface (que teve contribuições deste trabalho). Os resultados mostraram que o ePAD era mais efetivo na avaliação quantitativa de imagens na avaliação da resposta a drogas em tratamentos de câncer que ferramentas tradicionais (Rubin et al, 2014). É importante notar que essas ferramentas tradicionais são aplicações nativas desktop e que o ePAD mostra que é possível implementar uma versão $W e b$, com todas as vantagens das aplicações $W e b$, que tem um desempenho compatível com aplicações desktops. Incluindo, agora, visualização e marcação 3D usando planos ortogonais.

\subsection{Contribuições}

É importante salientar que o protótipo atual do cliente ePAD é um software complexo desenvolvido conjuntamente por dois grupos (ICMC-USP e Department of RadiologyStanford University), como já é tradicional em grandes projetos de pesquisa, e as contribuições relatadas neste texto são uma parte de um todo maior. Este trabalho recebeu sugestões e partes de código de outros programadores como também contribuiu com sugestões e código para outras partes do ePAD.

As principais contribuições deste trabalho são listadas a seguir: 
- Interface de visualização de imagens radiológicas em 3D. Essa interface mostra séries de imagens médicas usando os três planos de projeção ortogonais, os planos Axial, Frontal e Sagital, para visualização das lesões em 3 dimensões em navegadores Web. Isso é feito da mesma maneira que ferramentas nativas (desktop).

- Protótipos de vídeo das três interfaces para marcação de lesões em 3D. Essas marcações são representadas como regiões 3D numa série de imagens que representam uma seção do corpo humano. Esses protótipos levaram a escolha do cursor esférico como ferramenta de marcação.

- Protótipo do cliente ePAD com marcação 3D. Protótipo do cliente com a funcionalidade de visualização e marcação 3D com cursor esférico.

- Demonstração da viabilidade de uma ferramenta para marcação de lesões em 3D em imagens radiológicas que é uma aplicação cliente Web pura (usando apenas HTML5 + JavaScript). Foi demonstrado que uma ferramenta dessas pode ter velocidade de processamento suficiente para aplicações interativas com imagens num contexto médico, apesar das limitações que aplicações executando em um navegador tem. É interessante salientar que foram utilizadas tecnologias recentes, como HTML5 e WebGL e que há dois anos atrás uma solução, como a desenvolvida por este trabalho, seria impossível. Demonstrar a viabilidade da solução técnica é também muito importante.

\subsubsection{Colaborações}

A colaboração entre os grupos de pesquisa do ICMC-USP e da Stanford University resultou em ganhos perceptíveis para aos usuários do ePAD, provocando interesse de pesquisadores nacionais e internacionais. A versão futura do ePAD, com o módulo de marcações em 3D, será lançada em breve e conta com a colaboração do ACRIN - American College of Radiology Image Network.

\subsubsection{Publicação Relacionada ao Trabalho}

Como resultado deste trabalho, foi publicado o seguinte trabalho no jornal Translational Oncology ${ }^{14}$ :

\footnotetext{
${ }^{14}$ http://www.transonc.com/article/S1936-5233(14)80004-1/abstract
} 
"Automated Tracking of Quantitative Assessments of Tumor Burden in Clinical Trials" (RUBIN, D.L.; WILLRETT, D.; O’CONNOR, M.J.; HAGE, C.; MOREIRA, D. A., 2014);

\subsection{Dificuldades e Limitações}

As maiores dificuldades encontradas, durante a realização deste trabalho, incluem o tempo curto disponível de pesquisadores e profissionais de radiologia para contribuir com seus conhecimentos e experiências. Foi percebido que a dificuldade foi ainda maior para atrair a atenção e ajuda dos pesquisadores e profissionais de radiologia e de saúde do Brasil.

Outras dificuldades consistiram no trabalho colaborativo e paralelo na implementação do protótipo, havendo disparidades de entendimento entre os envolvidos sobre os rumos do projeto, mas que foram resolvidas conjuntamente com decisões prudentes do orientador deste projeto e o chefe do grupo do Department of Radiology-Stanford University, professor Daniel Rubin.

\subsection{Trabalhos Futuros}

Como principais trabalhos futuros, podemos destacar:

- A integração da edição 3D com a nova arquitetura de plug-ins do ePAD. Isso deve ocorrer antes de novembro deste ano (2014) na nova versão do ePAD que vai ser mostrada na $100^{\text {th }}$ RSNA em Chicago USA.

- Experimentação com novos tipos de interfaces 3D. Durante a pesquisa sobre as três propostas de interfaces (com os protótipos de vídeo), novas sugestões de interfaces surgiram. Em especial, a marcação 2D da lesão em algumas camadas e a posterior interpolação dessas marcações, pelo computador, para formar uma marcação 3D.

- Como o ePAD é uma aplicação Web, ele também pode funcionar em tablets ou computadores com telas sensíveis ao toque. Assim, seria possível investigar novos modos de interação com as imagens e marcações usando-se interfaces gestuais. 


\section{Referências}

Almeida, AGC; Bortolon, S; Berger, M e Seibel Junior, H. 2008. Integração de pacs software livre em aplicações médicas: Gerenciamento de pesquisas clínicas multicêntricas e de prontuários digitalizados. In: Sociedade Brasileira de Computação. WIM - Workshop de Informática Médica. Belém, PA, Brazil: SBC2008 - XVIII Congresso da SBC. p. 235-238.

Almeida, M. B. e Bax, M. P. 2003. Uma visão geral sobre ontologias: pesquisa sobre definições, tipos, aplicações, métodos de avaliação e de construção. Ci. Inf., Brasília, v. 32, n. 3, 7-20. DOI= 10.1590/S010019652003000300002.

AIM. 2014. Annotation and Image Markup. AIM Toolkit Release Notes https://wiki.nci.nih.gov/display/AIM/AIM+Toolkit+Release+Notes, acesso em Mar. 2014.

Antoniou G, Harmelen F. 2008. A Semantic Web Primer. $2^{a}$ edição. The MIT Press.

Ashburner, M; Catherine, A.; Judith, A.; Botstein, D; Butler, H; Cherry, JM; Davis, AP; Dolinski, K; , Dwight, SS; Eppig, JT; Harris, MA; Hill, DP; Issel-Tarver, L; Kasarskis, A; Lewis, S; Matese, JC; Richardson, JE; Ringwald, M; Rubin, GM e Sherlock, G. 2000. The Gene Ontology Consortium. Gene ontology: tool for the unification of biology. Nat. Genet.. May 2000;25(1):25-9.

Berners-Lee, T., Hendler, J. e Lassila, O. 2001. The Semantic Web. Scientific American, 34-43, http://www.scientificamerican.com/article.cfm?id=the-semantic-web, acesso em Jan. 2011.

Branstetter BF. 2007. Basics of Imaging Informatics. Radiology 243 (2007), 656-667.

Breitman, K.K. 2005. Web Semântica: a internet do futuro. LTC, Rio de Janeiro. ISBN 85-216-1466-7.

Bui, AAT; Taira, RK, (Editors). 2010. Medical Imaging Informatics. 1 Edição, Springer, 446p., Hardcover ISBN: 978-1-4419-0384-6.

Cantor D, Brandon J. 2012. WebGL Beginner's Guide. Packt Publishing.

DICOM. 2009. The DICOM Standard. Technical report. ftp://medical.nema.org/medical/dicom/2009/, acesso em Jan. 2011.

Freitas, F; Schulz, S e Moraes, E. 2009. Pesquisa de terminologias e ontologias atuais em biologia e medicina. RECIIS. Revista eletrônica de comunicação, informação \& inovação em saúde (Edição em português. Online), v.3, n.1, p.8-20, mar., 2009.

Golbreic, C; Horridge, M; Motik, B e Shearer, R. 2007. OBO and OWL: leveraging semantic web technologies for the life sciences. In Proceedings 6th International Semantic Web Conference (ISWC 2007), (Springer, in the press). 
Grau, B C, Horrocks, I, Motik, B, Parsia, B; Patel-Schneider, P e Sttaler, U. 2008. OWL2: The Next Step for OWL. Web Semantics: Science, Services and Agents on the World Wide Web. Volume 6, Issue 4, November 2008, Pages 309-322. Semantic Web Challenge 2006/2007. doi:10.1016/j.websem.2008.05.001.

Gruber, T. R. 1993. A translation approach to portable ontology specifications. Knowl. Acquis. 5(2), 199-220. DOI= http://dx.doi.org/10.1006/knac.1993.1008.

Guermeur, D e Unruh, A. 2010. Google App Engine Java and GWT Application Development. Packt Publishing. Olton, UK. ISBN 978-849690-44-7.

Haux R. 2010. Medical informatics: Past, present, future. International Journal of Medical Informatics 79 (2010) 599-610.

Horridge, M., Knublauch, H., Rector, A., Stevens, R. e Wroe, C. 2004. A practical guide to building OWL ontologies using the protégé-OWL plugin and CO-ODE tools edition 1.0. Technical report, University OfManchester. http://www.co-ode.org/resources/, acesso em Dez. 2010.

Horrocks, I. P., Patel-Schneider F. e Van Harmelen F. 2003. From SHIQ and RDF to OWL: The Making of a Web Ontology Language, Journal of Web Semantics 1 (1) 7-26.

Huang, HK. 2010. PACS and Imaging Informatics: Basic Principles and Applications. $2^{\mathrm{a}}$ edição revisada. ISBN: 978-0-470-37372-9.

Huang, HK. 2004. Pacs and Imaging Informatics: Basics Principles and Applications. John Wiley and Sons, Inc., Hoboken, New Jersey, 2004.

Kereki, F. 2011. Essential GWT: Buinding for the Web with Google Web Toolkit 2. Addison-Wesley, Pearson Education. Boston, USA, ISBN-13 9878-0-321-70514-3.

Klyne, G., Carroll, J. J. e McBride, B. (Editors). 2004. Resource Description Framework (RDF): Concepts and Abstract Syntax - W3C. http://www.w3.org/TR/2004/REC-rdf-concepts-20040210/, acesso em Set. 2009.

Korenblum, D; Rubin, D; Napel, S; Rodriguez, C e Beaulieu, C. 2010. Managing Biomedical Image Metadata for Search and Retrieval of Similar Images. Journal of Digital Imaging. DOI: 10.1007/s10278-010-9328-z.

Koutelakis, GV; Lymperopoulos, DK. 2006. Pacs through web compatible with dicom standard and wado service: Ad- vantages and implementation. Proceedings of the 28th IEEE EMBS Annual Inter- national Conference, p. 2601-2605, Sept 2006. New York City, USA.

Kundu S, Itkin M, Gervais DA, Krishnamurthy VN, Wallace MJ, Cardella JF, Rubin DL and Langlotz CP, 2009. The IR RadLex project: an interventional radiology lexicon--a collaborative project of the Radiological Society of North America and the Society of Interventional Radiology. J Vasc Interv Radiol 20(4): 433-5.

Langlotz, CP. 2006. RadLex: A New Method for Indexing Online Educational Materials. RadioGraphics 2006; 26:1595-1597. doi: 10.1148/rg.266065168 November 2006.

Potel M. 1996. MVP: Model-View-Presenter: The Taligent Programming Model for C++ and Java. Taligent, Inc.

Motik B, Grau BC, Horrocks I, et al. 2009. OWL 2 web ontology language: Profiles. W3C working draft, W3C, http://www.w3.org/TR/owl2-profiles/, acesso em Dez 2010. 
Noy, N. F. e McGuinness, D. L. 2001. Ontology Development 101: A Guide to Creating Your First Ontology. Stanford Knowledge Systems Laboratory Technical Report KSL-01-05.

Patel-Schneider, P. F., Hayes, P. e Horrocks, I.. 2004. OWL Web Ontology Language Semantics and Abstract Syntax, W3C Recommendation (10 February 2004).

Pollock, J. 2009. Web Semantic for Dummies. Wiley Publishing. Indianápolis, USA. ISBN: 978-0-470-39679-7.

Prior, FW; Erickson, BJ; Tarbox L. 2007. Open Source Software Projects of the caBIG ${ }^{\mathrm{TM}}$ In Vivo Imaging Workspace Software Special Interest Group. J Digit Imaging. DOI: 10.1007/s10278-007-9061-4.

Reichertz, PL. 2006. Hospital information systems — past, present, future. International Journal of Medical Informatics (2006) 75, 282-299.

Rosset, C; Rosset, A e Ratib, O. 2005. General Consumer Communication Tools for Improved Image Management and Communication in Medicine. Journal of Digital Imaging. Volume 18, Number 4, 270-279, DOI: $10.1007 / \mathrm{s} 10278-005-6703-2$.

Rosset, A; Spadola, L; Pysher, L e Ratib, O. 2006. Informatics in radiology (infoRAD): navigating the fifth dimension: innovative interface for multidimensional multimodality image navigation. doi: 10.1148/rg.261055066, January 2006, RadioGraphics, 26, 299-308.

Rosset, A; Spadola, L e Ratib, O. 2004. OsiriX: An Open-Source Software for Navigating in Multidimensional DICOM Images. Journal of Digital Imaging. Volume 17, Number 3, 205-216, DOI: 10.1007/s10278-004-10146.

RSNA. 2011. What is RadLex?. Technical report. http://www.rsna.org/Informatics/radlex.cfm, acesso em Jan. 2011.

Rubin, D. L.; Shah, N. H. \& Noy, N. F. 2007. Biomedical ontologies: a functional perspective. Briefings in Bioinformatics, 2008, 9, 75-90.

Rubin DL, Mongkolwat P, Kleper V, Supekar K and Channin DS. 2008a. Medical Imaging on the Semantic Web: Annotation and Image Markup. In: 2008 AAAI Spring Symposium Series, Semantic Scientific Knowledge Integration, Stanford University.

Rubin DL, Rodriguez C, Shah P, Beaulieu C. 2008b. AIM iPad: Semantic Annotation and Markup of Radiological Images. AMIA Annu Symp Proc. http://protege.cim3.net/cgibin/wiki.pl?XMLMasterPlugin.

Rubin DL, Shah NH e Noy NF. 2008c. Biomedical ontologies: a functional perspective. Brief Bioinform 9(1): $75-90$.

Rubin DL, Willrett D, O’Connor MJ, Hage C, Kurtz C, Moreira DA. 2014. Automated Tracking of Quantitative Assessments of Tumor Burden in Clinical Trials. Translational Oncology, 2014.

Serique KA, Snyder A, Willrett D, Rubin DL, Moreira D. 2012. Using the Semantic Web and Web Apps to Connect Radiologists and Oncologists. 2012 IEEE $21^{\text {st }}$ International WETICE, 2012.

Shah, N. H. e Musen, M. A. 2007. Which Annotation did you mean? Technical report, Stanford Center for Biomedical Informatics Research. http://bmir.stanford.edu/publications/view.php/ which_annotation_did_you_mean, acesso em Dez. 2010. 
Shah, S. 2008. Web 2.0 Security: Defending Ajax, RIA and SOA. Course Technology, Boston, USA. ISBN-13: 978-1-58450-550-1.

Smith, B., Ashburner, M., Rosse, C., Bard, J., Bug, W., Ceusters, W., Goldberg, L. J., Eilbeck, K., Ireland, A., Mungall, C. J., The OBI Consortium, Neocles Leontis, Rocca-Serra, P., Ruttenberg, A., Sansone, S. A., Scheuermann, R. H., Shah, N., Whetzel , P. L. e Lewis, S. 2007. The OBO Foundry: coordinated evolution of ontologies to support biomedical data integration. Nature Biotechnology, 25, 1251-1255.

Tang P, Coye M. 2003. Key Capabilities of an Electronic Health Record System: Letter Report. Institute of Medicine (IOM), 2003.

Vaughan, D. 2010. Ext GWT 2.0: Take the user experience of your website to a new level with Ext GWT. Packt Publishing. Olton, UK. ISBN 978-849511-84-1.

Weber-Jahnke J H, Mason-Blakley F. 2011. SIGHIT Record. 


\section{Apêndice A - Questionário aplicado com usuários}

\section{Pesquisa ePad - Desenhando Regiões de Interesse (ROI)}

Tempo estimado: 10 minutos (aproximadamente)

O ePad (electronic Physician device ou dispositivo eletrônico Médico) é uma ferramenta online, independente de sistema operacional, para anotações semânticas e está sendo desenvolvido por nosso grupo de pesquisa no ICMC-USP em conjunto com o Imaging Informatics Lab (LII) Dept. de Radiologia - Stanford University.

ePad é de uso gratuito.

Esta pesquisa é feita de maneira confidencial e nenhuma identifação será requisitada.

Esta pesquisa refere-se a diferentes maneiras de se desenhar Regiões de Interesse (ROI) em imagens radiológicas usando o ePad. O objetivo é obter opiniões e sugestões para as diferentes abordagens em desenho de ROls. 3 simulaçōes em vídeo exibem as diferentes abordagens. Agradecemos por suas respostas. Estas serão consideradas para desenvolvimentos futuros para 0 ePad.

Os videos devem ser tocados na máxima qualidade e em tela cheia para melhor visualização.

Continue $»$

$7 \%$ completed

\section{Pesquisa ePad - Desenhando Regiões de Interesse (ROI)}

\section{Status}

Status:

Estudante de Medicina

Residente

Médico Colaborador

Radiologista Faculdade/Praticante

« Back Continue»




\section{Pesquisa ePad - Desenhando Regiões de Interesse (ROI)}

\section{Status (Ano de Residência)}

Ano de Residência:

* Back Continue *

\section{Pesquisa ePad - Desenhando Regiões de Interesse} (ROI)

\section{Área de Medicina}

Área de Medicina:

Radiologista

Outra área

Outro profissinal de saúde

« Back Continue $"$ 


\section{Pesquisa ePad - Desenhando Regiões de Interesse (ROI)}

\section{Simulação A}

A) Video entitulado ePad Simulação ROI 3D:

O vídeo começa depois de a série de imagens do paciente ser aberta.

A descrição abaixo encontra-se nas legendas do vídeo. Você pode pular diretamente para o vídeo.

Aqui está a aplicação ePad. Podemos ver os 3 planos. O Axial, o Frontal e o Sagital.

Escolheremos a fatia de no. 52 no plano Axial. Com o cursor do mouse no plano Axial,

Se movermos o botão de rolagem do mouse para cima ou para baixo, veremos as fatias mais para cima ou mais para baixo no plano Axial.

Podemos ver o mesmo efeito no plano Frontal ao movermos o botão de rolagem do mouse $e$ também no Sagital. 
Agora, clicaremos no botão do cursor 3D para selecionar uma região 3D no plano Axial.

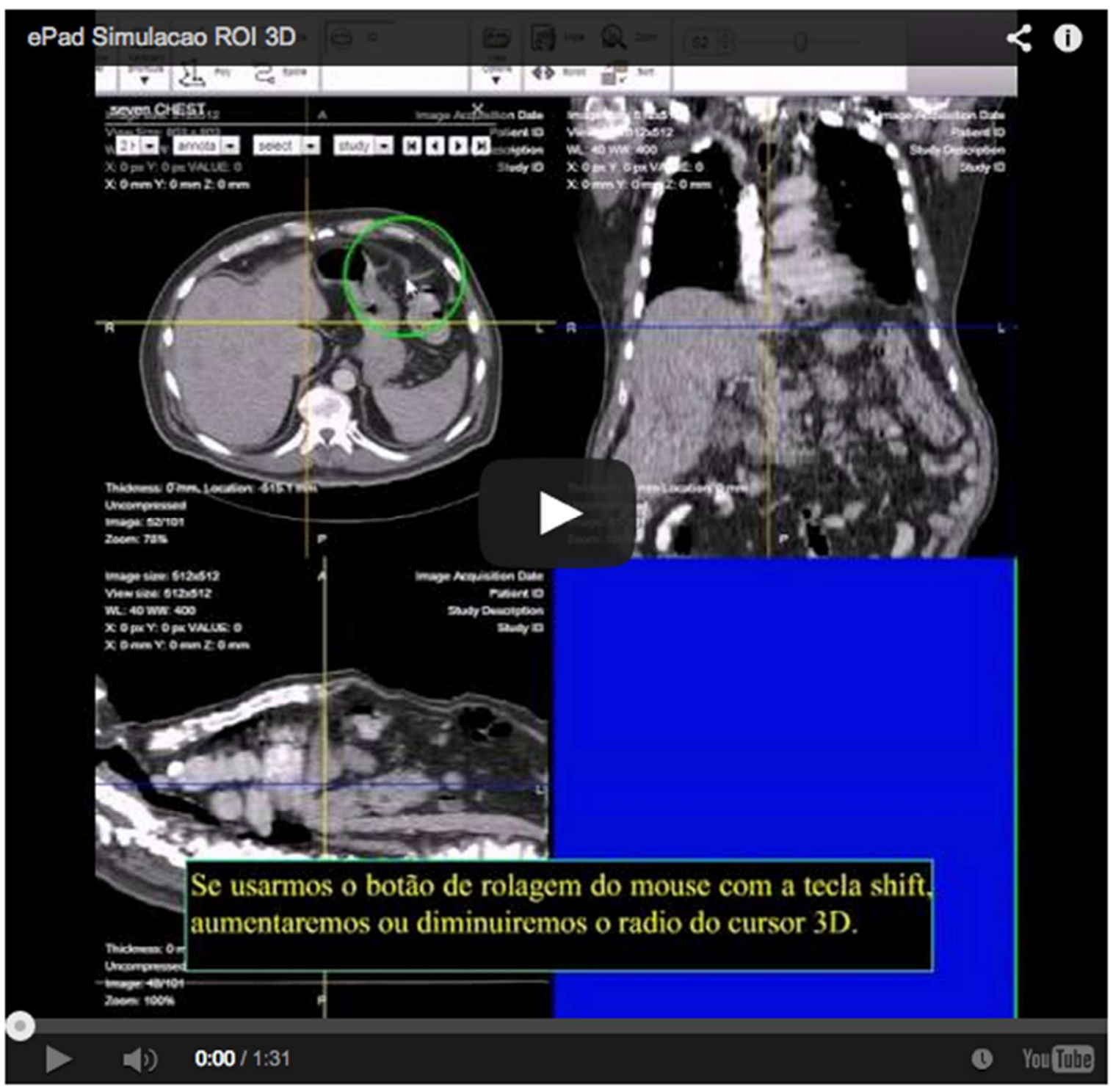


A abordagem apresentada ajuda o usuário a desenhar Regiōes de Interesse 3D com um pincel esférico. O usuário consegue desenhar nos três planos resultando em uma superfície 3D não uniforme.

Questão A1: Já usou algum software para desenhar Regiōes de Interesse (ROIs) 3D e anotar informações sobre as mesmas em imagens médicas?

Questão A2: Conseguiu visualizar os ROls 3D verdes nos três planos como uma boa representação de um ROI?

Questão A3: Com relação ao video que acabou de assistir: achou todo o procedimento mostrado para desenho de ROIs 3D intuitivo?

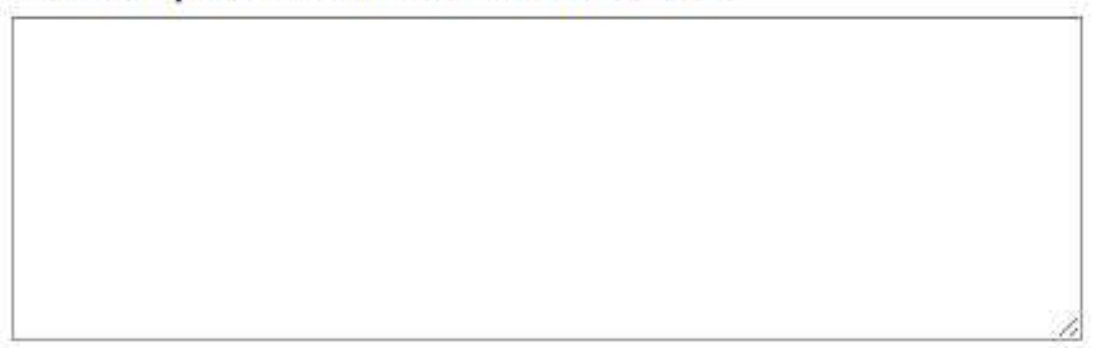

Questăo A4: teria outra opiniăo ou sugestăo para esta abordagem?

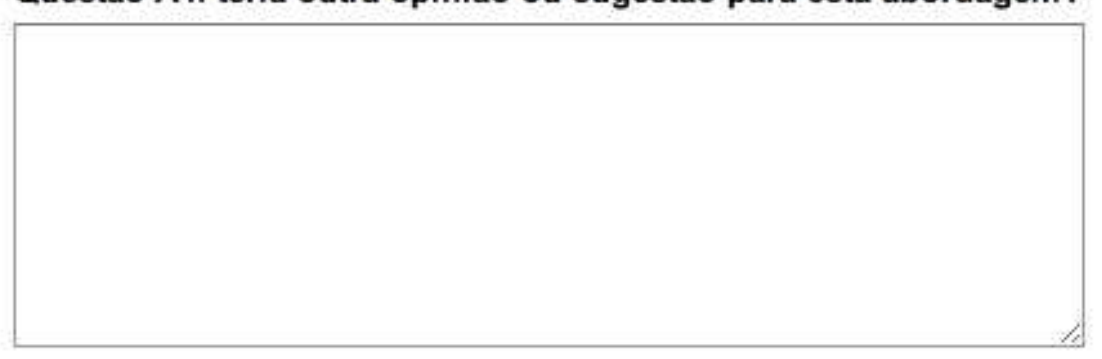

* Back Continue $:$

$69 \%$ completed

Powered by

을 Google Forms
This content is neither created nor endorsed by Google.

Report Abuse - Terms of Service - Additional Terms 


\section{Pesquisa ePad - Desenhando Regiões de Interesse (ROI)}

\section{Video B}

B) ePad Similaridade de Cores de Pixels

A descrição abaixo encontra-se nas legendas do vídeo. Você pode pular diretamente para o vídeo.

E, agora, usaremos algo chamado de variação de similaridade de cores de pixel. Ele seleciona uma área onde as cores dos pixels estão dentro de um intervalo de valores.

Se o usuário não está satisfeito com a área selecionada, ele pode usar a seleção por desenho livre. Será automaticamente adicionada à area selecionada anteriormente.

Se movermos o botão de rolagem do mouse com a tecla shift para cima, veremos a área selecionada aumentar de acordo com o aumento da variação de cores dos pixels e vice-versa.

Se o usuário não estiver satisfeito com a área selecionada, ele poderá utilizar um cursor circular para delimitar a área.

ePad Similaridade Cores Pixels
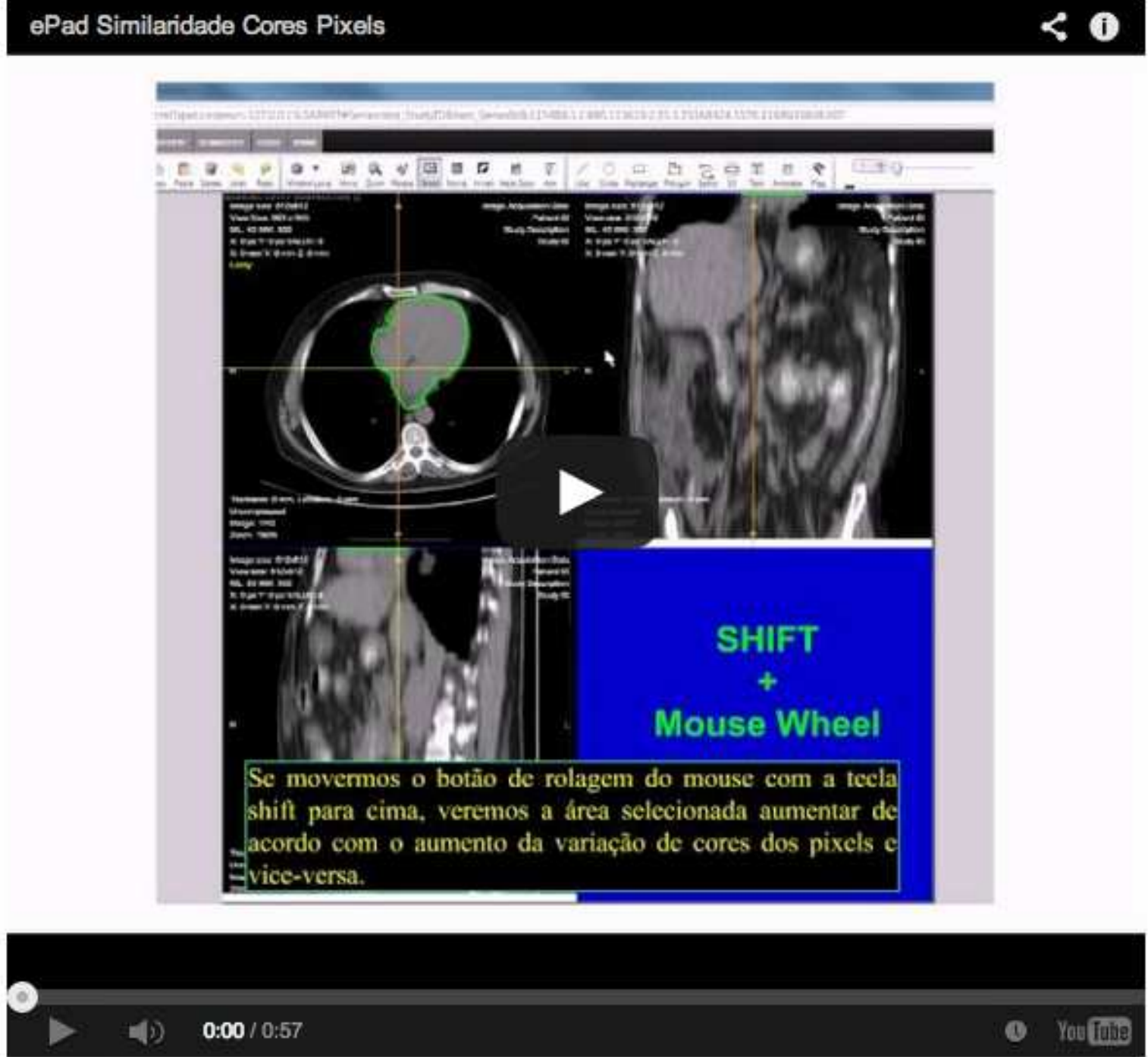
A abordagem apresentada ajuda o usuário a selecionar ROls com maior exatidão de borda dependendo no intervalo de cores dos pixels. O usuário pode ajustar esse intervalo para uma área a ser selecionada. Isso pode ser feito automaticamente em múltiplas fatias e uma superfície 3D será obtida.

Questão B1: Já usou a ferramenta de Seleção Difusa do Photoshop, GIMP ou outro editor de imagens? Esta ferramenta permite selecionar uma área baseada em bordas visiveis para recorte ou pintura.

Question B2: Acha que esta abordagem facilitaria o desenho de ROI em imagens médicas? Seria melhor que a solução do item A? 
Questão B3: Nós usamos o valor da cor do pixel como filtro de grupo de pixels (por exemplo, podemos fazer o programa agrupar pixels com valores variando de 56 a 120). Há outras características do pixel que consideraria mais apropriadas para agrupar os pixels (por exemplo, relacionado a pixels vizinhos)?

Questão B4: teria outra opiniāo ou sugestão para esta abordagem?

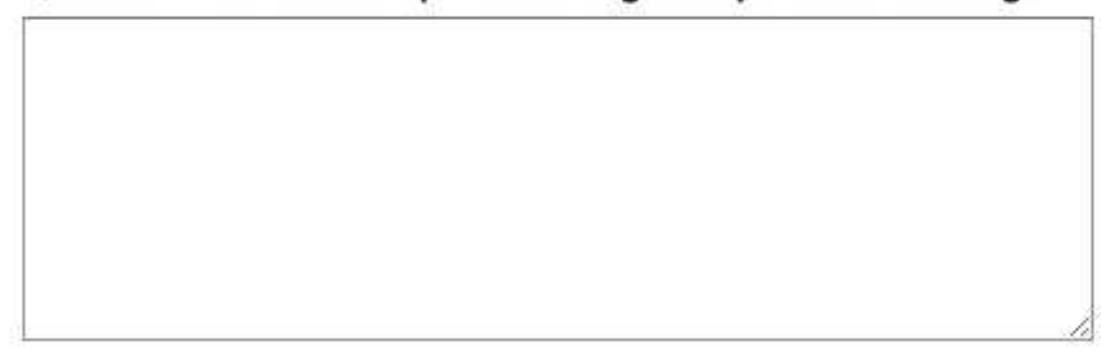

* Back Continue.

\section{Pesquisa ePad - Desenhando Regiões de Interesse (ROI)}

\section{Video C}

C) ePad Detecção de Bordas:

A descrição abaixo encontra-se nas legendas do vídeo. Você pode pular diretamente para o vídeo.

$E$, agora, usaremos a deteção de bordas. Vamos fazer zoom na fatia e selecionar uma região especifica.

As bordas foram detectadas mas a área selecionada não foi fechada.

Desse modo usaremos uma cruz amarela no centro do cursor circular como um cursor de desenho livre, assim, fechando a área selecionada 


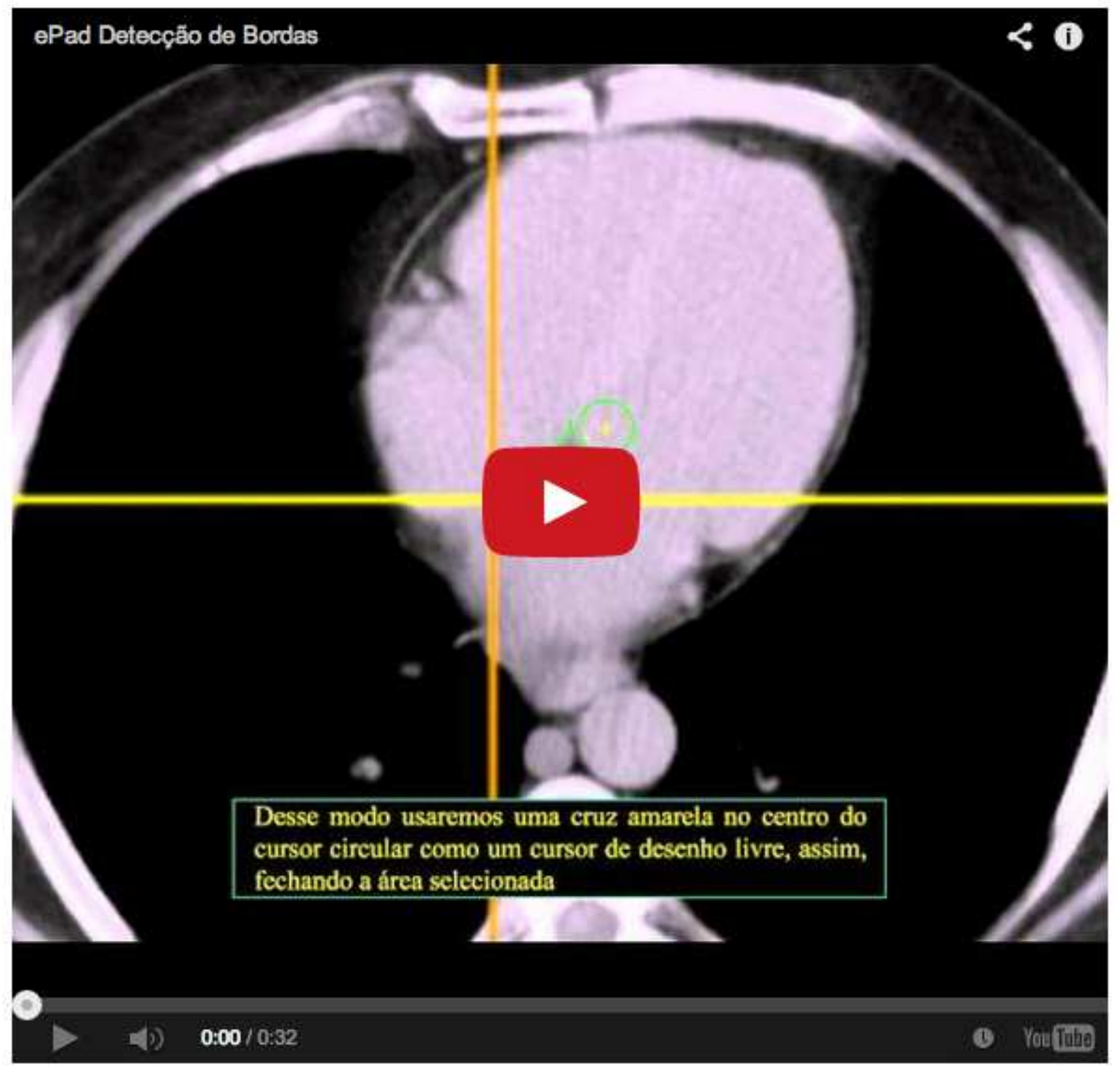

Essa abordagem pode ser realizada automaticamente em múltiplas fatias obtendo uma superfície de ROI 3D.

Questão C1: $O$ fato de programas que detectam bordas produzem regiōes abertas seria um problema para você? Acha que, nos tipos de ROls que você trabalha, as bordas são bem definidas o suficiente para usá-las em ROls? 
Questão C2: Acha que esta abordagem facilitaria o desenho de ROI mais que os vídeos dos itens $A$ e B?

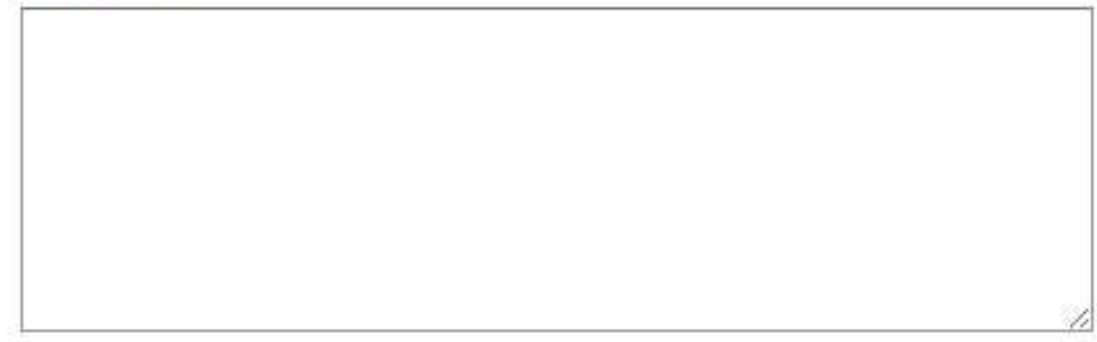

Questão C3: teria outra opinião ou sugestão para esta abordagem?

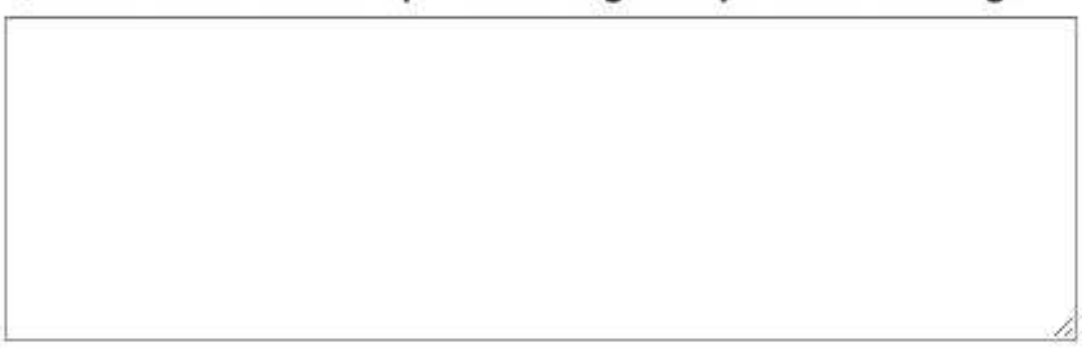

\& Back Continue $:$

\section{Pesquisa ePad - Desenhando Regiões de Interesse (ROI)}

\section{Comentários Gerais}

Pode deixar seus comentários gerais aqui sobre os videos ou sobre a pesquisa.

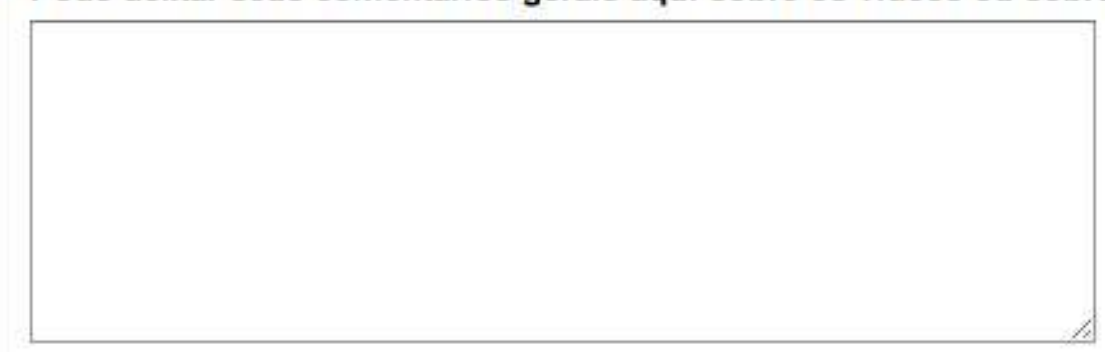

« Back Continue * 


\section{Pesquisa ePad - Desenhando Regiões de Interesse (ROI)}

\section{Agradecemos pelas respostas}

Obrigado por fazer parte desta pesquisa!

Gostaria de avaliar as novas versões do ePad pela internet? Se sim, deixe seu e-mail aqui ou envie para dilvan@icmc.usp.br (Assunto: Epad tester)

Seu e-mail aqui

* Back Submit

Never submit passwords through Google Forms.

100\%: You made it. 


\section{Apêndice B - Resultados do questionário aplicado aos usuários}

\begin{tabular}{|c|c|c|c|}
\hline Status: & & & \\
\hline & Estudante de Medicina & 0 & $0 \%$ \\
\hline Radiologista & Residente & 0 & $0 \%$ \\
\hline Médico Colaborador & Médico Colaborador & 2 & $33.3 \%$ \\
\hline Residente & $\begin{array}{l}\text { Radiologista } \\
\text { Faculdade/Praticante }\end{array}$ & 3 & $50 \%$ \\
\hline Pesquisador em Radiologia & $\begin{array}{l}\text { Pesquisador em } \\
\text { Radiologia }\end{array}$ & 1 & $16.6 \%$ \\
\hline
\end{tabular}

\section{Status (Ano de Médico Colaborador):}

Todos os médicos colaboradores responderam que estão no primeiro ano.

Área de Medicina:

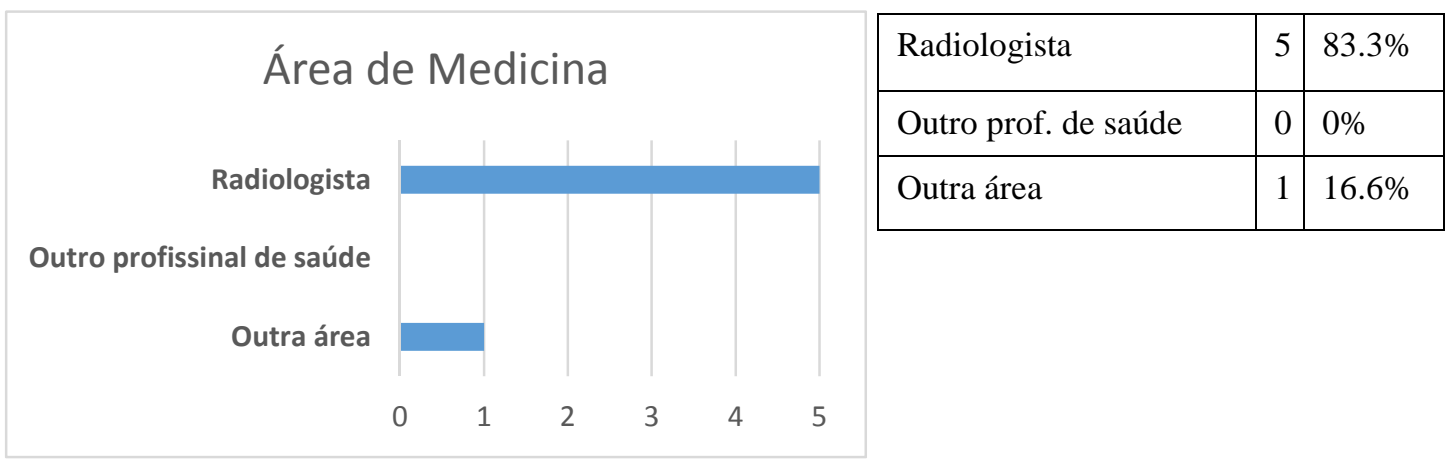

Questão A1: Já usou algum software para desenhar Regiões de Interesse (ROIs) 3D e anotar informações sobre as mesmas em imagens médicas?

Resposta: Todo responderam negativamente.

Questão A2: Conseguiu visualizar os ROIs 3D verdes nos três planos como uma boa representação de um ROI?

Resposta: A resposta foi unânime: sim.

Questão A3: Com relação ao vídeo que acabou de assistir: achou todo o procedimento mostrado para desenho de ROIs 3D intuitivo?

Resposta: Todos responderam afirmativamente.

Questão A4: teria outra opinião ou sugestão para esta abordagem? 
Resposta: Um dos participantes do questionário respondeu: "Podemos desenhar quaisquer formas além de uma esfera? Talvez possamos determinar pontos sobre certos planos e, então, o software poderia interpolar o desenho geométrico. Outro participante respondeu negativamente.

Questão B1: Já usou a ferramenta de Seleção Difusa do Photoshop, GIMP ou outro editor de imagens? Esta ferramenta permite selecionar uma área baseada em bordas visíveis para recorte ou pintura.

Resposta: Um dos médicos colaboradores já usou, mostrando conhecimento sobre a ferramenta, e o outro não.

Question B2: Acha que esta abordagem facilitaria o desenho de ROI em imagens médicas? Seria melhor que a solução do item A?

Resposta: Um dos participantes afirmou que depende da lesão de interesse, suas características atenuantes e o propósito do usuário. O outro respondeu sim. É muito melhor e gostaria de saber quão bom seria selecionar dentro de um órgão. O exemplo, para ele, possui grande diferença em atenuação (pulmão vs. tecido macio), fazendo o algoritmo parecer mais robusto.

Questão B3: Nós usamos o valor da cor do pixel como filtro de grupo de pixels (por exemplo, podemos fazer o programa agrupar pixels com valores variando de 56 a 120). Há outras características do pixel que consideraria mais apropriadas para agrupar os pixels (por exemplo, relacionado a pixels vizinhos)?

Resposta: Um dos usuários respondeu que depende na morfologia e homogeneidade da lesão. Outro disse não ter certeza.

Questão B4: teria outra opinião ou sugestão para esta abordagem?

Resposta: Os usuários respondem negativamente sobre a abordagem mas um deles acrescenta que a voz de narração do vídeo precisa melhorada.

Questão C1: O fato de programas que detectam bordas produzem regiões abertas seria um problema para você? Acha que, nos tipos de ROIs que você trabalha, as bordas são bem definidas o suficiente para usá-las em ROIs?

Resposta: Todos os participantes responderam que o fato de a detecção de bordas produzir regiões abertas não seria um problema. Um deles enfatiza que detecção de bordas seria muito útil.

Questão C2: Acha que esta abordagem facilitaria o desenho de ROI mais que os vídeos dos itens A e B?

Resposta: Um dos usuários respondeu que esta abordagem facilitaria e que seria melhor. $\mathrm{O}$ outro respondeu que depende.

Questão C3: teria outra opinião ou sugestão para esta abordagem? Resposta: Todos os usuários responderam negativamente.

\section{Comentários:}

Não houve comentários.

Contatos Recebidos para Testes Futuros:

Recebemos um contato de possível usuário para testes da próxima versão a ser lançada do ePAD. 